Part II. of Volume II. will be published on November 15, 1903.

\title{
The Fauna and Geography of the
}

\section{Maldive and Laccadive Archipelagoes}

\author{
Being the Account of the Work carried on and \\ of the Collections made by an Expedition \\ during the years 1899 and 1900
}

Edited by

J. Stanley Gardiner, M.A.

Fellow of Gonville and Caius College and late Balfour Student of the University of Cambridge.

VOLUME II. PART I.

With Plates XXVI-XXXIV

CAMBRidge:

at the University Press.

London: C. J. Clay and Sons,

Cambridge University Press Warehouse,

Ave Maria Lane.

Price Fifteen Shillings net. 


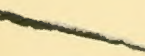




\section{The Fauna and Geography of the}

Maldive and Laccadive Archipelagoes VOLUME II. PART I. 
Zloñom: C. J. CLAY AND SONS, CAMBRIDGE UNIVERSITY PRESS WAREHOUSE, AVE MARIA LANE,

AND

H. K. LEWIS, 136, GOWER STREET, W.C.

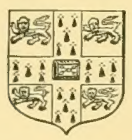

Blasgow: 50, WELLINGTON STREET.

Fleip\}ig: F. A. BROCKHAUS.

new gork: THE MACMILLAN COMPANY.

Gombay and Calcutta: MACMILLAN AND CO., Lnd. 


\title{
The Fauna and Geography of the
}

\section{Maldive and Laccadive Archipelagoes}

\author{
Being the Account of the Work carried on and \\ of the Collections made by an Expedition \\ during the years 1899 and I 900
}

Edited by

$$
\text { J. Stanley Gardiner, M.A. }
$$

Fellow of Gonville and Caius College and late Balfour Student of the University of Cambridge.

VOLUME II. PART I.

With Plates XXVI-XXXIV
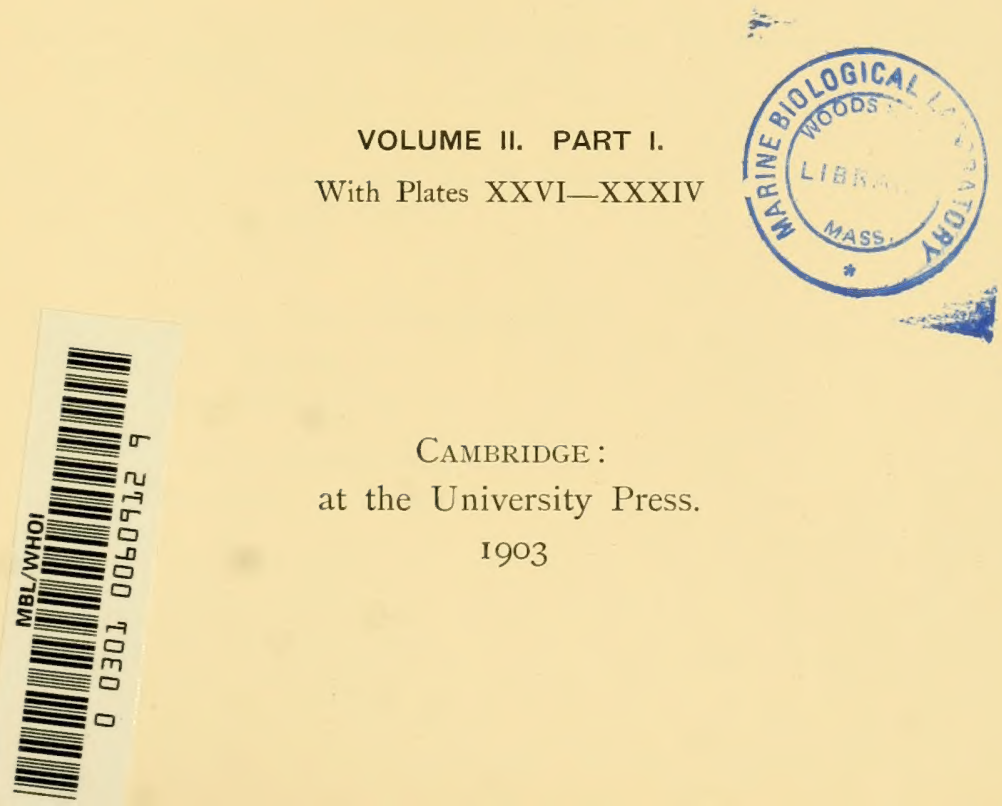

CAMbridge :

at the University Press.

1903 
CAMBRIDGE :

PRINTED BY J. AND C. F. CLAY, AT THE UNIVERSITY PRESS. 


\section{CONTENTS OF VOL. II. PART I.}

\section{Reports.}

1. The Alcyonaria of the Maldives. Part I. The Genera Xenia,

Telesto, Spongodes, Nephthya, Paraspongodes, Chironephthya, Siphonogorgia, Solenocaulon, and Melitodes. With Plates XXVI and XXVII . . . . . . . .

By Prof. Srdney J. Hrckson, M.A., D.Se., F.R.S.

2. The Alcyonaria of the Maldives. Part II. The Genera Sarcophytum, Lobophytum, Sclerophytum, and Alcyonium. With Plates XXVIII-XXXI . . . . . . .

By Edith M. Pratr, M.Sc.

3. Nudibranchiata, with some Remarks on the Families and Genera and Description of a New Genus, Doridomorpha. With Plate XXXII . . . . . . . . . .

By $\operatorname{Sir}$ Charles Eliot, M.A., K.C.M.G.

4. Marine Crustaceans. IX. The Sponge-crabs (Dromiacea). With Plate XXXIII . . . . . . . . . . 574 By L. A. Borradaile, M.A.

5. On a Land Planarian from Hulule, Male Atoll, with a note on Leptoplana pardalis Laidlaw . . . . . . . . By F. F. LaidLaw, B.A.

6. Lagoon Deposits. With Plate XXXIV.

I. General Account . . . . . . . . .

By J. Stanley Gardiner, M.A.

II. Report on Certain Deposits . . . . . . 584 By Sir John Murray, K.C.B., F.R.S. 



\title{
THE ALCYONARIA OF THE MALDIVES.
}

\section{PART I.}

\section{THE GENERA XENIA, TELESTO, SPONGODES, NEPHTHYA, PARASPONGODES, CHIRONEPHTHYA, SIPHONOGORGIA, SOLENOCAULON, AND MELITODES.}

\author{
By Sydney J. Hickson, M.A., D.Sc., F.R.S., Beyer Professor of Zoology in the \\ Owens College, Manchester.
}

(With Plates XXVI and XXVII.)

\section{INTRODUCTION.}

THIS collection of Alcyonaria from the Maldive archipelago is of more than ordinary interest. In most eases the species of Alcyonaria have been founded on a single specimen obtained from a single dredging or on two or three specimens obtained from a single locality. The interest of the present collection lies in the fact that specimens were obtained from a considerable number of dredgings made in several of the atolls or off the reefs of a very extensive archipelago, and consequently an opportunity is afforded for the study of the variation of form, colour, and other features within the limits of a wide area. I have no hesitation in saying that the general impression gained by the study of single specimens of the different genera from a reef is usually an erroneous one, because it cannot give due weight to the important facts of the possible variations of a species living in surroundings and under conditions which are, within certain limits, identical. If we were to take at random, for example, a specimen of Tubipora from the reef off $\mathrm{N}$. Celebes, and compare it with another specimen taken at random from the reef at Ternate, it is probable that so many differences would be found in the shape of the colony, the size of the tubes, the distance of the platforms, etc. in the two specimens that it would be thought necessary to make two species, one for the Celebes specimen and one for the Ternate specimen; but anyone who walks along the $\mathrm{N}$. Celebes reefs at low tide will find in one morning not only the reputed Ternate species but a complete series leading from that up to the reputed Celebes species, and beyond it.

When I went out to Celebes the first thing I did was to collect specimens of Tubipora, having already obtained a knowledge of the genus in Europe from books and museums, but the conclusion I came to was that there is only one species which varies on the one reef within limits almost as wide as the limits of all the hitherto described species of the genus.

G. II. 
The collection made by Mr Gardiner in the Maldives affords an opportunity of judging of the extent of variation possible in one group of islands of some other genera that are widely distributed.

In the case of the genera Spongodes and Solenocaulon, for example, it is clear that there is a very great range of variation in form, colour, and in the size and shape of the spicules. They exhibit a number of "facies" which form an almost uninterrupted series between the types that have been described as distinct species. Now these facies are not confined to any one island of the Maldive archipelago, nor are they clearly separated from similar facies found in other parts of the tropical Indian and Pacific Oceans. If each facies represents a distinct species, then we have the very remarkable phenomenon of a large number of closely related species distributed over a very wide geographical area and competing in the struggle for existence, with approximately equal success, in many localities of this wide area. If, on the other hand, all the facies together represent but one species, then we have an example of a species that is capable of an extraordinary range of variation in circumstances which are approximately identical.

As it is impossible to prove either one of these propositions without recourse to experiments in cross breeding, the only course to pursue, as a temporary measure, is to place in a separate species those facies which appear to be discontinuous with others in their form and distribution, and to collect into one species those facies that are connected by sufficiently continuous series of intermediate links.

This is the course I have adopted in this paper.

As an example of the method I may refer to the genus Solenocaulon, in which we have no less than eight specimens from different islands of the Maldive archipelago connected together to form a series, and one specimen which I have called S. ramosa distinguished from them in the tube-formation of the stem, the retractility of the polyps and other characters. This last I regard as a distinct species at present, but I think it is quite possible that a series of intermediate forms between it and $S$. tortuosum may be found which will ultimately necessitate the abandonment of the specific name.

It is a question of very great importance as bearing upon the species problem, whether the varying forms and colours of these Alcyonarians are due to sporadic variation irrespective of their environment or to distinct inherited characters.

If we were to trace the history of 20 eggs of a brown divaricate Spongodes fertilised by the spermatozoa of another brown divaricate spongodes, and settled down within a restricted area of a single reef, should we expect to find that all the young Spongodes developed from them were brown divaricates $(B D)$, or should we expect to find that some of them were red conglomerates $(R C)$, others yellow flabellates $(Y F)$, etc. ? If they are all $B D$, with of course variations in minor particulars, then we should be justified in believing that the brown colour and the divaricate manner of branching are not only transmissible by inheritance, but are so transmitted because they are of some importance to the species in the struggle for existence. If on the other hand the young Spongodes are of the facies $B D, R C, Y F$, etc., then we should be justified in believing that the characters of the colour and mode of branching are of little or no importance for the species in the struggle for existence, but are due to the direct action of the environment (e.g. sunlight, food supply, strength of currents, proximity of neighbouring zoophytes, presence of epizoic crustacea, etc.). 
Conversely, we may argue that if the colour and mode of branching are of little importance in the struggle for existence of the species the offspring of a single pair of parents will probably show a great range of variation in these characters, $B D \times B D$ giving rise to $B D$ 's, $R C^{\prime}$ s, $Y F^{\prime \prime}$ s, etc. in varying proportions.

It is impossible to believe that the struggle for existence has much influence upon the colour of these Alcyonarians. There is no evidence that the colours can be of assistance to the species either as apatetic colours, hiding the individuals from their enemies by resembling the surroundings or some other dangerous zoophyte, or as aposematic colours, signalising some dangerous sting or abhorrent taste.

Spongodes are, so far as my experience goes, extremely conspicuous in their proper surroundings, and do not mimic any other zoophyte that is usually associated with them on the same reef. If they were of the nature of warning colours we should expect to find them on the Müllerian principle of one or two distinct kinds, and arranged in simple patterns instead of the endless shades of tone and tint and kaleidoscopic arrangement that they exhibit. It is difficult to suggest any use that these colours can be to the Alcyonarian, and they should be regarded as being of a purely physical and chemical character, as the green of chlorophyll and the red of haemoglobin, and having no biological significance.

The exact form and mode of branching of the colonies must in my opinion depend very largely upon the external conditions of the individuals. Just as a tree or shrub will vary in form according to its exposure to the wind, the character of the soil, and the proximity of other shrubs and trees, so will a Spongodes vary in form according to the strength of the tides flowing over it, the amount of food these tides bring, the proximity to other zoophytes, the exposure to sunlight, and other external conditions. The external conditions that may influence the growth of a Spongodes are so many that it is not surprising that we find so many differences in the style of ramification. One specimen may be free to expand in any direction and receive the full benefit of all the sun's rays that penetrate to the depth of water in which it lives, whereas another not a foot away may be impeded in one direction or another by the branches of a great Madrepore and sheltered from the heat and light of the sun by the shadows which the great coral casts. It appears to me therefore far more probable that the critical condition of life for a Spongodes is not that it should branch in any one pattern that is inherited from its parents, but that it should be able to adapt itself to any one combination of the great variety of conditions which it may happen to meet in the course of its development. Apart from the purely physical conditions determining the shape of a colony, there is one biological condition which is probably of very great importance. It is well known to those who have handled museum specimens of Spongodes and many other Alcyonarians that Crustacea of various kinds are frequently found entangled in the branches; and Mr Gardiner has called my attention in his manuscript notes to these Crustacea and the striking similarity of their colours to the colours of their host. It is very probable that these Crustacea render an important service to the Spongodes in keeping their surfaces free from the larvae of Sponges, Barnacles, sedentary worms and other animals, and it is also probable that the character of the ultimate ramifications is due in no small measure to the size and shape of these important epizoites. The manner in which the epizoic crabs affect the growth of Pocillopora, Seriatopora, and other corals, and form galls, is well known. There is some reason to believe, as stated on p. 495, that the tubes of Solenocaulon are caused by the Alpheids which infest 
this Briareid in a similar manner. It is unreasonable to suggest that Spongodes is not also influenced in its growth by its epizoic crabs. In fact it may be that the differences known to systematists as divaricate, glomerate and foliate growth are due to the crabs, and not to the inherent characters of the species of Spongodes.

The colour and mode of branching of these Alcyonarians being unsatisfactory characters for purposes of specific classification, there remain the spicules and the more minute internal anatomy to appeal to. While appreciating very fully the assistance that the examination and measurement of spicules renders in some cases, I am convinced that in many genera the spicules are liable to very great variation, and are very untrustworthy for our purpose. A discussion of this point must however be postponed until my researches have been completed. It is upon the anatomical characters of the anthocodiae and the general canal system connecting the polyps that we must ultimately base our division of the genera into specific groups. This however involves the careful investigation of a large number of wellpreserved specimens belonging to each genus from several localities, and can only be accomplished by degrees and in the course of many years. It is not possible, however, for any zoologist who undertakes to write an account of such a collection of Alcyonarians as the one made by Mr Gardiner in the Maldives to undertake this task for all the genera he may find in it. Miss Pratt has shown in Part II. of this paper the manner in which the work may be done in the case of two or three closely-related genera. On the other hand it is to my mind very desirable that a general account of such collections should be published as soon as possible, and to do this a provisional arrangement of the specimens in specific groups should be made.

It appears to me that the proposal recently made by Bernard (3), so far as I can understand it, is open to many objections. The use of a number instead of a name is not only of no advantage, but it is very dull and uninspiring. The prominence that is given to the locality in the case of these shallow water-marine forms is also to my mind undesirable.

This Part contains an account of all the Alcyonacea, with the exception of the genera Alcyonium, Sarcophytım, Lobophytum, and Sclerophytum, and of all the Gorgonacea Scleraxonia.

The most abundant species of Alcyonacea belong to the genera Sarcophytum, Lobophytum, and the new genus Sclerophytum. These genera have been carefully studied by Miss E. M. Pratt, and are described in a separate paper. The remainder belong to the genera Telesto, Xenia, Spongodes, Chironephthya, Siphonogorgia, and Heliopora. The Gorgonacea Scleraxonia are represented by the genera Solenocuulon and Melitodes. The Stolonifera appear to be rare in the Maldives. Not a single specimen of the genus Clavularia was obtained. Mr Gardiner informs me that the genus Tubipora is very scarce throughout the Maldives; "one of my boys brought me a small piece (decaying) from the edge of the W. reef at Hulule. I saw one colony at Maradu, Addu Atoll, but do not remember to have seen it growing elsewhere." The absence of Clavularia from the Maldives is interesting in view of its immense abundance on the coral reefs of many parts of the Malay archipelago, Torres Straits, and elsewhere in the S. Pacific. It does not appear to occur on the coast of Ceylon, of the Malay peninsula, or of Singapore, nor on the other hand in the Red Sea, Zanzibar, or East Coast of Africa. 
Tubipora, however, is abundant on the coast of Zanzibar, the Seychelles, and the Red Sen, very rare in the Maldives, and I have Professor Herdman's authority for saying that it must be scarce or rare off the coast of Ceylon, as not a single specimen occurs in his extensive collection from those waters. It is difficult to account for the scarcity of Tubipora in these regions, as on most of the coral reefs of the world it is one of the most abundant and luxuriant Alcyonarians. The absence of the characteristic Zanzibar genera Coelogorgia and Lemnalia from the Maldives is also a noteworthy feature.

On the other hand the genus Heliopora, which is so widely distributed on the reefs of the Malay archipelago, Torres Straits, and Pacific Ocean, is also abundant in the Maldives. Mr Gardiner writes that at Hulule Male "Heliopora occurs practically everywhere near the reef inside the boulder zone if other corals grow. It does not, however, live near the velu (lagoonlet, Hulule being a faro or small atoll). It is not at all common to the west, but great masses are found to the east, usually dead in the centre with plates growing out all round, the tops just awash at low-tide springs. Some of the masses are five to six feet across, but none have any great thickness. All now lie freely (not attached) on the sand. The polyps are but rarely expanded in the daytime, and then only towards the bases of the branches, that is, in the shade. The corallum does not appear to be bored by any other organism."

Speaking more generally he writes, "Heliopora is nowhere of any special importance in building the reefs. It may be found almost anywhere towards the outer sides of the atolls on the reefs. Small colonies may grow on the reef flat, but they are very rare."

The genus Xenia does not appear to be very abundant, nor to reach a large size. The specimens sent to me were found at Addu in the extreme S. of the archipelago and at N. Male in the northern half, and this suggests that the genus probably occurs sporadically throughout the archipelago. The Maldives, however, do not seem to be as favourable for the growth of this form as the Chagos archipelago in the S., Zanzibar and the Red Sea to the west, or such localities as New Britain, Torres Straits, and the coast of Celebes and Ternate.

Spongodes appears to be extremely abundant and varied in character. When all the specimens are placed side by side, however, there is no one feature to be observed to distinguish them from the Spongodes of other reefs. The genus appears to be widely spread over the whole of the Red Sea, Indian Ocean, Malayan seas, and the tropical Pacific Ocean. It is remarkable that the genera Nephthya and Paraspongodes are so rare, being represented by only one specimen of each.

The genus Chironephthya (W. and S.), which was for many years after its discovery by the Challenger expedition known to occur at a depth of 200 fathoms in Japanese waters, has recently been described by Hiles (12) from New Britain in shallow water, probably occurs in shallow water at Funafuti (cf. Whitelegge 24, Siphonogorgia macrospina), occurs off Singapore (e. coll. Bedford), off Ceylon (e. coll. Herdman), and is now shown to be abundant in depths of about 20 fathoms in the Maldive archipelago. The genera Solenocaulon and Siphonogorgia appear to have a distribution very similar to that of Spongodes. 


\section{Family Xeniidae.}

Genus Xenia. Savigny.

In writing upon this genus I must explain that I do not include in it those species which belong to the genus Heteroxenia of Kölliker. This explanation is necessary in view of the recently published paper by Kükenthal (16) in which the proposal is again brought forward to merge Heteroxenia into Xenia.

The genus Heteroxenia was established by Kölliker for a species found at Port Denison in Australia which exhibited dimorphism, and was named Heteroxenia Elisabethae. Klunzinger (14) in 1879, upon the examination of some specimens of Xenia fuscescens which he found in the Red Sea, threw some doubt on the validity of the genus Heteroxenia.

$\mathrm{Up}_{\mathrm{p}}$ to this point no detailed account had been given of the structure of the small polyps which Kölliker regarded as siphonozooids, and it was a question whether they were really siphonozooids or young polyps not yet developed into their adult form.

In 1895 G. C. Bourne (4) examined and described the siphonozooids of a specimen of a species which he attributed to Heteroxenia Elisabethae (Köll.) from Zanzibar, and Ashworth (1) subsequently examined the same specimen and confirmed Bourne's determination of the species.

Both Bourne and Ashworth made careful anatomical examinations of the specimen, studying in minute detail and with the best histological methods the structure of the siphonozooids, and they came to the conclusion that there are true siphonozooids in this species, and that they can be distinguished without difficulty from young autozooids. It does not appear from Kükenthal's recent paper that he has made any anatomical investigation of a species of Heteroxenia, and the arguments used in defence of his proposal show no advance on those of Klunzinger which were considered and rejected by Bourne and Ashworth.

Whether the specimens collected by Klunzinger in the Red Sea, and named by him Xeniu fuscescens Ehr, are or are not identical with Heteroxenia Elisabethae is a point upon which I will not venture to express an opinion, but I cannot refrain from saying that it is premature at present to assert that they are. I cannot therefore accept Kiikenthal's view that the genus Heteroxenia should be suppressed. It is unfortunate that no specimens of a dimorphic Xeniid are to be found in Mr Gardiner's collection, and that only eight specimens of one species of Xenia were discovered in the Maldives. At present therefore it appears that the genus Heteroxenia is confined to the exceptionally hot waters of N. Australia, the Red Sea, and Zanzibar, together with one species Heteroxenia capensis with distinct characters from cooler water off S. Africa.

No specimens have yet been observed in the extensive collections of Alcyonaria that I have examined from the Maldives, Ceylon, Singapore, and the Malay archipelago. If, by any chance, the single specimen of Heteroxenia Elisabethae in the Museum Godeffroy, which Kölliker examined, was wrongly labelled, and did not originally come from Port Denison in Australia, the geographical distribution of the genus might not seem so extraordinary as it is. It is true there is no definite reason for doubting the locality of Kölliker's specimen, but it is noteworthy that notwithstanding the careful investigations of Saville 
Kent, Haddon and others in Torres Straits and elsewhere the occurrence of this genus in tropical Australian waters has not been confirmed.

In conclusion I may say that although I cannot accept Kukenthal's proposal to merge Heteroxenia into the genus Xenia, I think it is just possible that this is the course which will ultimately have to be adopted. If it can be shown that notwithstanding the difference in character of the young autozooids and the siphonozooids the latter do develop later the character of the adult autozooids, then the genus must go. This can only be proved by the examination and comparison of a large number of specimens from the same locality. Until this is done it is not only very inconvenient to the systematist but contrary to the best principles of scientific investigation to suppress the genus.

\section{Xenia garciae Bourne.}

Two specimens, one from the reef at Maradu, Addu Atoll, and one from Hulule, Male A., were obtained by Mr Gardiner.

The former consists of about fourteen clumps, perfectly white in colour, attached to what appears to be a piece of shell $60 \mathrm{~mm} . \times 30 \mathrm{~mm}$. in size. Some of the clumps are free, and represent single colonies, others are constricted or lobed, and may represent two or more colonies fused together. Each clump or colony is very flat, rising in the centre only 2 or 3 millimetres from the shell.

The second specimen (from Male A.) consists of 10 clumps, pale bluish-green in colour, attached to a rounded knob of dead madrepore, coated with nullipore coral. Some of the clumps are free, others are attached at the base in pairs or triplets, and I think it is probable that each pair or triplet represents one branched colony. An interesting point of difference between the specimens is that in the last-named each clump rises 4 or $5 \mathrm{~mm}$. from the base of attachment, showing a pronounced stalk (sterile portion).

A careful examination of the polyps shows that both specimens clearly belong to Bourne's species from Diego Garcia, and the differences in colour and height may be accounted for by differences of age or position on the reef.

It is not necessary to publish the measurements of the polyps I made. They agree very closely with those given for the species in Dr Ashworth's table (2). I may say, however, that I have compared the polyps with one taken from $\mathrm{Mr}$ Bourne's type specimen, which was kindly lent to me for the purpose, and there can be no doubt of the identity of the species.

From N. Male, 30 fathoms N. of the atoll, Mr Gardiner obtained six very small specimens of a species of Xenia closely related to Xenia garciae. They are too young to place definitely in any of the hitherto described species. 


\section{Family Telestidae (Milne Edwards).}

\section{Genus Telesto (Lamaroux).}

Two distinct species of this genus were found in the collection from the Maldives. One of them is probably Telesto trichostemma (Dana), and the other is new. The new form I propose to call Telesto rubra. The specimens of Telesto trichostemma were dredged in 25 fathoms in Mulaku Atoll and in 24 fathoms Miladumadulu Atoll.

One fragment of the new species was found in the same dredging in Mulaku, and the other in Mahlos Atoll, 23 fathoms. It is to be noticed that both specimens of the new species are freely encrusted with a sponge, a Prosuberites, in the case of the Mahlos specimen, and a Leptosia sp. $\mathrm{n}$, in the case of the Mulaku specimen. The Telesto trichostemma, however, is entirely free from sponge encrustations.

The occurrence of encrusting sponges on Telesto has been recorded by Dana (5) in the case of Telesto fruticulosa, by Wright and Studer (23) in Telesto trichostemma from Torres Straits, and by Miss Hiles (12) in T. rupicola from Blanche Bay.

In a former paper (10) I suggested that Telesto should be removed from the family Clavulariidae and placed among the Alcyonidae. At the time I wrote that paper I had very little acquaintance with the genus, and I am now in agreement with May (17), who suggests the retention of Milne Edwards' family Telestidae in a position intermediate between the Clavulariidae and the Alcyonidae.

\section{Telesto rubra sp. nov.}

Specimen A. Mulaku Atoll, 25 fathoms. Fine mud and rubble at the edge of the lagoon.

Specimen B. Mahlos Atoll, 23 fathoms, N.E. lagoon.

Both of these specimens are unfortunately fragmentary, and as the base is missing I have no knowledge of the method by which the colony is fixed to the bottom. 'The species is easily recognised, however, by the bright pink to red colour of the tubes. The spicules of the body-walls of the axial and lateral polyps become firmly fused together to form a solid tubular skeleton, perforated by numerous irregular and minute channels, traversed by strands of mesogloea. These tubes have a remarkable similarity in their construction to the tubes of the genus Tubipora, but are distinguished by the presence of eight distinct longitudinal ridges (Fig. 2).

In Telesto trichostemma Studer states that "the spicules surrounding the elongated digestive cavities of the primary and secondary axial polyps lie in such intimate contact with one another that, in the older parts of the colony, they form a continuous calcareous cylinder. Towards the base this is further strengthened by the horny substance secreted between the spicules." These tubes show as in $T$. rubra eight longitudinal ridges. In 1. trichostemma, and in other species of Telesto which form a tubular skeleton that remains rigid on drying or slight treatment with caustic potash, the spicules appear to be bound together by a horny substance developed in the mesogloea. In the new species this is not the case, no appreciable amount of horny substance being noticed either in the sections of decalcified or in dried specimens. The rigidity of the skeleton is entirely due to the 
calcium carbonate, and prolonged boiling in caustic potash does not soften the tubes or permit of the isolation of the spicules.

The anthocodiae are completely retractile, and when that part of the body-wall of a polyp is examined which is situated at the junction of the anthocodia with the non-retractile portion, a few isolated spindle-shaped spicules can be seen. These spicules are very different in form to those of any species of Telesto that has hitherto been described, and it is perfectly certain that they grow very rapidly in size until they become as firmly fixed or fused together as are the spicules in the tubes of Tubipora (Figs. 5 and 6).

In Telesto trichostemma it will be noticed that according to Studer (23) it is only in the "older parts of the colony" that continuous calcareous cylinders are formed. In T. rubra, on the contrary, the spicules at the base of the verrucae of the youngest buds are fused to form a continuous calcareous skeleton. The secondary branches and the young polyps are given off from the axial polyps at an angle which is almost a right angle. This is another feature in which the new species seems to be peculiar.

The tentacles of the retracted polyps are, in spirit, snow white or pale yellow. They exhibit a row of about eight pinnae on each side, and each pinna is supported by a curved spindle-shaped spicule $0.14 \mathrm{~mm}$. in length. There is also a series of rod to spindle-shaped slightly tuberculated spicules on the aboral side of the rachis of each tentacle (Figs. 3 and 4).

In the specimen of $T$. trichostemma in the same collection the tentacles are quite free from spicules.

The general surface of ectoderm of nearly all parts of the colony is destroyed by the encrusting sponge.

I am greatly indebted to Professor Topsent of Rennes for examining these sponges, and very kindly sending me a report upon them.

The sponge that occurs on the Mahlos atoll specimen is Prosuberites epiphytum (Lamarck). Professor Topsent tells me further that the blue-green colour is due to the Beggiatoaceae which frequently invade Terpis fugax, and were named by Carter Hypheothrix coerulea.

The sponge that occurs on the Mulaku specimen appears to be a new species of the genus Leptosia.

The characters of the new species may be diagnosed as follows:-Colony consisting of single upright axial polyps bearing a few secondary branches of the same nature. Several young polyps are borne by the main stem and secondary branches. All the polyps are completely retractile, the young polyps forming verrucae about $2 \mathrm{~mm}$. in height. The axial polyps, branches, and verrucae $1.75 \mathrm{~mm}$. in diameter in the Maldive specimens. Body-wall of the axial polyps and verrucae supported by a firm, perforated, tubular, calcareous skeleton, which is pink in colour. Very few free spindle-shaped spicules at the growing edges of the tubes. External surface of the tubes marked by eight longitudinal ridges. Tentacles of the polyps white or pale yellow, with eight or nine pinnae on each side supported by white curved spindles $(\cdot 14 \times 015)$ and other spicules. Locality, Maldive Islands, $23-25$ fathoms.

Telesto trichostemma Dana (5); Wright and Studer (22 and 23).

From Mulaku Atoll, 25 fathoms, fine mud and rubble, and Miladumadulu Atoll, 24 fathoms, from one of the eastern passages.

G. II. 
One of the specimens which, with some hesitation, I place in this species consists of three stems, one of which is connected with a characteristic flattened, anastomosing stolon growing on a sponge. The longest stem is $115 \mathrm{~mm}$. in length, and a little over $1 \mathrm{~mm}$. in diameter. The stems consist of a single axial polyp, bearing numerous lateral polyps, situated at an acute angle to it. As in T. trichostemma from Torres Straits, the spicules of the older parts of the colony join to form a solid cylinder marked externally by eight longitudinal ridges, but after boiling in caustic potash for some time the spicules can be separated into groups or clusters, and I cannot find that they are supported by a definite horny substance.

The spicules are very irregular in shape, but correspond in general form with those figured by Studer, they are however decidedly larger than those of the Challenger specimens, for whereas Studer gives $0.2 \mathrm{~mm}$. as the greatest length, there are very few of the larger spicules in my preparation less than $0.24 \mathrm{~mm}$. in length.

Studer states that the Challenger specimens were covered with an encrusting sponge. It is therefore remarkable that the Maldive specimen is not, considering the fact that both specimens of Telesto rubra from the same locality are so covered.

The Challenger specimen of this species was obtained in shallow water in Torres Straits, and it may be questioned whether it is really identical with the species figured and very imperfectly described by Dana from the Fiji Islands.

In the Maldive specimens most of the polyps are fully expanded, but the remainder show that the anthocodiae can be retracted as completely as in Telesto rubra. The tentacles are quite devoid of spicules, and are of a reddish-brown colour. They bear about 12 pinnae on each side.

The second specimen from Miladumadulu Atoll is only a fragment. It is much whiter than the Mulaku specimen, and the polyps are all retracted. Unfortunately the bottle containing this specimen was broken in transit, and it was quite dry on arrival.

The distinctions between the species of the genus Telesto have not at present been very clearly defined, and further anatomical investigation is desirable before any such definition is attempted.

I have examined specimens which have been attributed to the species Telesto rupicola from Bahia and from Jamaica in the collection of the British Museum, and have been much impressed with the general similarity in habit to these specimens from the Maldives. In the minute skeletal characters, however, the Maldive specimens resemble more closely the description given of 'T'. trichostemma from 'Torres Straits by Studer, and they differ, moreover, from T: rupicola in their opaque reddish-brown tentacles.

I have also examined a specimen of Telesto from the Persian Gulf, having close affinities with von Koch's Telesto prolifera from the Gulf of Siam, and a specimen labelled $T$. aurantiacu from Kurrachee in the collection of the British Museum.

I am inclined to believe that all these species ought to be merged into one, a very variable and widely distributed species, which should be called 'T' rupicola (Miiller). Until, however, further anatomical investigation has been made I think it is desirable to keep the American form distinct as $T$. rupicola, and to call the others $T$. trichostemma (Dana). There are not enough specimens in Mr Gardiner's collection to determine the extent to 
which the species varies in form in one group of islands. The species $T$. aurantiaca ought to disappear from the literature as Lamaroux' description of it is far too incomplete to be any guide to its determination.

\section{Family Nephthyidae Verrill.}

This family has recently been rearranged by Kükenthal (15), who recognises now only four genera; Ammothea, Paraspongodes, Nephthya, and Spongodes. Unfortunately we are still in almost complete ignorance of the anatomy of any of the species, and there are many reasons for regarding Kükenthal's new system as not entirely satisfactory. In the revised genera Nephthya and Spongodes the anthocodiae are supported on the outer side by one or more than one specially long spicule, the supporting bundle (Stiitzbiindel). These are not present in the other two genera. The genera Ammothea and Nephthya have the anthocodiae arranged in "catkins," in the other two genera the anthocodiae are in bundles or isolated.

As regards the "Stuitzbiindel" there may be observed in many colonies considerable variations in different regions, some anthocodiae possessing a very well-marked Stuitzbuindel, and others having no sign of one. On the other hand the very pronounced "catkin" arrangement which is seen in many specimens shades off into bundles with closely-set anthocodiae in a manner which often makes the determination of the genus a difficult one. For example, I had some difficulty in determining whether the arrangement of the anthocodiae in the specimen which I have referred to Nephthya inermis is or is not a "catkin" within the meaning of the definition. For the present, however, it is best to work upon Kukenthal's system, which possesses the great advantage of reducing very materially the number of ill-defined genera which appear in our literature.

Of the genus Spongodes about 70 species have been described from the Red Sea, East Coast of Africa, Malay Archipelago, China, Japan, Australia, New Guinea, New Britain (see 15, 17, 19). It is a remarkable fact that only one species, Spongodes (Morchellana) spinulosa. has been described from the Indian Ocean (9), and only one species of Nephthya ( $N$. burmaensis Ridley). The genus is very abundant in the Maldives, as the following notes show. I have a specimen from the Persian Gulf. I have several specimens from Singapore. It oceurs on the coast of Ceylon, and probably is abundant all over the Indian Ocean.

Time has not permitted me to make a detailed examination of all the specimens, and I feel that the task of attempting to identify them with any of the seventy defined species or to describe any of them as new to science would yield results out of all proportion to the labour involved. The presence of so many specimens of different forms of growth, of colour, of spiculation living under very similar conditions in one group of islands suggests very forcibly that all these specimens represent but different facies of one variable species. Anatomical investigation of a thoroughly searching character can alone determine this point, and until it is made the task of species-making should in my opinion be suspended. A very large number of the new species that have been described are founded upon one small specimen.

We have no information to guide us as to the changes that take place during the growth of a colony from a height of $20 \mathrm{~mm}$. to a height of $200 \mathrm{~mm}$., nor the influence that variations in depth, in the strength of tides, or the nature of the sea-bottom, the associated crab, mollusks, and other creatures have upon the colour, form, and size of the colonies. 
We must remember that nearly all the specimens that are brought to Europe from the tropical seas preserved in spirit are small specimens. They are probably also young specimens of large species. Full-grown specimens may reach a size of 300 to $400 \mathrm{~mm}$. or more in diameter, but these are not easy to detach from their base of attachment, and it is, as a rule, impossible to preserve them satisfactorily and send them home.

The study of the Spongodes collection from the Maldives throws, however, a little light on one or two points of general interest.

In the first place we find in this one archipelago a very wide range of variation. The colour of the spicules varies from pure white (as in the specimen from Kolumadulu) through many shades of yellow, orange, brown, pink, red, purple, chocolate to black (as in the stalk of the specimens from Fadifolu).

In some forms the spicules are enormously large, in others they are relatively small.

A few forms with very divaricate branches are found, but others have a remarkably compact habit of growth.

These differences are not more pronounced between specimens found in the extreme north of the archipelago and those in the extreme south. On the contrary, the specimens from the same atoll are sometimes most diverse in colour. For example, the large coarse golden-yellow specimens from N. Male, 20 fathoms S.W. of the atoll, are in marked contrast to the delicate chocolatecoloured specimens from 24 fathoms in the shoal at the centre of the atoll, and the pale yellow form, like Spongodes flabellifera found in the S. atoll in 25 fathoms. Three small specimens from Hulule Male, 25 to 30 fathoms, are so much alike in colour, spiculation and size of anthocodiae that they clearly belong to the same species, and yet they are of such different form of growth that they might be delegated to different divisions of the genus. The specimen from Miladumadulu in the north of the archipelago is very closely related to the single specimen from Addu in the extreme S. They are much more closely related than are the two duskybrown specimens and the two red divaricate specimens which were obtained in the same dredging in the Fadifolu atoll. There is nothing to show that geographically there are any limits to the distribution of the species within the archipelago. There are probably no characteristic features distinguishing the Spongodes of one atoll from that of another. But we can go further than this and say that there are no characteristic features which appear to distinguish the Spongodes of the Maldives from those of suitable localities in the other regions of the Indian and Pacific Oceans. There are specimens from the Maldive archipelago that clearly belong to the same species as specimens in my collections from Singapore, New Britain, and Fiji. There can be no doubt that specimens are present in the Maldives, which under our present system would be referred to Holm's species (13) Spongodes spinifera, founded on a specimen obtained in the Fiji Islands, to Kükenthal's species (15) Spongodes splendens, founded on a specimen obtained in 'Ternate, to Studer's species (22) S. flabellifera, obtained in Jap:n.

All these facts appear to me to point to the conclusion that the species of the genus Spongodes are extremely variable, and have a very wide geographical range in tropical waters. Whether there is only one true species is a question to which with our present want of exact anatomical knowledge no answer can be given. I am convinced, however, that the characters upon which new species have been founded in recent years in such large numbers are untrustworthy for the purposes.

Two lines of inquiry might yield interesting results. Firstly, there should be a careful 
anatomical comparison of the structure of the stomodaeum, mesenterial filaments, and canal systems of two or three distinct facies, and secondly, a numerical statement of the range of variation in the length of the spicules of the Stuitzbuindel, the number of anthocodiae on the secondary branches and other measurable characters in the different parts of one large colony.

The following is a list of the specimens sent to me of the genus Spongodes.

From Miladumadulu, 24 fathoms; in an E. passage. A small specimen about $30 \mathrm{~mm}$. in height, having the general form of $S$. splendens (Kükenthal). Stalk and branches white, anthocodiae pink.

Another small specimen from the same atoll 20 fathoms, off the reef. This is a little larger than the first specimen. The colour of the anthocodiae is darker, and extends on to the secondary branches, where it shades off into orange.

From Mahlos Atoll, 23 fathoms. A small specimen, about $30 \mathrm{~mm}$. in height, with divaricate branches, having a close resemblance to the description given of Spongodes rubra (May) from the Philippines. The stalk and branches are red. The spicules of the tentacles white.

From the same atoll 22 fathoms, passage to $\mathrm{N}$. of Fainu, two small specimens, one white with purplish red supporting spicules, the other yellow with orange terminal branches.

From Fadifolu, 25 fathoms. Middle of N. part of atoll. Two beautiful but small specimens of a form similar to that described as Spongodes flabellifera (W. and S.). They are of a delicate shade of pale yellow, with white anthocodiae.

From the same atoll 14-20 fathoms there are four specimens. Two are of a dusky-brown colour, and are of the same facies as the two specimens mentioned. The other two are more divaricate, with larger anthocodiae, and the colouring is very remarkable. The stalk is black to very dark brown, the branches red, and the anthocodiae white. The form of growth is very similar to that of S. rubra (May).

From the same atoll and dredging a very fine specimen $100 \mathrm{~mm}$. in height with a stalk $30 \mathrm{~mm}$. is preserved, coming nearest to Kükenthal's species S. splendens. The stalk is yellow, branches yellowish-red, terminal branches red, and the crown of tentacles white.

From N. Male one specimen from 20 fathoms S.W. of atoll, and two specimens labelled Hulule, Male A., answer to the description of Spongodes spinifera Holm.

There can be little doubt that these specimens are closely related to the specimen upon which Holm (13) founded his species, although they appear to be older and more fully developed examples of it. The characteristic features of the species are (1) the enormous spicules of the walls of the branches, (2) the very long projecting chief spicule of the Stuitzbiundel, and the dark gold or yellow ochre colour.

I may here call attention to two serious misprints in the literature of the species. In Holm's paper (p. 39) the length of the spicules of the wall of the branches is given as $0.7 \mathrm{~mm}$. It is quite clear that the statement on p. 40 that these spicules may attain a length of $7 \mathrm{~mm}$., however, is the correct one.

In Kükenthal's table (15) of the species of Spongodes the length of these spicules is given as $4 \mathrm{~mm}$., an obvious misprint for $7 \mathrm{~mm}$.

The specimen from 20 fathoms is $100 \mathrm{~mm}$. in height, with a stalk $35 \mathrm{~mm}$. in length by 30 in diameter. The spicules of the wall of the branched portion of the colony are very 
large, and irregularly scattered. Many of them reach to the extreme length of $7 \mathrm{~mm}$., and frequently exhibit one bifurcated extremity. The colour of the colony is dark golden.

The two specimens from Hulule, Male, are rather smaller. The spicules of the walls of the branched portion are not quite so large as in the N. Male specimens, not exceeding $6 \mathrm{~mm}$. in length, and I have noticed only a very few with a bifurcated extremity. The spicules, however, in this part of the colony and in the polyps are rather stouter in build than in the 20 fathom specimen, the largest spicules of the former specimens being about $5.5 \times 0.7 \mathrm{~mm}$. and of the latter $7 \times 0.7 \mathrm{~mm}$.

From N. Male, 24 fathoms. Three specimens of a dark-chocolate colour, having the general form of S. splendens (Kükenthal), were obtained near the shoal at the centre of the atoll.

From N. Iale, 25 fathoms. One specimen yellow in colour, having the form of S. fabellifera, was found in the middle of the S. atoll.

From N. Male, 27 fathoms. A fragment, from a form similar to the last-named facies.

From Hulule, Male Atoll, 25 to 30 fathoms. Four small specimens. One uniformly pale yellow. Three with yellow stalks and branches, red supporting spicules, white tentacles. The form of growth is variable in the three last-named specimens. They would be regarded perhaps as young specimens of Spongodes splendens.

From S. Nilandu, 25 fathoms, W. Passage. This is a small specimen $30 \mathrm{~mm}$. in height, of very compact form of growth, similar in some respects to S. glomerata (May). Associated with it were a red chiton and a pelecypod.

From Kolumadulu, 35 fathoms. This specimen, about $40 \mathrm{~mm}$. in height, is perhaps the most beautiful of the series. The stalk is white, the branches and anthocodiae also white, but the main stem contains a few large scattered pale purple spicules. It has a close resemblance in many respects to Holm's species Spongodes pallida, but the lowermost expanded branches are most delicately fringed so as to have an appearance like fine lace.

From Haddumati, 40 fathoms. A small specimen of a pale brown colour related to the last named.

Two specimens from Suvadiva Atoll, 25 fathoms. Across the mouth of a passage. The specimens are about $80 \mathrm{~mm}$. in height, with a maximum expanse across the arms of $80 \mathrm{~mm}$. The base is missing in both specimens. From a thick main stem several branches arise, which may again divide into several branches of the second order, which bear the clusters of anthocodiae. There are 15-20 anthocodiae in each cluster. The colour is uniformly rose-pink in the main stem and branches, but somewhat dark in the terminal twigs and anthocodial clusters. The colour appears to be entirely due to the spicules, which are long, delicate spindles, irregularly scattered on the surface branches. These spicules vary considerably in size. They are on an average $5 \mathrm{~mm}$. in length, but many are $7 \mathrm{~mm}$., and a few that $I$ have measured were $9 \mathrm{~mm}$. in length. These are, I believe, the longest spicules known in the group of the Alcyonaria. In the anthocodiae one or two spicules $3 \mathrm{~mm}$, in length, predominate, projecting one or two millimetres beyond the tentacles. The rest of the spicules of the anthocodiae are small and slightly curved. They appear to be smaller $(0.75-0.5$ in length) than in the type-specimen $(1.0 \mathrm{~mm}$.). They are also thicker.

The specimens agree better with the description of W. and S.'s species S. macrospina than with that of any other, but in the extraordinary length of the spicules of the branches and in the smaller of the secondary spicules of the anthocodiae they present differences which in the opinion of some authors might be regarded as of specific value. 
From the same atoll, 31 fathoms. A specimen about $45 \mathrm{~mm}$. in height, having the general form of S. splendens (Kükenthal), with pale yellow stalk, yellow branches, and purplish-red supporting spicules.

From the same atoll, 39 fathoms. A small very divaricate form with white stalk and stem, but the terminal branches and supporting spicules bright orange in colour.

From Addu Atoll, 25 fathoms. Near a passage. A small red specimen of very compact habit, like the specimen from S. Nilandu.

In addition to the numerous specimens of the genus Spongodes in the collection there are two specimens which must be referred to the same family, but as one of them is probably a young colony and the other only a fragment of a colony I have not very carefully studied them.

\section{Nephthya inermis Holm. (?)}

Kolumadulu Atoll, 22 fathoms, near W. Passage. This specimen is of a dull brown colour. It is $50 \mathrm{~mm}$. in height, with a stalk $25 \mathrm{~mm}$. in length. It appears to be closely related to Holm's specimens from the Hirudo Straits, Japan, 36 fathoms. Holm's largest specimen was $550 \mathrm{~mm}$. in height.

\section{Paraspongodes pustulosa (W. and S.) (?)}

Mahlos Atoll, 23 fathoms. Inner part of passage to S.E. This specimen is apparently only a portion of a branch. It is $50 \mathrm{~mm}$. in length, with numerous irregular purplish-red spicules in the superficial parts of the coenenchym and yellow spicules in the crown and tentacles. Wright and Studer's specimen (described under the genus Scleronephthya) came from a depth of 18 fathoms off the Philippine Islands.

\section{Family Siphonogorginae.}

\section{Genus Chironephthya (Figs, 8, 9, 10).}

The genus Chironeplthya was constituted by Wright and Studer (22) for three species obtained by the Challenger expedition on the Hyalonema ground, Japan, in 345 fathoms. The genus has somewhat the form of a Nephthya, but undoubtedly approaches most closely to the genus Siphonogorgia (Köll.). According to the authors, however, it differs in that it "is essentially distinguished from Siphonogorgia by the fact that the polyps occur along the entire course of the branches, and are less retractile." As regards the first of these, the distinction breaks down in the fact that in the species Siphonogorgia pustulosa, described by the same authors in the supplement to the Alcyonaria and in Kükenthal's species $S$. miniacea and $S$, cylindrica (15) the polyps, i.e. the anthocodiae, occur all along the branches as in Chironephthya. As regards the retractility of the polyps, a point upon which less stress can be laid, as I have previously pointed out, it must be noted that the polyps of Siphonogorgia pustulosa (W. and S.) do not appear to be much more retractile than those of Chironephthya. The increase of knowledge of these two genera shows that they are very closely related, and should perhaps be merged into one. The three species hitherto known do not appear to me to differ very materially from one another, and it is highly probable that when more specimens are obtained from the same ground intermediate varieties will be found. In 1900 Miss Hiles (12) described two fragments of a Chironephthya with characters 
most closely approximating to the description of $C$. scoparia. This specimen was obtained by Dr Willey in shallow water off the coast of New Britain. I have recently discovered in a collection made by Mr Bedford at Singapore a specimen of Chironephthya from 10 fathoms of water, which I hope to describe in a future memoir. In Mr Gardiner's collection from the Maldives there are several specimens obtained in water of about 20 fathoms in depth which present several features of particular interest.

Since the publication of the Challenger reports, then, we have learned firstly that the genus is not confined to deep water, and secondly that it has a wide geographical distribution in the eastern seas. It must also be noted here in anticipation of the special description which follows that notwithstanding certain features in which the species or "facies" resemble one another, there is such a well-marked variability in other important structures that it is extremely difficult to determine even provisionally the range of specific characters. It really becomes a question whether it is more convenient to consider all the specimens hitherto obtained to belong to one widely distributed but very variable species, or to describe almost every specimen that is obtained as a new species. Our knowledge is not yet sufficiently advanced to adopt the former course, and the latter appears to me to be contrary to the general trend of increasing knowledge and quite unscientific.

Chironephthya variabilis. New species.

The specimens collected by Mr Gardiner may be arranged as follows:

From Mahlos Atoll 20 fathoms, N.E. Lagoon. Two complete specimens $(A, B)$ and several fragments $(C)$.

From Mahlos Atoll, 22 fathoms, N. Fainu. One complete specimen $(D)$ and fragment $(E)$.

From Mahlos Atoll, 23 fathoms. Several fragments $\left(F^{\prime}\right)$.

From S. Nilandu, 24 fathoms. One complete specimen $(G)$ and some fragments $(H)$.

There are also smaller fragments from dredgings in nearly all the atolls.

The sizes of the complete specimens were

$$
\begin{aligned}
& A, 45 \mathrm{~mm} \text {. in height. } \\
& B, 34 \mathrm{~mm} \text {. in height. } \\
& D, 50 \mathrm{~mm} \text {, in height. } \\
& G, 65 \mathrm{~mm} \text {. in height. }
\end{aligned}
$$

The most striking feature in connection with these specimens is the extraordinary variability in colour. The colour of the spicules of the anthocodiae is usually in marked contrast to that of the general coenenchym. The spicules of the anthocodiae are arranged in a well-developed circlet round the base of the tentacles, which I shall for brevity call the "crown," and in a triangle guarding the lower part of the aboral surface of the tentacles. These triangles I shall call for the same reason the "points" (Figs. 9 and 10).

The range of colours is as follows:

A. General coenenchym speckled red and yellow at the base, yellow in the upper part of the stem and branches, very pale yellow crown and points.

B. G. C. dark red at the base fading into pink in the upper part of the stem and branches; crown and points dark purple. 

purple.

C. G. C. yellow, shading into pink at the termination of the branches, crown and points

D. G. C. red, with a few yellow spicules occurring irregularly among the red ones; crown and points yellow fading into white, the spicules of the crown being more frequently yellow than those of the points.

E. G. C. yellow; crown and points purple.

F. G. C. pink; crown and points purple. (Some fragments have G. C. yellow.)

$G$. G. C. of the stem red, fading into yellow in the main branches; crown and points orange.

The specimen $D$ (Fig. 8) having a total height of $50 \mathrm{~mm}$. has a stalk (barren stem) $23 \mathrm{~mm}$. in length, it is slightly expanded at the base, where it is $8 \mathrm{~mm}$. in diameter and $6.75 \mathrm{~mm}$. at the level of the lowest branch. It bears ten small branches, given off irregularly from all sides of the stem, and some of the larger of these bear rudimentary branchlets. The anthocodiae are crowded at the termination of the branches, but occur more scattered on all parts of the branches and main stem above the stalk. Specimen $G$, having a total height of $65 \mathrm{~mm}$., has a stalk $36 \mathrm{~mm}$. in length. The expanded base of attachment is $11.25 \mathrm{~mm}$. wide, and the stalk narrows to a diameter of $3.5 \mathrm{~mm}$. at the level of the lowest branch. There are only six short branches, the longest being $10 \mathrm{~mm}$. in extreme length.

Further description of these complete specimens is unnecessary, as it is perfectly obvious that they are young colonies which would have altered very materially in form and probably in colour also had they grown to the full size.

The fragments $(H)$ from the same locality are in all probability branches of a larger colony which may have reached its maximum size. On these we find a cluster of four or five anthocodiae at the extremity, and others scattered at intervals of $3-5 \mathrm{~mm}$.

It is impossible to say from the evidence of this collection to what size the colonies may grow. I have seen a specimen obtained by Professor Herdman off Ceylon which is over 1 foot in diameter.

In none of the specimens can it be said that there is a very clearly defined spiral arrangement of the anthocodiae, although on some branches an ill-defined spiral arrangement can be observed. I do not consider that the spiral arrangement of the anthocodiae can be used as a character of any specific importance, as it is clearly subject to considerable variation.

In order to discover if possible some character which would be useful as a guide to specific identification I made a careful examination of the anthocodiae of several specimens and branches, carefully comparing the arrangement of the spicules of the crown and points of neighbouring tentacles and polyps. The result was rather disappointing, as a considerable variation was observed throughout. The arrangements of the spicules of the point are not alike even in tentacles of the same polyp, and the range of variation in anthocodiae of the same branch is surprising. However, the investigation has yielded certain general results which may be stated as follows. In the crowns of Chironephthya variabilis (Figs. 9, 10) there are usually about ten rows of spicules arranged parallel with one another, and at right angles to the long axis of the anthocodiae. In the points there are four large and prominent spicules arranged en chevron, of these the two outer ones are usually larger than the inner. The outer and larger spicules are frequently bent slightly in the middle. The two outer spicules of the chevron are the largest spicules of the anthocodiae. In the angle of the chevron other spicules intrude, the number of which varies with the age of the anthocodiae.

G. II. 
The size and shape of the spicules vary considerably. In young anthocodiae, as for example on $D$ (Fig. 9), the largest spicules of the points were $0.5 \mathrm{~mm} . \times 0.04 \mathrm{~mm}$, and the spicules of the crown $0.5 \mathrm{~mm} . \times 0.015 \mathrm{~mm}$. In older anthocodiae, as for example on $F$, they were respectively $0.6 \times 08$ and $0.5 \times 0.4$, and in $E 0.7 \times 0.085$ and $0.5 \times 0.05$ (Fig. 10).

The spicules of the points in $E$ might be described as tightly packed, a large number being wedged into the basal part of the triangle, and in the crown the greater stoutness of each spicule causes them to lie much closer together than in the crown of $D$. This tight packing of the spicules of the older specimens renders the anthocodiae much less retractile than in the younger specimens. There is another series which is less regular. The spicules of the anthocodiae of the youngest specimens are usually white, or pale yellow, those of the oldest purple. It is usually in the purple specimens that we find the tightest packing of the spicules. Thus in $D$ the spicules are white, in $F$ orange, and in $E$ purple. It seems a reasonable proposition to suggest that the colouring matter of these spicules changes from white to purple as the colony approaches the light, or as they increase in age, and that the noticeable variations in the series are due to local differences in surroundings.

Before comparing Chironephthya variabilis with the species C. dipsacea, C. scoparia, and C. crassa of Wright and Studer (22), it may be pointed out that these authors do not state definitely that the measurements given below refer to the largest spicules of the polyps, but it is probable that this was their intention.

\begin{tabular}{|c|c|c|c|c|c|c|}
\hline & $n$ & variabilis (mihi) & $T$ & C. dipsacea & C. scoparia & C. crassa \\
\hline $\begin{array}{l}\text { Crown } \\
\text { Spicules }\end{array}$ & $0.5 \times \cdot 015$ & $0.5 \times 0.05$ & $0.5 \times 0.04$ & $0.2 \times 0.03$ & $0.7 \times 0.04$ & $0.67 \times 0.05$ \\
\hline $\begin{array}{l}\text { Point } \\
\text { Spicules }\end{array}$ & $0.5 \times 0.04$ & $0.7 \times 0.85$ & $0.6 \times 0.08$ & $0.12 \times 0.017$ & $0.54 \times 0.03$ & $0.9 \times 0.13$ \\
\hline
\end{tabular}

If Wright and Studer's measurements refer either to the greatest size or to the average size of the spicules in these situations it is clear that the range is much greater between $C$. dipsacea and $C$. crassa than it is between any two examples that $I$ have studied in this collection. As regards the arrangement of the spicules Wright and Studer state that in $C$. dipsacea and $C$. scoparia the spicules of the points are arranged in a $\Lambda$-shaped manner, but no detailed description or figure has been given.

I may say, however, that from a careful examination of the type specimens in the British Museum I am convinced that the arrangement of the spicules of the points in all three of the Challenger species is essentially the same as it is in C. variabilis mihi. There are variations in size and in crowding as in the Maldive specimens, but the four principal spicules of the points can be recognised in most of the anthocodiae I examined. Turning now to the question of the colour. A glance at the type specimens of the Challenger species shows how variable is the colour of the spicules. The description given by the authors is accurate so far as it goes, but as a matter of opinion it does not appear to me to give enough detail of the differences in colour between branch and branch of the same specimen, or the gradual fading of one colour into another on the stem, as to do full justice to the subject. I think that any impartial naturalist who carefully examined these specimens would say that colour is a character of very little value in the attempt to separate these three species.

It is not my purpose to go fully into the accounts given of the arrangement of the 
anthocodiae, the mode of branching, the size of the spicules of the coenenchym and the other characters of the Challenger specimens; but I think it will be found in the future that it is not adrisable to recognise in them more than one species. I propose to give a new specific name to the Maldive specimens for various reasons, but $I$ am prepared to admit that the specific distinctions between them and the Challenger specimens are slight and unimportant.

I think, however, it will be found that in the specimens proposed to be named $C$. variabilis the spicules are on an average larger and more regularly arranged in the coenenchym, that the colour, branching and arrangement of the anthocodiae are more irregular (i.e. less in conformity with a spiral arrangement), and the anthocodiae rather larger and more retractile than in the Challenger species. It is better, however, to leave the matter in an undecided position until more specimens are obtained from a depth of over 200 fathoms.

The next question is, How are we to distinguish the genus Siphonogorgia from Chironephthya now that the two characters given by Wright and Studer as diagnostic of the latter genus have broken down?

Having carefully compared the specimens of Chironephthya variabilis with Siphonogorgia mirabilis from the Maldive archipelago, I would suggest that the name Chironephthya be retained for the species or facies with a formi and mode of branching resembling that of the genus Nephthya, with anthocodiae rarely completely retracted in preserved specimens, and with four principal spicules arranged en chevron in the points of the anthocodiae (Figs. 9 and 10); and that the name Siphonogorgia be retained for species or facies of more massive Gorgonia-like form of growth, with anthocodiae capable of complete retraction within the general coenenchym and with spicules irregularly placed or arranged in a fan-like manner in the points of the anthocodiae (Fig. 11).

As regards the second of these characters it may be pointed out that in Siphonogorgia pendula (W. and S.) and the variety of Siphonogorgia pendula described by Kuikenthal as ternatana, the anthocodiae do not appear to be completely retractile. But Kükenthal's variety would be more properly referred to the genus Chironephthya, and the type must be regarded as an intermediate form between the two genera which it is convenient for the present to retain in the genus Siphonogorgia on account of its Gorgonia-like form.

As regards the third character, Siphonogorgia pendula (W. and S.) and Kükenthal's variety ternatana have the spicules of the "points" arranged in a manner very similar to that of Chironephthya. There is no very careful description or figure of this feature, in other species, owing to the retractility of the anthocodiae rendering the observation a difficult one.

In the specimens from the Maldives which I have referred to the species $S$. mirabilis an examination of nearly a hundred anthocodiae showed that only in a few rare cases there are four prominent spicules arranged en chevron as in Chironephthya; but in the majority of cases there is one prominent median spicule with four or five bent spicules arranged fanwise on each side of it, as shown in Fig. 11.

The species Siphonogorgia macrospina described by Whitelegge (24) from Funafuti from a few fragments appears to me to be more correctly referred to the genus Chironephthya.

It is probable from the literature of the subject that in most of the species of Siphonogorgia the arrangement of these spicules is similar to this, and it is also probable that this arrangement is intimately associated with the power of retraction of the anthocodiae. 
Siphonogorgia mirabilis Klz. (Figs. 11 and 12.) Klunzinger (14) and Kuikenthal (15).

Two fragments, A, from Suvadiva Atoll, 25 fathoms across the mouth of the passage, B, from Fadifolu Atoll, 70 fathoms outside atoll N.W. on steep slope.

These two fragments differ in some important particulars from Klunzinger's species and from one another, but it will be more convenient at present to name them Siphonogorgia mirabilis Klz., and to point out the chief points of disagreement with the type specimen than to refer them to a new species.

Fragment A from Suradiva may be only a primary branch of a large colony. It is $110 \mathrm{~mm}$. in length, with nine branches on one side and five on the other. Only one of these branches shows any tendency to further ramification.

In specimen $\mathrm{B}$ it is possible we have an almost complete specimen with only the base missing. It is $100 \mathrm{~mm}$. in length, and is very much broken up, but some of the longer branches exhibit secondary and even tertiary ramification.

Both of these fragments have a dirty-blackish crust, formed by an epizoic sponge, covering both stem and branches. In specimen B this crust is so thick on many of the branches and a part of the main stem as to completely hide the red colour of the coenenchymal spicules, but in $\mathrm{A}$ the red colour can be seen through the sponge, as also in the main stem and some of the branches of B. The sponge belongs to the genus Halisarca, and I am informed by Professor Topsent it probably belongs to the species $H$. Dujardini. In both specimens anthocodiae can be clearly seen, and are particularly noticeable owing to their bright yellow colour.

The specimens agree with the original specimen of Siphonogorgic mirabilis in the following particulars.

The colonies branch in one plane, sometimes dichotomously. The stem and branches are almost cylindrical, the finest branches irregularly angular. The extremities of the finer branches are blunt, and bear from 4-6 anthocodiae. The anthocodiae occur on all sides of the branches and twigs, but are scarce on the larger branches, and fail altogether on the lower part of the stem (specimen B).

The spicules of the coenenchym are spindles covered with warts and knobs, and of a deep red colour. They are irregularly arranged on the main stem and larger branches, but almost parallel with the axes on the smaller branches. The spicules of the anthocodiae are yellow in colour, slender spindles, with sparse warts and tubercles.

The most important point of difference to be observed between the Maldive forms and the type lies in the size of the spicules. According to Klunzinger the largest spicules of the coenenchym are $0.5 \mathrm{~mm} . \times 0.128$ broad. In the Maldive forms some of the largest spicules are $4 \mathrm{~mm} . \times 0.2 \mathrm{~mm}$, but the average is about $2 \mathrm{~mm} \times 0.15 \mathrm{~mm}$. The size of these large spicules varies so much in some of the species that it is doubtful whether much reliance can be laid upon the figures given by some authors as being by any means exclusive. Kölliker in his original description of Siphonogorgia godeffroyi states that the spicules vary from $1-4 \mathrm{~mm}$. in length. In the Challenger series the sizes of these spicules are given by Wright and Studer as follows, S. pallida $2 \times \cdot 3$, S. pustulosa $2 \times \cdot 38$, S. pendula $2 \cdot 8 \times \cdot 224$, S. Köllikeri $1 \cdot 2 \times 0 \cdot 2$, and the spicules of Kükenthal's species were S. cylindrata $3.7 \times 0.4$, S. miniacea 1:3 $\times 0.14$. It is to be observed, however, that in none of the descriptions of the species these spicules are said to be so small as $0.5 \mathrm{~mm}$. in length as stated to be the ease by Klunzinger in $S$. mirabilis. From the fact that Klunzinger's excellent work is unfortunately hampered by many 
misprints, coupled with a study of the lowermost of his four figures marked $d$, which appears to be the point of a large spicule 2 or more $\mathrm{mm}$. in length, and that the author does not comment on the small size of these spicules as compared with those of $S$. godeffroyi, a doubt may arise as to whether $0.5 \mathrm{~mm}$. in his description is not a misprint for $5 \mathrm{~mm}$.

Even if the spicules are so small as they are stated to be in Klunzinger's specimen it does not seem to me that this is a sufficient reason for making the Maldive specimens into a new species. The size of the spicules of Alcyonarians varies very much in different localities and conditions of growth, and there might well be a considerable range in this respect in one species that occurs over such a wide range as the Red Sea and the Maldives.

Klunzinger makes a note at the end of his description that "Beim Trocknen tritt die Bindesubstanz durch ihre weisse Farbe vor und giebt dem Ganzen ein staub- oder schaumartiges Ansehen oder wie weiss und roth gesprenkelt und das Roth tritt zurück."

I have found that on drying a small portion of one branch of specimen B that the encrusting sponge turns white, and gives the specimen very much the appearance described by Klunzinger. It is quite possible, therefore, that what this author describes as the superficial connective tissue is in reality an encrusting sponge.

The bright yellow colour of the spicules of the anthocodiae which forms such a very conspicuous feature of these specimens is a minor point of resemblance with the type of $S$. mirabilis. In Siphonogorgia pustulosa (W. and S.) we have a similar combination of yellow spicules in the anthocodiae with red spicules in the coenenchym. In S. cylindrata (Kük.), the spicules of the anthocodiae are also pale yellow, the spicules of the rest of the colony being yellow.

The slender spicules of the crown and points of the anthocodiae vary in size, but average about $: 3 \mathrm{~mm}$. in length, i.e. only a trifle longer than those of the type specimen. The arrangement of the spicules in the points, i.e. on the aboral side of the tentacles, has been described above under the genus Chironephthya.

The geographical distribution of the genus Siphonogorgia, as it is at present known, is interesting. Specimens have been obtained from the Pelew Islands, Ellice Islands (Funafuti), N.W. Australia, New Hebrides, Malay archipelago, and one specimen hitherto found in the Red Sea. The discovery of Siphonogorgia in the Maldives fills up a gap between the extreme East and West limits, and suggests that it may occur in other suitable localities of the Indian Ocean.

\section{Family Briareidae.}

\section{Genus Solenocaulon (Gray).}

The general features of this genus were first described by Gray (8). Subsequently Genth (6) described with considerable detail an Alcyonarian from the Philippines, which he named Solenogorgia tubulosa. Later on Studer (21) in describing a new species (Solenocaulon grayi), gave reasons for including Genth's specimen in Gray's original genus Solenocaulon. Six years ago Germanos (7) in his paper on the Gorgonacea of Ternate gave a historical review of the genus, and added three new species.

In Germanos' interesting and important contribution to our knowledge of the genus he proposed to arrange the six known species into two groups as follows: 
1. Sub-genus Sclerosolenocaulon.

\author{
Solenocaulon tubulosa, Genth. \\ Solenocaulon sterroklonium, Germ. \\ Solenocaulon diplokalyx, Germ.
}

2. Sub-genus Malacosolenocaulon.

\author{
Solenocaulon tortuosum, Gray. \\ Solenocaulon akalyx, Ternate. \\ Solenocaulon grayi, Studer.
}

A careful consideration of Germanos' laborious investigation in the light thrown upon the subject by Mr Gardiner's fine collection and the type specimens in the British Museum has led me to the conclusion that this arrangement of the species is not satisfactory. The first and most important character that is used by this author for the separation of the sub-genus Sclerosolenocaulon from Malacosolenocaulon is the presence of a stalk. It appears to me to be still a matter of doubt whether there are any specimens of Solenocaulon without in stalk, since the original specimen described by Gray certainly has a stalk, which is solid, and the specimen attributed to the same genus by Studer was incomplete at the base, and therefore afforded no evidence on the subject. The specimen upon which Germanos bases his species S. akalyx consisted only of "zwei grosse Stuicke," and as no description, figure, or even statement is given of the base of attachment, it is reasonable to suppose that it was missing. The stalk is also missing in the only specimen that has hitherto been described of the species S. grayi, Studer. It is difficult to understand how Germanos could have overlooked these facts in drawing up his classification, unless it is supposed he uses the word stalk "Stiel" in a sense which is not usual. As regards the character of the axis which plays an important part in this classification, I may say that Studer's description of the axis "aus durch Hornmasse verbundenen, losen, spindel-förmigen Spicula bestehen" accurately describes the axis of Mr Gardiner's specimens. I cannot understand what is meant by the statement that in the branches of Solenocaulon tubulosa, S. sterroklonium, and $S$. diplokalyx the spicules are fused to form a solid axis. If we are to understand that the calcareous spicules are fused together to form a solid calcareous rod as in the axis of Corallium or the tubes of Tubipora, then it may be regarded as a character of specific or even of subgeneric importance, but Germanos brings little evidence to prove that this is the case. In many of the smaller branches of my specimens I find the spicules of the axis so tightly packed together as to form a porous calcareous rod as figured by Genth, which does not break up on boiling in $5 \%$ potash, but as Genth adds, "Die verschmolzenen Spicula gehen ohne merkliche Grenze in die freien über." Whether the spicules do or do not become so tightly packed as this in the branches depends upon the rapidity of growth of the individual branch, and is not of the slightest systematic importance. If the spicules fused in some forms to form a solid axis in the stem or stalk and not in others, we should have a character of prime importance, but the axis of the stem and stalk is admittedly the same in all species.

The species Solenocaulon tortuosum Gray and Solenogorgia (Solenocaulon) tubulosa Genth differ from one another principally in the fact that the latter gives off from the main tubular stems several short grooved blunt branches bearing numerous anthocodiae. In the 
former these branches are rather longer and narrower. In S. grayi (Studer) the grooved branchlets are much longer, more delicate, and pointed or knobbed at the extremity. S. $t u b u$ losa is therefore as regards its form intermediate in character between $S$. tortuosum and S. grayi. If we eliminate these characters of form there is, it appears to me, very little to distinguish the species. Now in considering the growth of a form like this we must not leave out of consideration the fact that spirit specimens prove that usually and perhaps always, the tubes of Solenogorgia contain epizoic Crustacea belonging to the genus Alpheus. The general appearance of the groove on one side of the non-tubular terminal branchlets, in specimens similar in form to that described by Studer as $S$. grayi, suggests that these Crustacea are in the habit of running along them in search of food, and retreating to the tubular parts for protection. The general characters of the groove are the smoothness of the surface as compared with the outer convex side of the branch, the absence of anthocodiae, and the relatively pale colour. These are characteristics which we should expect to find if any part of the surface of a coral were constantly irritated by the feet of an active little crustacean. Now it is well known that in many forms of corals such as Pocillopora, Seriatopora, Millepora, etc. one effect of a symbiotic crab on the growth is the formation of a spherical or oval gall, the margins of the affected part being hypertrophied and growing round and enclosing the animal that causes the irritation. Similarly, barnacles of various species cause gall-like growths of the coenenchym in various Madreporaria, Millepora, Gorgonia, and other Alcyonaria. An examination of the surface enclosed or about to be enclosed by the galls of Pocillopora, Seriatopora, and Millepora shows a smoothness of the surface, and, in Nillepora, an absence of polyps similar to that shown in the groove of the Solenocaulon branchlets.

It appears to me therefore very probable that the tubular character of Solenocaulon is of the nature of a gall produced by an active crustacean, and that the degree to which it affects the secondary and tertiary branches depends, not upon any inherent specific character of the Solenocaulon, but upon the number or activity of the symbiotic erustacea.

Whether this explanation is true or not, it is not satisfactory from a systematic point of view to distinguish as distinct species specimens which differ from one another principally in their form of growth. The many striking similarities that there are between $S$. tortuosum of Gray, S. tubulosa of Genth, and $S$. grayi of Studer in the shape and arrangement of the spicules and other characters suggest very forcibly that they all belong to one widely distributed species.

This conclusion receires considerable support from the examination of the very rich and interesting collection of the specimens of this genus made by Mr Gardiner, and I shall therefore place them all, except one which I believe to be the type of a new species, in one species.

\section{Solenocaulon tortuosum Gray. (Fig. 13.)}

It will be convenient to give in the first place a list of the specimens, with a short description of each one.

A. A small specimen of a pale pink colour. About $145 \mathrm{~mm}$, in height. Stalk $75 \mathrm{~mm}$. long, $5 \mathrm{~mm}$. in diameter. Most of the lateral flattened branchlets short. Suvadiva, 43 fathoms. Lagoon. Hard rubble. 
B. A dried specimen rather broken, but of approximately the same size and form of growth as A. Pale cream colour. Suvadiva, 37 fathoms. Near a passage. Hard sand.

C. A specimen about $170 \mathrm{~mm}$. in height with axis divided into two main branches (Fig. 13). Stalk $60 \mathrm{~mm}$., bifid at base. There are few narrow grooved branchlets. Colour, orange-brown. Suvadiva, 38 fathoms. In a passage. Rubble bottom.

D. Two fragments, with rather longer grooved branchlets than in A. Colour, a rich pink, darker in tone than A. Fadifolu, off W. side, 22 fathoms. Weed, sand, and small coral.

E. A specimen in fragments. It was probably twice as large as $\mathbf{A}$ when complete. In this there are several long, deeply grooved branchlets over $15 \mathrm{~mm}$. in length. The parts that form complete tubes are very restricted in extent. Dull pale brown in colour. Mulaku, 22 fathoms. Weed and sand.

F. Another somewhat smaller specimen, with several very long almost flattened branchlets. None of the branches among these fragments show the completely tubular condition. Colour, dull pink. Mulaku, 32 fathoms. Mud, weed, and sponges.

G. A specimen also in fragments, with several fairly long grooved branchlets, but freely tubular on the branches. The colour varies from dull pink to dull pinkish brown. S. Male, 28 fathoms. Hard white sand.

H. A complete specimen. About $180 \mathrm{~mm}$. in length, with a very long stalk broken at the extremity and a divided axis as in $\mathrm{C}$ (Fig. 13). Very few long grooved branchlets. Freely tubular. Colour, pinkish brown. Stalk fading to white at base. S. Nilandu, 25 fathoms. W. of atoll.

K. The largest specimen in the collection, but very much broken. The stalk is relatively short. The axis and primary branches form complete tubes throughout nearly the whole of their extent, but there are some large projecting flattened or grooved branchlets $80 \mathrm{~mm}$, and more in length. The colour is brown. N. Male, 27 fathoms. N. of atoll. Broken shells.

L. A small fragment of the same general character as $K$, but rather more pink in colour. N. Male, 28 fathoms. Near shoal, W. centre. Sand.

M. A very small fragment of same general characters as $K$, but bright orange in colour. Mahlos Atoll, 23 fathoms. Passage. N.E. lagoon.

In this series of specimens from the same group of islands we have a series of links connecting together the well-known and well-described species belonging to the genus. The careful examination of the specimens A, B, and C from Suvadiva, and a comparison of the spicules and tentacles, sections of the stalk and axis with the description given by Genth convinced me that these specimens belong to the species $S$. tubulosum.

A comparison however of specimens $\mathbf{G}$ and $\mathbf{K}$ with the type specimens of $S$. tortuosum in the British Museum exhibited no differences either in general mode of growth or spiculation that would justify a separation of them from the original species. 
The fragment $\mathrm{L}$ moreover exhibits branches which have a remarkable resemblance in their form and the manner in which the anthocodiae are distributed upon them to those of Studer's species S. grayi.

The specimen $\mathrm{F}$ from Mulaku I should place with Gray's species Leucoella cervicornis, were it not for specimen $\mathbf{E}$, which is intermediate in character between Leucoella cervicornis and Solenocaulon grayi. The spicules of F cannot be distinguished from those of the type specimen of Leucoella cervicornis. The other specimens cannot be so easily placed in any known species, but appear to form intermediate stages of growth or modification between those already referred to. It appears to me that the facts above mentioned point to the conclusion that all these specimens of the genus Solenocaulon from the Maldives belong to one species, and by the general custom of priority should be referred to Gray's species Solenocaulon tortuosum. Such a conclusion, however, would not be justified without reference to other characters than the mode of growth.

That there are differences between the spicules in my preparations cannot be denied, but when due allowance is made for the variation in size and shape of the spicules of the various parts of one specimen there remains such a strong family likeness between them all, including Leucoella cervicornis, that the differences cannot be expressed in words or figures. When the different accounts of the spicules of the genus are compared there is a surprising similarity rather than difference in their character to be noticed. I have collected, for example, the length-measurements given of the long-thorned spicules of the axis, and they are as follows.

S. tubulosum (Genth) 0.36 circa. S. grayi (Studer) 0:37-0.4. S. tortuosum (Studer) 0.30.4. S. tortuosum (Ridley) 0:38. Leucoella cervicornis (Ridley) 0.35-0.42. S. sterroklonium (Germanos) $0.2-0.38$. These figures are sufficient to show that in the matter of this measurement there is a remarkable uniformity even in specimens so far apart as Torres Straits and the Maldive archipelago, and as other measurements show corresponding results the spicules do not afford sufficient grounds for splitting the genus up into species.

The next feature it was necessary to investigate was the character of the verrucae. I carefully selected branches from several of the specimens from the Maldives, and dried them slowly by exposure to the air in the laboratory, and then examined them with a 1 inch objective. In all cases some of the polyps were contracted so much that the spicules of the tentacles were below the level of the verrucae. In others which were not so completely retracted there could be seen an arrangement of the spicules at the back of the tentacles and in the neck of the anthocodiae (i.e. what I have called on p. 488 the crown and point spicules) similar to that described and figured (Fig. 17) by Genth. Another point of considerable importance I found in studying one of the polyps of a specimen, and that is the presence of rough and somewhat irregular spindle-shaped spicules supporting the pinnules, in the manner described and figured by Genth, $0.2 \mathrm{~mm}$. in length. The presence of these spicules in Genth's specimen from the Philippines, and in this specimen from the Maldives, is especially noteworthy.

In conclusion I may say that I propose to name the specimens of Solenocaulon in the collection as follows:

A B C Solenocaulon tortıosum, Facies tubulosum Genth,

D G H K II Solenocaulon tortuosum, Facies tortuosum Gray,

L E Solenocaulon tortıosum, Facies grayi Studer,

F Solenocaulon tortuosum, Facies cervicornis Gray.

G. II. 
Solenowulon ramast. Yer species (Figs 1f, 15, 16, 17.)

Lncalirs. Suradira Lagown. Caarse sand and rubble. 39 tathoms. One specimen.

With the usual system I hare little doubt this specimen would be made the trpe of a nem genus, but after the examination of the other specimens of the genus it is only with sume hesitation that I propose to constituie a new species for it.

The charactes br which it is distinguished from all the other specimens of Solencaulon in the collection, and inderd from the other described species of the genus (including Leucoella), might be acounted for as looal rariations. But, bearing in mind, that no less than three spocimens $\mathrm{A}, \mathrm{B}$, and $\mathrm{C}$ of the ordinart hind came from the Suradira lagoon at the same depth, this consideration luses a grea: deal of weight. Verertheless it is just possible that the character of the curents at the spot where this was found intuencing the srmbiotic crusvece in some war or another mar have prudueed this abnormal form of growth. It is possible that a ditieren: and larger species of crustacean mar have sheltered in the branches, driving awar the normal species. therebr causing the large beli-like shelters, and prerenting the formation of the narmorer tubes. I do not think that any such causes are so likels to hare afieted the other features in which it diriters trom the other specimens of the collection.

The spomimen is ters much broken. but by puting the framments together I have reckoned that when taken it was about $250 \mathrm{~mm}$ in height. It is probable, howerer, that this measurement is considerably shor of the tutal length of the specimen when it was alive. There is no stalk or base of attachment.

The most characteristic feature of the specimen is the presence of three complete belts, and one incomplete belt on the aris, and one incomplete beli on a branch. These belts are formed in the same manner: and have the same signiticance as the tubes of Solenooxtun trituswh. Ther are simply flattened winglike outgrowhs from the axis or branch Which entrace a carits and fuse where they meet at their extremities (Figs. 15, 16).

These belts are tium $15-20 \mathrm{~mm}$, in diameter abore, and from $22-23 \mathrm{~mm}$, in diameter Belom, and abour $20 \mathrm{~mm}$ in length. Ther are situated on the aris at intervals of about $30 \mathrm{~mm}$. The incomplea belts are very similar to the complete ones in size and form, but the sides are not fused opposite to the axis

In one or wo of the fragments there are places where a branch is rerr much flattened and espanded, and these are undorbiedly to be resarded as commencing belts (Figg. 1.5).

Cnformazly there is no direct eridence as to what these belts contained, but it is re: probate that iher sbeltered some epizoic crustacean or other animal. The resemblance of the impertece belts to the growing crab-galls of a Seriatopora or Pocillopora is rery swiking.

In its thichest par. (nearest to the missing stalt) the aris is roughls crlindrical in form, atd about $5 \mathrm{~mm}$. in diameser. It is scored with irregularly arranged longitudinal groores. Atore the lowest belt it is more tlattened, and about 5 mm. in thickness, but from this point zpwarls ibe extent of fatening is rer: irregular, some parts being much broader than others.

Tre smerure of the axis apprars to be precisely similar to that of $S$. tortuosum, the crit subsamee of the cencral part and the softer rascular bark haring the same general aypearance in the two species. 
The spicules of the aris and of the branches are so remarkably similar to those of the other species that I cannot distinguish them. A very striking feature, however, of the new species is the fact that none of the polyps are completely retracted into the verrucae, and this gires the specimen a much more spiny or hirsute appearanse.

The incomplete retractility of the polsps is due to the fact that the spieales of the crown and the points are not only more numerous and therefore more clusels set, but distinctls thicker than thes are in the other species.

I hare rery carefully compared some polyps of nearly all the specimens of solenocaulon from the Maldives, and in none of them could I tind the same number or character of these spicules as in the new species.

The pinnulae of the tentacles are supported bs spindle-shaped spieules, but these again are stouter than in the corresponding spicules of $\mathbf{S}$. tortuasum.

The colour of the specimen is dark brown. It mill be observed that this colour is rery difierent to the pale pink, cream, and orange colours of the other specimens of stenocaulor. from Suradira.

\section{Fumilr Melitodidae.}

\section{Preliminary note on the genus Melitodes (Terrill).}

In the collection from the Maldires these sereral specimens belonging to the genus Yelitodes and the species problem presents itself again with exaggerated diffeulties.

The specimens are all rery brittle and considerably broken. so that the exaet form of the whole colong is difficalt to determine, but exceedingly well-marked difierences bemeen individual specimens can be observed in the size of the nodes, the length and thickness of the internodes, and the colour of both nodes and internodes.

From Hulule, Male Atoll, alone I hare already noticed the five principal varieties given in the following table.

\begin{tabular}{|c|c|c|c|c|c|c|}
\hline & \multicolumn{2}{|r|}{ Tales } & \multicolumn{4}{|c|}{ Intersajes } \\
\hline & Colour & Diametet & Cotour & Length & & Diameter \\
\hline 1 & Fellots & f mm. swollen & Fed & $7-13 \mathrm{~mm}$ & & $2 \mathrm{~mm}$ \\
\hline$\underline{2}$ & Fellow & Imm, not swollen & White & $23-24 \mathrm{~mm}$ & & 2 nes. \\
\hline 3 & Red & $1 \mathrm{~mm}$ swollen & White & $5 \mathrm{~mm}$ & & $05 \mathrm{~mm}$ \\
\hline$\$$ & Fellow & $3 \mathrm{~mm}$ slightl! swollen & Pink & $15 \mathrm{~mm}$ & & $2 \mathrm{~mm}$ \\
\hline 5 & Red & $1 \mathrm{~mm}$ slightly swollen & Gray & $10 \mathrm{cmm}$ & 1 & $0-75 \mathrm{~mm}$ \\
\hline
\end{tabular}

From Addu Atoll. There are four rarieties, apparently quite disinet from one another and from the Hulule, Male, varieties. 
From these two atolls no less than nine species might be made which could be fairly well defined by measurements of nodes and internodes and by colour; but on the other hand the three or four varieties from Miladumadulu, one from North Male, two from Suvadiva, and one from Felidu, make up a series which is almost complete between the extremes. The examination of the spicules does not help us in the matter very materially. There is so much variation in the size and shape of the spicules in every individual specimen that the comparison between one specimen and another is very difficult, but of the many preparations of spicules that $I$ have made there is not one that can be recognised as belonging to a distinct form of growth. The preparations prove that the spicules of all varieties have a general family resemblance, but beyond that it is impossible to speak definitely.

The problem, however, is complicated in this case by the fact that $\mathrm{Mr}$ Gardiner from observations on the reef came to the conclusion that there is more than one species. I feel, therefore, that it is necessary, before definitely expressing my own opinion, to submit some of the specimens to a further anatomical examination. The publication at the present moment, however, of the fact that this interesting series of Melitodes varieties does occur, appears to me to be advisable, although the detailed description of them must be necessarily delayed.

\section{LITERATURE.}

1. J. H. Ashworth. "The Structure of Xenia Hicksoni." Quart. Journ. Micr. Sci. 42. 2. "The Xeniidae." Willey's Results, Pt. IV.

3. H. M. Bernard. "On the Unit of Classification for Systematic Biology." Proc. Camb. Phil. Soc. XI. 4.

4. G. C. Bounne. "On the Structure and Affinities of Heliopora coerulea, etc." Phil. Trans. 1895.

5. J. D. DANa. "Zoophytes." Philadelphia, 1846.

6. C. Gexth. "Ueber Solenogorgia tubulosa." Z. f. Wiss. Zool. xvir. 1867.

7. N. K. Germanos. "Gorgonaceen von Ternate." Kükenthal's Ergebnisse, 1896, and Abhand. Senck. nat. Ges, xxiII. 1.

8. J. E. GraY. "Description of Two New Genera of Zoophytes (Solenocaulon and Bellonella)." Proc. Zool. Soc. 1862.

9. J. E. GraY. "Description of New Species of Spongodes." P. Z. S. 1862, p. 30.

10. S. J. Hickson. "The Alcyonaria (Stolonifera)." Trans. Zool. Soc. Vol, XIII. (1894).

11. "The Alcyonaria and Hydrocorallinae of the Cape of Good Hope." Cape Town, 1900.

12. I. Hiles. "The Stolonifera and Alcyonacea." Willey's Results, Part II. 1899.

13. O. HoLx. "Beiträge zur Kenntniss der Alcyonidengattung Spongodes." Zool. Jahrb. virr. 1895. 
14. C. B. Klunzinger. "Die Korallthiere des rothen Meeres." Part I. 1847.

15. IV. KüкENThaL. "Alcyonaceen von Ternate." Kükenthal's Ergebnisse, Abhand. Senck. nat. Ges. xxiIr. 1. xv. 6.

16. W. Kükenthal. "Versuch einer Revision der Alcyonarien." Zool. Jahrb. System.

17. W. MAY. "Beiträge zur Systematik und Chorologie der Alcyonaceen." Jen. Zeits. f. Naturwiss. Bd. xxxiII. 1899.

18. F. Müller. "Ueber Balanus armata, etc." Arch.,f. Naturg. Jg. xxxm. 1867.

19. H. PütTer. "Alcyonaceen des Breslauer Museums." Zool. Jahrbücher. System., Bd. xiI. Hft. 5, 1900.

20. S. O. Ridley. "Contributions to our Knowledge of the Alcyonaria." $A . M$. $H$. March 1882.

21. Th. Studer. "Uebersicht der Anthozoa Alcyonaria der Gazelle." Monats. $k$. Akad. Wiss. Berlin, 1878.

22. E. P. Wright and Th. Studer. "Aleyonaria of Challenger." Vol. xxxi.

23.

Supplement to "Alcyonaria of Challenger." Vol, xxxiI.

24. Th. Whitelegge. "The Alcyonaria of Funafuti." Memoirs Aust. Museum, v. 1897.

\section{PLATE XXVI.}

FiG. 1. T'elesto rubra, n. sp. A portion of a colony with four secondary branches (b). At v.v. are seen the verrucae of the lateral polyps. $g$. a barnacle gall. All the parts that are shaded are covered with the encrusting sponge Prosuberites, which is coloured blue-green with Beggiatoaceae. The unshaded parts show the red colour of the skeleton through a very thin lamina of the sponge. $\times 1 \frac{1}{2} \mathrm{ca}$.

Fig. $:$. A portion of the calcareous skeleton of Telesto rubra after treatment with caustic potash to show the ridges $(r, r)$ and the irregular perforation of the tubes.

FIG. 3. Side view of one of the tentacles of Telesto rubra to show the eight pinnae (p.p.), each supported by one spicule, and the smaller spicules supporting the axis of the tentacle $s p$.

FrG. 4. One of the spicules of the pinnae of Telesto rubra isolated. $\times 200$.

FIG. 5. One of the red spindle-shaped spicules of Telesto rubra at the base of the anthocodia, which increase rapidly in size, fuse, and form the solid tubular skeleton, $\times 200$.

Fig. 6. Two spicules of the same region of Telesto rubra very much younger and smaller than the one in Fig. 5. $\times 200$.

FIG. 7. A characteristic spicule of Telesto trichostemma. $\times 150$.

Fig. 8. Chironephthya variabilis, n. sp. A sketch to show the general form of the colony. $\times 1 \frac{1}{2}$ ca. 
Fig. 9. An anthocodia of specimen D of Chironephthya variabilis showing the arrangement of the spicules in the crown $(C)$ and points $(P)$. This arrangement is characteristic of what appears to be young polyps.

Frg. 10. An anthocodia of specimen E of Chironephthya variabilis, showing the spicules in both crown $(C)$ and points $(P)$ larger and more crowded than in specimen $\mathrm{D}$.

Frg. 11. Arrangement of the spicules in the points of Siphonogorgia mirabilis, showing one prominent median spicule and the others smaller and arranged in the manner of a fan on each side of it.

FIG. 12. A small piece of the terminal branch of Siphonogorgia mirabilis, the surface being covered with the sponge Halisarca. Sp. cut edge of the sponge. Coen. the large spicules of the coenenchym as seen when the sponge is scraped off. Anth. anthocodiae projecting through the sponge.

Fig. 13. Solenocaulon tortuosum Gray. Specimen C from Suvadiva. Nat. size. It shows $t$. the tubular secondary branches, and $b . b$. the very short free terminal branchlets.

\section{PLATE XXVII.}

Fig. 14. Solenocaulon ramosa, n. sp. A small portion of a large colony. It shows at B.B. two large belt-like growths on the main stems, and at $b . b$. the long free terminal non-tubular branches.

Figs. 15, 16. Two stages in the formation of the belts of Solenocaulon ramosa.

Fig. 17. A terminal branch of Solenocaulon ramosa, n, sp., showing the non-retractile anthocodiae, Anth.

FIG. 18. A terminal branch of Solenocaulon tortuosum from the Maldives for comparison with Fig. 17. 


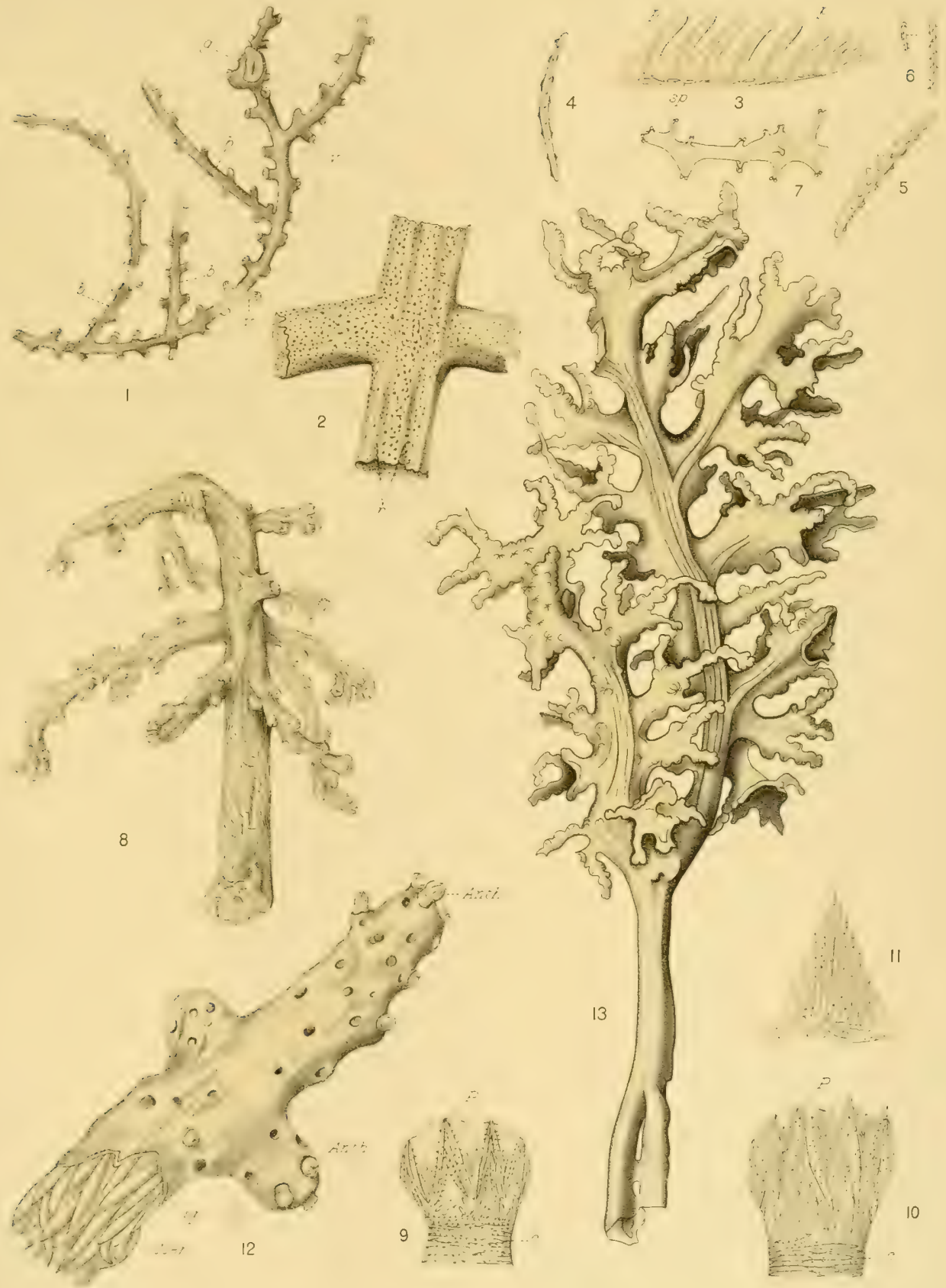





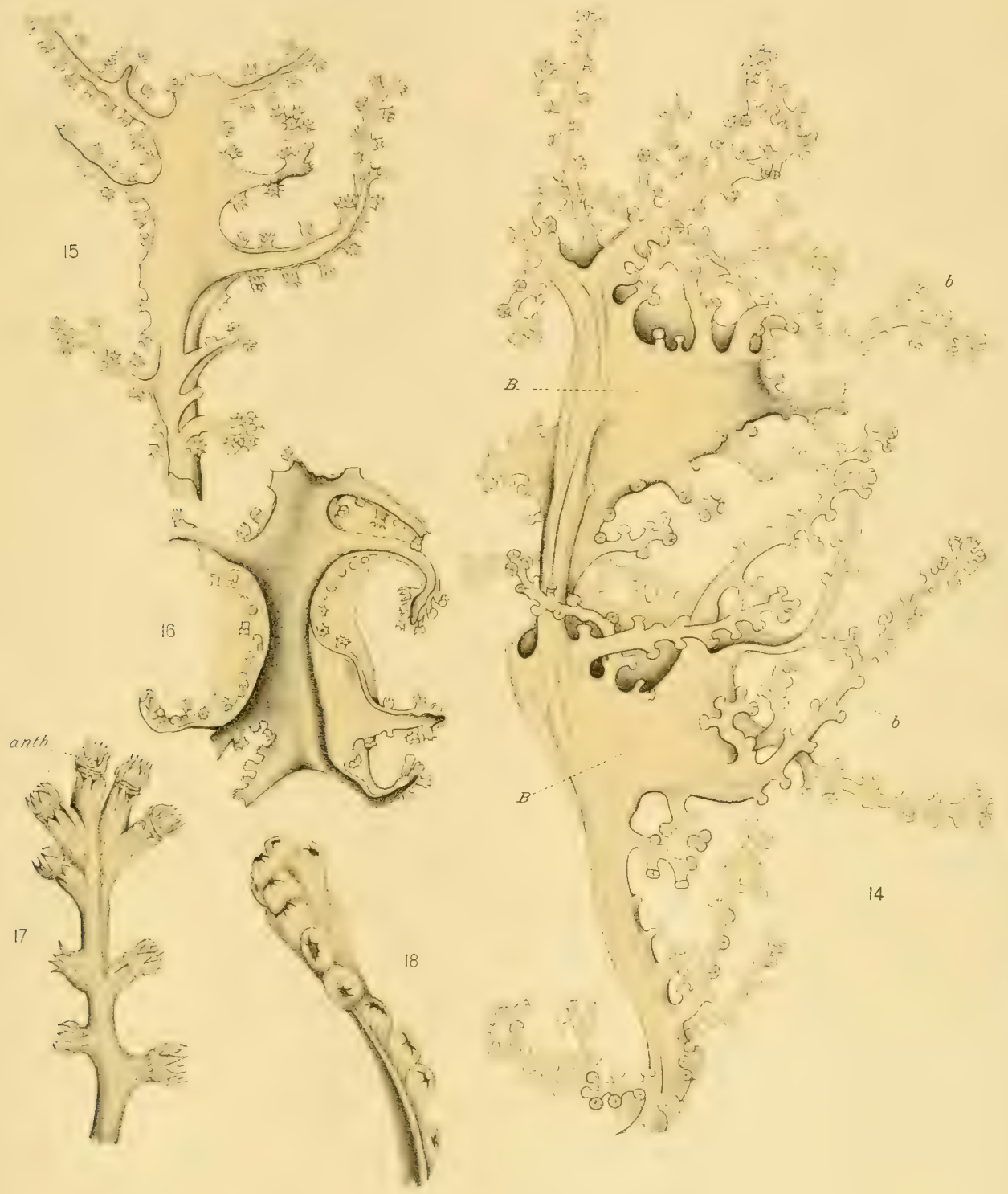





\title{
THE ALCYONARIA OF THE MALDIVES.
}

\author{
PART II
}

\section{THE GENERA SARCOPHYTUM, LOBOPHYTUM, SCLEROPHYTUM, AND ALCYONIUM.}

By Edith M. Pratt, M.Sc. Vict., Late Honorary Research Fellow of the Owens College, Manchester.

(With Plates XXVIUI-XXXI.)

\section{CONTENTS.}

I. Introduction, with Observations on the Genera . . . . . . . 504

II. Genus Sarcophytum . . . . . . . . . . . . . . . 505

(1) S. ehrenbergi. (2) S. glaucum. (3) S. latum. (4) S. boettgeri. (5) S. roseum n. sp.

(6) S. tenuis n. sp.

III. Genus Lobophytum

(7) L. pauciflorum.

IV. Genus Sclerophytum n. gen. . $\quad$. . . . . . . . . .

(8) Sc. capilale n. sp. (9) Sc. densum. (10) Sc. hirtum n. sp. (11) Sc. polydactylum. (12) Sc. palmatum n. sp. (13) Sc. gardineri n. sp. (14) Sc. durum n. sp. (15) Sc. querciforme n. sp.

V. The Relations of the above Genera. - . . . . . . . . . $\quad$. 532

VI. Genus Alctonium . . . . . . . . . . . . . . . . 534

(16) A. pachyclados.

VII. Literatur 


\section{INTRODUCTION.}

THE genus Sarcophytum was founded by Lesson in 1831, its distinguishing feature being the mushroom-shape of the colony. Klunzinger in 1877 included in the genus a form which is not mushroom-shaped, and which he termed Sarcophytum pauciflorum. Marenzeller in 1886 separated those forms which are mushroom-shaped from those which are not, and for the reception of the latter he established the genus Lobophytum, of which he described several new species. This genus was based upon the form of the colony, the dimorphic character of the zooids, and the form and size of the spicules.

When examining examples of several species in the collection which have been attributed to Lobophytum, I observed that while all the specimens have the lobed form characteristic of the genus, some differ from others in that they are extremely hard and brittle. This I found is due to the presence of enormous spicules which occur throughout the colony in very considerable numbers. In some cases siphonozooids were observed to be very minute, and could only be distinguished with the aid of the microscope, while in a few instances they were apparently absent.

In addition to the abundant supply of excellently preserved material in the collection from the Maldive Islands, the zoological laboratories of the Owens College contained other collections of similar material, which through the kindness of Professor Hickson were placed at my disposal. These included Mr Stanley Gardiner's collection from Funafuti, Dr Willey's collection from New Guinea, New Britain and Lifu, and Professor Haddon's collection from the Torres Straits. I have also been allowed to make a cursory examination of Professor Herdman's collection from Ceylon. It was, therefore, possible for me to make an investigation of the anatomy of the genus Lobophytum, which hitherto had not been attempted, and also to make a comparative study of the anatomy of many species, which have been attributed to this genus, from many different localities. The general results of these investigations are contained in the present paper. A more detailed account of the comparative minute anatomy will, I hope, be published later.

An interesting and important result of my research was the discovery of a large and extremely well-marked superficial canal system in those species of the genus Lobophytum with minute siphonozooids, which occurs also in those with apparently no siphonozooids. In the former this canal system was observed to be in intimate connection with the minute siphonozooids, but it is absent or only rery feebly developed in those species with large siphonozooids. Further investigation led me to the conclusion that the present definition of the genus, which is based upon the form of the colony, dimorphism and the character of the spicules, is artificial and inefficient, because it is founded upon insufficient evidence.

All the species of the genus Lobophytum divide naturally into two groups; one includes all those species whose anatomy is similar to the species panciflorum, which has no special superficial canal system, but is provided with comparatively large siphonozooids; the other group includes all the remaining species of the genus, whose general anatomy is similar to that of the species densum, a form with minute siphonozooids and a large superficial canal system. The important differences between the two groups of species clearly indicate that they are genetically as distinct from each other as each is distinct from the genus Sarcophytum or any other genus of the Alcyonaria. It is, therefore, necessary to separate the 
group of species with minute siphonozooids from the genus Lobophytum, and to establish a new genus for its reception. The characteristic hardness of many of the species suggests the generic title Sclerophytum.

In the collection from the Maldive Islands were young colonies of Lobophytum pauciflorum (fig. 12) and Sclerophytum densum (fig. 18), which were mushroom-shaped. Several similar colonies of Lobophytum and Sclerophytum occur also in Professor Herdman's collection from Ceylon. The mushroom-like form of young specimens of these two genera is interesting, and may lead to confusion in the identification of the genus, for the mushroom-like form of the colony is held to be characteristic of the genus Sarcophytum. We have now evidence, however, that it is not confined to that genus.

It has already been shown that well-grown specimens of Lobophytum and the new genus Sclerophytum may be very similar in form and appearance, but very different in anatomical structure. Specimens of Sclerophytum occur also in the collection, which differ considerably: in outward form, but which are identical in structure (Sclerophytum durum, figs. 29 and 30). The form of the colony alone cannot, therefore, be recognised as a generic or even a specific character.

In many cases the spicules of Sarcophytum, Lobophytum, and the new genus Sclerophytum are distinct from each other, and may be easily recognised, but this cannot be regarded as an established rule, for the zoned spicules supposed to be characteristic of Lobophytum occur also in Sarcophytum latum and roseum (sp. nov.); the tuberculate spicule occurring throughout Sclerophytum is to be found also in Sarcophytum in the species plicatum, boettgeri, and apparently in nigrum.

The following species which I have examined would be retained in the genus Lobophytum:-pauciflorum, crassum, and hedleyi. The new genus Sclerophytum (p. 516) will include the species densum, confertum, marenzelleri, tuberculosum, which have hitherto been attributed to Lobophytum.

All the specimens of the Alcyonidae in the Maldive Islands collections were examined for reproductive organs. In the majority of cases they were apparently absent. The remaining specimens contained ova usually exhibiting several stages of development in a single colony. There does not appear to be a single specimen with male cells in the whole collection.

\section{GENUS SARCOPHYTUM (Pl. XXVIII. figs. 1-6, 9-11).}

This genus was first founded by Lesson in 1831 (p. 92), and forty-four years appear then to have elapsed without any further account of it. Moseley in 1875 (p. 19, Pl. VIII. fig. 2, Pl. IX. fig. 9) carefully described the general anatomy of a species belonging to this genus. Lesson's definition was amended by Marenzeller, 1886 (p. 351), and again by Wright and Studer, 1889 (p. 244).

After carefully comparing in detail the anatomy and histology of several species included in the genus I find that Wright and Studer's definition holds good, as far as it goes, for all the species which I have examined. It is necessary to mention, however, that the mushroom-like form of the colony is not confined to this genus, but occurs among young specimens of the genera Lobophytum and Sclerophytum. Moseley's account of the general

G. II. 
anatomy is valuable as a basis for the comparison of other species, and is of material assistance in the establishment of certain generic features.

Six species of Sarcophytum occur in the collection from the Maldive Islands, three of which have been recorded from other localities, one is a new variety of an old species, and two species are new. The species are:-glaucum, latum, boettgeri, var. nov., roseum, sp. nov., tenuis, sp. nov.

Siphonozooids. Owing to the difference in contraction of preserved specimens it is difficult to obtain any specific standard of measurement of the autozooids. A series of measurements of the siphonozooids of several specimens belonging to the same species, however, show them to be of almost uniform size. The size of a siphonozooid in the preserved condition therefore appears to be almost constant for a species, and may be looked upon as a specific character. The length of the stomodaeum of a siphonozooid varies to a certain extent in different species, but is almost constant for a single species. It will be seen from the appended table that the stomodaeum of the siphonozooids is an important factor in the determination of the species' ${ }^{1}$.

\begin{tabular}{c|c|c|c|c|c|c}
\hline & S. glaucum & S. ehrenbergi & S. latum & S. plicatum & S. tenuis & S. roseum \\
\hline $\begin{array}{c}\text { Surface diameter } \\
\text { of siphonozooids }\end{array}$ & $-2 \mathrm{~mm}$. & $-37 \mathrm{~mm}$. & $-33 \mathrm{~mm}$. & $3 \mathrm{~mm}$. & $-3 \mathrm{~mm}$. & $\cdot 45 \mathrm{~mm}$. \\
$\begin{array}{c}\text { Transverse length } \\
\text { of stomodaeum }\end{array}$ & $-1 \mathrm{~mm}$. & $-18 \mathrm{~mm}$. & $-1 \mathrm{~mm}$. & $-1 \mathrm{~mm}$. & $\cdot 1 \mathrm{~mm}$. & $\cdot 12 \mathrm{~mm}$. \\
$\begin{array}{c}\text { Vertical length of } \\
\text { stomodaeum }\end{array}$ & $.16 \mathrm{~mm}$. & $-32 \mathrm{~mm}$. & $-3 \mathrm{~mm}$. & $.28 \mathrm{~mm}$. & $\cdot 2 \mathrm{~mm}$. & $\cdot 4 \mathrm{~mm}$.
\end{tabular}

By introducing lamp-black into the sea-water about living colonies of Sarcophytum, Mrr Gardiner observed currents entering the siphonozooids. After some time the blackened water was ejected by the autozooids, and in some cases by the same siphonozooids, showing that a reversal of the current had taken place within the colony.

The presence of numerous, well-marked, and regularly arranged siphonozooids in this genus as well as in the amended genus Lobophytum, enables the effectual aëration of the superficial portions of the colony, where metabolism is greatest, and is doubtless correlated with the absence of a special superficial canal system so well marked in Sclerophytum, in which the siphonozooids are very minute.

Autozooids. The autozooids are large, and are very similar to those of Lobophytum. The tentacles are much shorter and broader in proportion to their length than those of Alcyonium. They are of the simple pinnate character, with a single row of pinnules down each side. In some cases the pinnules are so small as to be easily overlooked. They are very similar to those of Lobopleytum.

The stomodaeum is usually long and in the preserved. state is convoluted. The siphonoglyph is not well-marked in any of the specimens in the collection, and can only be

\footnotetext{
1 The measurements were obtained by measuring several siphonozooids from different parts of a colony and taking

${ }^{2}$ S. plicatum was not in the collection from the Maldive an average.
} 
distinguished in stained preparations. The mesenteries are large and well developed in all the species which I have examined. The ventral and lateral mesenteries are provided with very stout, rounded mesenterial filaments, which are similar to those of the genus Lobophytum, but are larger and much more strongly marked than in the genus Sclerophytum. The dorsal mesenterial filaments are very long, and are grooved and ciliated as in many other genera of the Alcyonaria.

Zoochlorellae are fairly numerous in the endodermal tissues, canals and zooid cavities in all the species. In addition, rounded cells of a yellow colour occur in glaucum and latum.

Canal system. The canal system of this genus has been described and figured by Moseley (1881). It is similar to that of Lobophytum, but differs from Sclerophytum in the absence of a special superficial system. It is to a certain extent homologous with' the internal system of Sclerophytum. In Sarcophytum the principal longitudinal vessels are direct prolongations of the siphonozooids. In Sclerophytum, however, the siphonozooids terminate in the large vessels of the special superficial canal system, and as a rule are only indirectly connected with the longitudinal vessels of the internal canal system (p. 519).

The longitudinal vessels run more or less parallel with the longitudinal axis of the autozooids, and send off numerous branches, which may terminate in the coelenteric cavity of a neighbouring zooid, or ramify and anastomose in the substance of the mesogloea, and form a complete network. Some of the branches end in solid cords and strands in the mesogloea, in a manner described by Ashworth in Xenia (1899, p. 190). The strands and cords are not indicated in Moseley's figure. I found it impossible to perceive cilia on the walls of the vessels of the canal system.

In addition to this system of canals neighbouring autozooids are connected by means of short, straight canals which are provided with fairly long cilia (fig. 3). These vessels are described and figured by Moseley, but are not described as being ciliated. I have observed similar ciliated vessels in Lobopleytum, in living Alcyonium, in which they are less numerous, and in Sclerophytum, in which they are very few in number.

Growth. In all the species of the genus which $\mathbf{I}$ have examined the autozooids are most numerous at the margin of the capitulum (fig. 1), but in this portion of the colony they are usually smaller and appear to be younger than elsewhere. Growth, by the budding of new autozooids, is most vigorous in the same part. Where it is very rapid the margin is often thrown into folds as in Schenk's figure S. plicatum (1896, Taf. II. fig. 12). Often a young colony can be distinguished from an older one by the rounded, unbroken contour of the margin, but in both specimens of tenuis, which have attained a considerable size, the capitulum is tlattened, slightly concave, and the margin unbroken by folds (fig. 9). The siphonozooids are not very numerous at the margin, but are most common in the middle of the capitulum. They are apparently budded off from the endodermal canals usually in the proximity of the food-supplying autozooids. Young specimens of Sarcophytum and Lobophytum are usually mushroom-shaped, and are very similar in appearance, so that at first sight a young Lobophytum may be easily mistaken for a Sarcophytum. After carefully examining all the young specimens in this and in the other collections I find in every case that in Sarcophytum autozooids are most numerous at the margin of the capitulum (fig. 1), while in Lobophytum autozooids are least numerous, and siphonozooids most numerous at the margin (fig. 7). As growth of the capitulum proceeds in both genera chiefly by the budding of new autozooids, the growth of the colony in Sarcophytum is most vigorous at the edge 
of the capitulum, so that the colony retains its mushroom-like form throughout life. In Lobophytum, however, new autozooids are formed from any portion of the capitulum, and growth at the margin where autozooids are fewest is necessarily very slow, consequently as a colony grows it loses its primitive mushroom-shape and assumes a lobulated appearance ${ }^{2}$.

1. Sarcophytum ehrenbergi (Pl. XXVIII, figs. 1 and 2). Marenzeller, 1886 (p. 356, Taf. 1x. figs, 3 and 4 ).

Four small specimens were taken on the reefs at Hulule, Male Atoll, and two larger incomplete specimens at Goidu, Gorfurfehendu Atoll.

All the specimens agree fairly well with Marenzeller's description. The margin of the capitulum in young specimens is incurved, rounded and unbroken, in older colonies it is often convoluted. The colour in spirit is light greenish-brown. The autozooids are large and well-marked, and are more numerous round the margin, but this character is not so strongly marked as in tenuis (fig. 9) and latum.

Autozooids. The anthocodiae of fairly expanded autozooids are about $5 \mathrm{~mm}$. in length. The surface diameter of an autozooid cavity is $8 \mathrm{~mm}$. The tentacles are short and pinnate (fig. 2), and are about $1 \mathrm{~mm}$. in length. Spicules are present in the form of minute, slender, tuberculate spindles averaging $1 \mathrm{~mm}$. in length. These are arranged more or less longitudinally on the walls of the tentacles (fig. $2 s p$.), and not en chevron as in many of the species. The stomodaeum is very long and much convoluted. The mesenteries are large, the ventral and lateral ones being provided with very stout and rounded mesenterial filaments, which in the preserved condition are much convoluted at the beginning of their course. I have been unable to find reproductive organs in the mesenteries of any of the specimens.

The siphonozooids are very well marked and extend for a considerable distance into the interior of the colony, but they are not so numerous as in S. latum and many other species. They are regularly arranged in rings round the autozooids, and are most numerous in the middle of the capitulum, where from four to five may be counted in a straight line between two autozooids. The average surface diameter of a siphonozooid is $37 \mathrm{~mm}$, and is greater than in S. glaucum. The stomodaeum may be seen in surface view as a keyhole shaped aperture. Its average length is $32 \mathrm{~mm}$., which is quite twice that of $S$. glaucum. The eight mesenteries are not so well marked as $S$. latum. The spicules have been fully described and figured by Marenzeller (1886). They are very abundant near the surface of the colony, but are relatively scarce in the coenenchym.

Zoochlorellae are present in this as in other species, but I have not been able to find any of the rounded cells with yellow contents which are present in $S$. glaucum, etc.

S. elhenbergi, then, is characterised by:-(1) the form and distribution of the spicules which are numerous near the surface, but few in the coenenchym; $(2)$ the tough, firm texture of the colony; (3) the large size of the autozooids, which have large, stout, rounded ventral and lateral mesenterial filaments; and (4) the clearly defined large siphonozooids, apparently less numerous than in other species, with a long stomodaeum fully twice the length of that of S. glaucum.

I A young mushroom-shaped colony of Sclerophytum may be easily distinguished from Sarcophytum or Lobophytum by the ninute size or absence of siphonozooids. Where present, they can never be distinguished without the aid of a micro. scope. 
2. Sarcophytum glaucum (Pl. XXVIII. figs. 3 and 4), 1833. Quoy et Gaimard (p. 270, Pl. XXII. figs. 11 and 12), 1886. Marenzeller (p. 352, Taf. IX. figs. 1 and 2).

A single well-preserved specimen was taken on the reef of Hulule, Male Atoll. Mr Gardiner observed this species to have large lobes much covered with mucus, with the polyps not generally completely contracted when living, even if exposed to low tide.

Specimens from different localities vary considerably in size. This specimen is $22 \mathrm{~mm}$. high, the capitulum is $59 \mathrm{~mm} . \times 45 \mathrm{~mm}$. in diameter, and in the middle is $9 \mathrm{~mm}$. in thickness. The margin is thrown into four large folds. In the middle of the disc the autozooids, which when expanded are about $2 \mathrm{~mm}$. across the crown, are from $3-5 \mathrm{~mm}$. apart, but on the margin are younger, smaller and only about $1 \mathrm{~mm}$. apart. The siphonozooids are very regularly arranged between the autozooids, and are most numerous in the middle of the capitulum, where there may be from $6-13$ siphonozooids in a straight line between two autozooids; on the margin there are only from $1-3$ between two autozooids. The colour of the specimen in spirit is of a greenish stone colour, in the living condition the green colour is more intense. The specimen yields readily to the touch, but is fairly tough in texture. The stalk is short, thick and cylindrical, its surface is smooth and unwrinkled.

The species has so far been described from Australia, Red Sea, Tonga Island, Viti Island, and now Maldive Islands.

The autozooids are large, well-marked, and of a deep cream colour in spirit. Many of them are completely retracted. The average surface diameter of an autozooid cavity is $1-1.5 \mathrm{~mm}$. The tentacles when expanded are long and slender with short simple pinnules in a single row down each side. Small spicules in the form of slender spindles are imbedded in the walls of the tentacles, and are so arranged that when an autozooid contracts the tentacles come together to form a cone, and the delicate fleshy parts are enclosed in and protected by a conical cap of spicules. The average diameter through the contracted crown of tentacles is $1.4 \mathrm{~mm}$.

In the preserved condition the stomodaeum is much convoluted; the siphonoglyph is not readily seen, and, indeed, can only be distinguished in stained sections. The eight mesenteries are well-marked and provided with large mesenterial filaments, which are much convoluted at the beginning of their course. Each of the two dorsal mesenterial filaments has a groove running down the middle, lined by ciliated cells. The ventral and lateral mesenteries are rounded in cross section as in Alcyonium. I have observed no generative organs in this specimen, but in a specimen taken by Willey in Blanche Bay typical Alcyonarian ova mensuring from $\cdot 05-25 \mathrm{~mm}$. in diameter were seen on the mesenteries.

The siphonozooids are rounded on their external surface, with the mouth sunk in a slight depression in the middle. Their surface diameter, which appears to be constant, is about $2 \mathrm{~mm}$., and they are usually arranged with the broad diameter of the stomodaeum in a definite direction. Their length varies according to age or to the proximity of an autozooid. When seen in longitudinal section a siphonozooid is conical in shape, the external surface being the base of a cone. The coelenteric cavity is prolonged at its apex into a longitudinal endodermal canal as in the species described by Moseley (1875, Pl. XIII. fig. 2). The stomodaeum is very short and broad in this form, the average length being $16 \mathrm{~mm}$., which is only half the length in certain other species (see table, p. 506). It is $\mathrm{T}$-shaped in cross section, the siphunoglyph being well marked. 
The mesenteries are not so pronounced as in $S$. latum. The two dorsal have grooved and ciliated filaments, while the ventral have a very short, free edge, but no filaments. The lateral appear to end with the stomodaeum, and consequently present no free edge. The coelenteric cavities of neighbouring autozooids and siphonozooids are placed in direct communication with one another by means of short ciliated canals.

In addition to the zoochlorellae which are present in considerable numbers, rounded cells of a yellow colour (fig. 4) occur in the ectodermal as well as endodermal tissues. The cells have a nucleus, and are filled with a granular yellow matter, which is insoluble in spirit and apparently unaffected by weak nitric or hydrochloric acids, borax-carmine, haematoxylin, oil of cloves or of cedar wood, but is stained black by iron-brazilien. These cells will be more fully described and figured in a later publication.

The spicules are most numerous near the surface of the capitulum, but they are not so densely packed as in Alcyonium. In this portion of the colony they have the form of tiny clubs with small heads, spindles, or spiny rods. The clubs are $084-224 \mathrm{~mm}$. in length, and the rods and spindles about $5 \mathrm{~mm}$. by $\cdot 02-04 \mathrm{~mm}$. broad. Rods and spindles are numerous on the anthocodiae of the autozooids, and are arranged in regular oblique lines, so that when an autozooid is contracted, the soft parts are enclosed and protected by a conical cap of spicules (p. 509), which recalls the operculum of certain fossil corals.

The spicules of the eoenenchym are slender spindles similar in form to those occurring in the autozooids. They are from $56 \mathrm{~mm}$. long and about $018 \mathrm{~mm}$. broad. Spicules $07 \mathrm{~mm}$. broad are also present; they are about the same length, and covered with simple spines. The spicules of the stalk are larger and stouter than those of the capitulum, being $56-7 \mathrm{~mm}$. long and $12 \mathrm{~mm}$. broad. They are tuberculate, warted spindles, similar in form and sculpturing to those of the new genus Sclerophytum (fig. 20), but slightly smaller.

S. glaucum, then, is characterised by (1) its abundant mucous secretion, which gives to the colony in its living condition a slimy appearance; (2) its green colour, which however is somewhat soluble in spirit; (3) its soft, flexible texture; (4) the large size of the autozooids; and (5) the clearly defined siphonozooids, which differ from all other species which I have examined in the shortness of their stomodaea, and feebly marked mesenteries.

3. Sarcophytum latum, Dana, 1849 (Pl. LVIII. figs. 6 and 7), Dana, 1859, p. 125. Whitelegge, 1897, p. 215.

A single fragment of a colony was taken at Hulule, Male, Maldive Islands. It consists of a portion of the capitulum measuring $68 \mathrm{~mm} . \times 42 \mathrm{~mm}$. in diameter and about $10 \mathrm{~mm}$. in thickness, and a portion of the stalk. As in $\mathrm{Mr}$ Gardiner's specimen from Funafuti the autozooids are usually about $1 \mathrm{~mm}$. apart, and are much more numerous at the margin of the capitulum, where the autozooids are younger, and are consequently smaller than elsewhere.

The siphonozooids are fairly large, the average surface diameter of a siphonozooid being $.33 \mathrm{~mm}$. There are usually from 3 to 4 in a straight line between two autozooids. The siphonozooids are often arranged with the ventral edges of the stomodaea pointing in the same direction, but here and there may be seen in alternating rows with the ventral edges pointing in opposite directions. The stomodneum is longer than in S. glaucum, and is $3 \mathrm{~mm}$. in length. The eight mesenteries are all well-marked, the ventral and lateral mesenteries 
have free edges, but no filaments; the former are a trifle longer than the latter. The dorsal mesenteries have grooved ciliated filaments. Ciliated transverse vessels between the zooids are very numerous. The Internal Canal System is well marked. Yellow cells are present as in $S$. glaucum.

The autozooids are fairly large with well-marked characters. The diameter through the crown of a completely retracted zooid is $.8-.9 \mathrm{~mm}_{\text {, }}$ and of a fairly expanded zooid $1.2 \mathrm{~mm}$. The diameter gradually diminishes posteriorly so that some distance below the surface it is sometimes difficult to distinguish between the cavity of an autozooid and that of a siphonozooid, except in sections. The anthocodia of expanded autozooids average $3 \mathrm{~mm}$. The tentacles are short, pinnate, and blunt at the tip, averaging only $56 \mathrm{~mm}$. in length. The stomodaeum is long, with folded walls, and the siphonoglyph is not conspicuous. The eight mesenteries are extremely well marked, the muscle bands being clearly seen in sections. Ova are present on the mesenteries, measuring from $03-5 \mathrm{~mm}$. in diameter.

This species is interesting because of 'its lobed capitulum (Dana, fig. 7), and its warted and zoned spicules (Whitelegge, Plate X. fig. 1). In both these respects it approaches the genus Lobophytum.

4. Sarcophytum boettgeri. Schenk, 1896 (p. 72, Taf. II. fig. 9, Taf. IV. figs. 29 and 30), var.

A single complete specimen was taken at the Suvadiva Atoll from a depth of 31 fathoms. It agrees in many respects with Schenk's description of the species from the Moluccas, but differs from his specimen in size. The stalk is longer and more slender, the capitulum has a smaller diameter, and is much thinner than in the type species. The colour is of a warmer brownish shade, and the autozooids are slightly larger.

The specimen is $50 \mathrm{~mm}$. high. The stalk is $39 \mathrm{~mm}$. long, $25 \times 14 \mathrm{~mm}$. broad at the base, and gradually diminishing in diameter to $9 \times 7 \mathrm{~mm}$.

The autozooids are about $2.5 \mathrm{~mm}$. apart in the middle of the capitulum, but near the margin they are much more closely set. Many are expanded and measure about $1 \mathrm{~mm}$. through the crown of tentacles. The siphonozooids are numerous, but so minute that they are invisible to the naked eye.

Owing to the presence of numerous large spicules near the surface of the capitulum and throughout the stalk the colony is fairly hard to the touch, and is only very slightly flexible. Near the base of the stalk there is a rhizome-like outgrowth which is attached at its distal end to a fragment of a shell. This probably gives additional support to the colony. A similar outgrowth is to be seen in a specimen of Sclerophytum durum (sp. nov. p. 528) from 24 fathoms, S. Nilandu. The colour in spirit is of a pale greyish-brown.

The spicules near the surface of the capitulum are very closely packed. They are of the tuberculate warted type found throughout the genus Sclerophytum (figs. 20 and 31). They vary in size, but the largest are about $1 \mathrm{~mm}$. long by ' $1 \mathrm{~mm}$. in diameter. They are similar in form to those figured by Schenk, 1896 (fig. 28), but slightly larger. The spicules of the coenenchym and of the autozooids are long, slender rods and spindles, some of the latter with a few short spines. The largest of these spicules are about $5 \mathrm{~mm}$. long by $.04 \mathrm{~mm}$. broad. I have observed this form of spicule in every species of Sarcophytum which I have examined (fig. 8). Most of the spicules of the stalk are like those near the surface of the capitulum, but among them may be seen a few slender spiny spindles like those of the coenenchym of the capitulum. They resemble those figured by Schenk (figs, 29 and 30). 
5. Sarcophytum roseum (Pl. XXIX. figs, 10 and 11), sp. nov.

A single large fragment of a female colony consisting of a portion of the capitulum was taken at a depth of 25 fathoms to the west of South Nilandu Atoll. In spirit the specimen is of a beautiful brownish-pink colour, which was more vivid in the living condition. When taken it was associated with a red Chiton and a Lamellibranch. In the complete state the capitulum would be apparently cup-shaped.

The specimen yields slightly to the touch, and the surface is somewhat granular. The capitulum is apparently thickest in the middle, where it measures $11 \mathrm{~mm}$. Towards the margin it thins out, so that a radial section through the capitulum is wedge-shaped. In all other specimens of the genus in the collection the margin of the capitulum is curved downwards and inwards to a more or less degree. In S. latum the fold or seam is very slight, but in this species it is entirely absent (fig. 11). The capitulum is irregularly lobed at the margin, and its under surface is wrinkled and granular. Through the ectodermal tissues marginal zooids may be seen running parallel with the surface.

Autozooids. On that portion of the capitulum which is farthest from the margin the autozooids are 7 to $10 \mathrm{~mm}$. apart; near the margin they are much more numerous and are often less than $5 \mathrm{~mm}$. apart. Most of the autozooids are completely retracted, but here and there one may be seen with tentacles slightly expanded. Its colour is then seen to be of a deep rich pink showing up clearly against the pale pink background of the colony. The tentacles are short, simple and pinnate. The stomodaeum is convoluted in the preserved condition, and the mesenteries are well marked. Ova at various stages of development are present on the mesenteries, some of the largest being fully $5 \mathrm{~mm}$. in diameter.

The siphonozooids are clearly marked and can be easily seen without a lens; as in other species they are most numerous where the autozooids are fewest and vice versâ. Their average surface diameter is about $45 \mathrm{~mm}$. Their stomodaea are longer than in any other species which I have examined, and have an average length of $4 \mathrm{~mm}$.

The spicules are more numerous near the surfice than elsewhere, in this position being in the form of small clubs and spindles averaging $13 \mathrm{~mm}$. in length and $06 \mathrm{~mm}$. in breadth (fig. 10, I, II, III). In the coenenchym they are slender, pointed spindles with proportionately large tuberculate warts, which have a tendency to be arranged in zones as in $S$. latum and in Lobophytum. The spindles measure $2-4 \mathrm{~mm}$. Iong by $06-07 \mathrm{~mm}$. broad, and a very few crosses $3 \times 2 \mathrm{~mm}$. are also present in the coenenchym. In shape the pointed spindles resemble those of $S$. elerenbergi, but in that species the warts are smaller and have not a zonate arrangement. In this respect this species approaches $S$. latum, and the allied genus Lobophytum, but the spicules of $S$. latum are much broader in proportion to their length than those of this form.

6. Sarcophytum tenuis (Pl. XXVIII. fig. 6 and Pl. XXIX. fig. 9), sp. nov.

Two specimens, one with the lower portion of the stalk missing, and another more fragmentary, were taken well within the South Male Iagoon at a depth of thirty fathoms. The colony is in the form of a stalked disc $63 \times 58 \mathrm{~mm}$. in diameter, and $4 \mathrm{~mm}$. thick, excluding the anthocodiae of the autozooids. The portion of the stalk is $4 \mathrm{~mm}$. long, and $15 \times 5 \mathrm{~mm}$. in diameter. The autozooids and siphonozooids are borne only on the upper surface and margin of the disc. The specimen is soft to the touch, but is of a tough texture, and of a dull brown colour. 
Autozooids. The autozooids are most numerous round the margin, and most are almost completely expanded. In the middle of the disc they are from $5-10 \mathrm{~mm}$. apart, but on the margin they are crowded together in radiating lines. The anthocodia, or free distal portion of an expanded autozooid, is $4-4.5 \mathrm{~mm}$. in length with an average diameter of $1.3 \mathrm{~mm}$. through the crown of tentacles. The tentacles are of the simple type (with a single row of pinnules on each side), and are about $1 \mathrm{~mm}$. in length, so that they appear small compared with the large size of the anthocodia. The stomadaeum is long, and its walls are much folded. As in other species of Sarcophytum the siphonoglyph is not well marked. The mesenteries are very large, and are much convoluted in the preserved condition.

The siphonozooids are narrow and long, where their growth in length is not impeded by the proximity of autozooids. The surface diameter averages $3 \mathrm{~mm}$., so that they may be fairly easily seen with a lens. They apparently fill up all the spaces between the autozooids, and are consequently most numerous near the middle of the disc, where there may be as many as from 10-16 siphonozooids in a straight line between two autozooids. Nearer the margin there may be from $4-6$, but the autozooids are so crowded on the margin that the intervening siphonozooids cannot be counted except in sections. The stomodaeum is short, but is slightly longer than that of $S$. glaucum; its average length is $2 \mathrm{~mm}$. The mesenteries are apparently more conspicuous in this than in any other species which I have examined.

Spicules. This species is interesting because of its small, slender spicules, which are very few in number. It is very improbable that spicules have been dissolved out by an acid preservative because they are most numerous in the peripheral tissues, and in decalcified preparations the holes left by the spicules are small and few in number. As the specimens were taken in fairly deep water the sparsity of spicules may to a certain extent be due to their habitat.

The spicules are somewhat more numerous in the stalk than in the capitulum, but they appear to occur even there only near the surface, where they have the form of minute clubs $17 \mathrm{~mm}$. long and $.03 \mathrm{~mm}$. broad. These spicules are similar to those near the surface of the capitulum. The spicules of the coenenchym throughout the specimens are very slender, pointed spindles, straight or slightly curved and dotted with a few minute spines (fig. 6); they are about $5 \mathrm{~mm}$. long by $03 \mathrm{~mm}$. broad. Long, slender clubs, about $5 \mathrm{~mm}$. in length, with small heads also occur. A few of the slender spindles are regularly arranged en chevron in the walls of the anthocodiae of the autozooids, while shorter spindles occur on the tentacles.

The species differs from all others which $I$ have examined, in its soft, tough texture, in the sparseness and small size of its spicules, in its flattened disc-like form, and in the large size of its autozooids, which are extremely numerous on the margin of the disc. The siphonozooids appear to differ from those of other species in the length of their stomodaea $(2 \mathrm{~mm}$.$) and in their strongly marked mesenteries and filaments.$ 


\section{GENUS LOBOPHY'TUM.}

\section{Lobophytum (amended genus)ํㅗㄱ.}

As in Sarcophytum and Sclerophytum a colony consists of two parts:- the capitulum and the stalk. The capitulum is the superior portion of the colony, and bears the anthocodiae; on its.surface are the apertures of the zooids. The capitulum is supported by the stalk, by means of which the colony is attached to the substratum. The stalk has no zooid apertures of any description on its surface, but is penetrated to the base of the colony by the cavities of the primary autozooids.

As in Sarcophytum, all the species are dimorphic, autozooids and siphonozooids being both well narked. Young colonies are often mushroom-shaped (fig. 12), the capitulum representing the pileus of the mushroom. As the colony grows older irregular excrescences appear on apparently any portion of the surface of the capitulum. These often attain a considerable size, so that the original resemblance to a mushroom is entirely lost, and the cipitulum has an irregularly-lobed appearance (fig. 7). Calcareous spicules, imbedded in the mesogloeal and often ectodermal tissues, are to be found throughout the colony. They are usually very small, short and stout, or long and slender, and generally studded with large warts, arranged in zones? ${ }^{2}$. Throughout the genus they are apparently similar to those figured by Marenzeller (1886) in his original description. When clubs are present they are few in number, and are not crowded near the surface as in the new genus Sclerophytum, in Acrophytum and in Alcyonium.

The autozooids are very well-marked, and are similar in form and general structure to those of Sarcophytum, but much larger than Sclerophytum (figs. 2, 13, 22). The eight tentacles are slightly longer and more slender than in any species of Sarcophytum which I have examined. They are of the simple pinnate type with a single row of pinnules down each side, the pinnules apparently less numerous in the younger than in the older antozooids.

The stomodaeum is very well-marked, but the siphonoglyph is not easy to distinguish in the preserved state except in stained sections. All the mesenteries have mesenterial filaments. The two dorsal filaments are similar in form to those of Alcyonium, and to those of the siphonozooids, in that they are ciliated and grooved. The ventral and lateral mesenterial filaments are usually rounded in cross section, but here and there may be seen a filament which is slightly grooved down the middle. The ova are similar in size and shape to those of other Alcyonaria. I have been unable to find male cells in any of the specimens.

The siphonozooids are very similar in form and function to those of Sarcophytum. They have no tentacles, and only the two dorsal mesenteries bear mesenterial filaments. These zooids have no special digestive cells, and do not bear reproductive organs. They appear to be respiratory and excretory in function.

The canal system is well developed and is similar in general structure to that of Sarcophytum. It differs from Sclerophytum in the absence of a special superficial canal system, which is so well marked in that genus. As in Sarcophytum transverse ciliated

1 A detailed account of the general and minute anatomy of this genus will be published later.

this genus, for similar spicules are present in Sarcophytum

- The zoned character of the spicules is not confined to this genu:
latum. 
channels connect the coelenteric cavities of the zooids (fig. 3), which, by enabling the circulation of sea-water through every zooid, effectively aerate the internal parts of the colony.

7. Lobophytum pauciflorum. Marenzeller (PI. XXVIII. fig. 7 and PI. XXIX. figs. 12-14).

Two fragments of a large colony were taken in shallow water on the Hulule, Male, reef. Two young complete colonies, which had retained to some extent their mushroom-shape (fig. 12), were also dredged, one from 20 fathoms, Mahlos Atoll, and the other from 24 fathoms in the S.-E. passage of Kolumadulu Atoll.

This appears to be the most common as well as the most widely distributed species of the genus. It was first taken in the Red Sea and subsequently described by Ehrenberg (1834). It has since been recorded by many other writers: 1848, Dana, Alcyonium pauciflorum; 1877, Klunzinger, Sarcophytum pauciflora; 1886, Marenzeller, Lobophytum pauciflom. Also var. validum; 1897, Whitelegge, var. validum; 1900, Hickson and Hiles, Lobophytum pauciflorum. In distribution it is now known from the Red Sea, New Zealand, Andamans, T'onga, Moluccas, Funafuti, New Britain, and now Maldive Islands.

The spicules have been described by Klunzinger and by Marenzeller. As in all other species of the genus they are extremely small, elliptical, or cask-shaped, usually three times as long as broad, but some longer and some shorter. Tuberculated warts are usually arranged in zones on their surfaces, but here and there a spicule may be seen without warts. Spicules of the coenenchym are $16-24 \mathrm{~mm}$. in length, and are $064-08 \mathrm{~mm}$. broad. Those near the surface are similar in form, but smaller, with only two rows of warts; they are $08-128 \mathrm{~mm}$. long and $032 \mathrm{~mm}$. broad.

In all the specimens most of the autozooids are contracted, and in many cases are withdrawn to a considerable distance below the surface of the colony. Owing to the different degrees of contraction of individual autozooids in the preserved state their dimensions vary considerably. The average diameter of a fairly expanded autozooid through the crown is $1.8 \mathrm{~mm}$., and through the base of the tentacles $1.4 \mathrm{~mm}$. New autozooids are budded off from the endodermal canals near the surface at any portion of the capitulum, this giving to the colony its lobed form. As in Sarcophytum siphonozooids are formed also by budding from the endodermal canals, chiefly in the vicinity of the autozooids, except on the margin, where the siphonozooids are very numerous, and the autozooids very few.

The tentacles are fairly long and conical (fig. 13, tent.), their average length when fairly expanded being $8 \mathrm{~mm}$. They are of a simple pinnate character, each having down either side a single row of pinnules, averaging in a fairly expanded tentacle $13 \mathrm{~mm}$. in length. The pinnules are less numerous in the young than in the older zooids. In a mature autozooid the pinnules of a single tentacle are almost uniform in size, but in young autozooids they are largest at the tip, and gradually become smaller towards the base of a tentacle. The number of pinnules on the tentacle does not appear to be a constant feature, sometimes a tentacle has more pinnules on one side than on the other, but in such cases the autozooids may not be mature.

The siphonozooids (figs. 13 and 14, si.) are universally scattered in more or less straight lines between the autozooids over the whole of the upper surface of the capitulum. They are about $3 \mathrm{~mm}$. in surface diameter, and can therefore be seen with the unassisted eye. On the tips of the lobes there may be from two to five siphonozooids in a straight line between two autozooids, but on the sides sometimes as many as 10 to 15 . On the extreme 
margin of the capitulum the siphonozooids are extremely numerous, a contrast to Sarcophytum, in which the autozooids are most numerous in this position. The stomodaeum (fig. 14, s.) is short and straight, averaging $26 \mathrm{~mm}$. in length. The siphonoglyph is well marked.

As a rule, the length of a siphonozooid varies according to age, the young siphonozooids are extremely short, but the older ones may extend for quite a considerable distance into the interior of the colony. The diameter of a siphonozooid is greatest at the surface, and gradually decreases inwardly. Some distance below the surface the cavity is sometimes so narrow that, but for the presence of the dorsal mesentery filaments, it might be easily mistaken for an endodermal canal. Sooner or later a siphonozooid terminates posteriorly in the endodermal canal, from which as a bud it originated. The keyhole shaped mouth aperture of the stomodaeum, with well-marked ciliated siphonoglyph, and the eight mesenteries of a siphonozooid, may be easily distinguished in surface view (fig. 13).

\section{GENUS SCLEROPHYTUM.}

Sclerophytum, gen. nov. (Pl. XXVIII. fig. 8, Pl. XXIX. figs. 15-18, Pls. XXX. and XXXI.).

In the Introduction to this paper (pp. 504-5) I have given the most important reasons for the establishment of this genus, and for the inclusion in it of the following species, which have hitherto been attributed to the genus Lobophytum: $L$, densum $=$ Sclerophytum densum; $L$. densum, var. $=$ Sclerophytum, sp. nov. ${ }^{1} ; L$. confertum $=$ Sclerophytum confertum ${ }^{1}$; L. marenzelleri $=$ Sclerophytum marenzelleri ${ }^{1} ; L$. tuberculosum $=$ Sclerophytum tuberculosum ${ }^{1}$. In addition to these six new species were collected by Mr Gardiner on the Maldive reefs.

The genus Sinularia (W. May, 1899, p. 100), which is founded entirely upon the form of the colony and the character of the spicules, cannot be maintained. Further investigation of its single species $S$. brassica will doubtless result in its inclusion in the present genus.

Brief Diagnosis of Genus. Colony lobed and sometimes similar in form to Lobophytum. Corallum often hard and granular (exceptions given in table, p. 531). Colonies usually dimorphic, but the siphonozooids are very minute and exhibit unmistakable signs of degeneration. Autozooids are usually smaller than in Sarcophytum, Lobophytum and Alcyonium, and in some cases slightly degenerate. There are two well-marked canal systems, (i) superficial, and (ii) internal. The superficial canals in most species large and numerous, but this system absent or only feebly marked in Lobophytum, Sarcophytum and Alcyonium. The internal canal system is similar in many respects to that of Sarcophytum and Lobophytum, and penetrates down to base of colony. In Alcyonium the internal canal system is not well marked in the deeper portions of the colony.

Spicules-usually distinct from those of Sarcophytum or Lobophytum; they are generally large and of varied form. Tuberculate spicules occur throughout the genus. Minute clubs and spindles are crowded near the surface, and form a very much thinner crust than in Alcyonium or Acrophytum.

Great diversity of form is to be found among the representatives of the genus in the collection. The young colonies are more or less mushroom-shaped (fig. 18). Some specimens have a cup-shaped capitulum with marginal lappets-these are usually fairly young colonies

\footnotetext{
1. These species are not present in the collection.
} 
(fig. 30). Owing to the growth of new lobes, in older specimens the cuplike form is often obliterated (fig. 29). Many exhibit a more or less well-marked lateral compression. Some of the specimens have a short, broad stalk and a much lobed convex capitulum as in Sc. capitale (fig. 8), in which the branches are closely set. In some cases the lobes are long, slender, branched, and digitate as in Sc. polydactylum. Some specimens are long-stalked and erect with slender or stout, more or less arborescent branches as in Sc. querciforme and Sc. palmatum (figs. 33 and 26).

The mesogloea in which the spicules are imbedded varies in density in different species. It is most abundant in the soft fleshy forms. In species with very large spicules it is always very dense and stains readily.

The spicules are large compared with those of allied genera. Spicules 2-4 mm. in length, are common in many species, but in Sc. querciforme they attain a length of $6 \mathrm{~mm}$. and in Sc. durum are even larger, a fair number attaining $7 \mathrm{~mm}$. in length by $1.7 \mathrm{~mm}$. in breadth.

Most of the spicules have tuberculate warts on their surface (fig. 20) and vary considerably in shape. The most common type is the spindle with blunt or sharply-pointed ends. This form is found throughout, but is not confined to the genus, it occurs also in Sarcophytum (S. plicatum and S. boettgeri), and also in Sinularia, which, however, cannot be regarded as a true genus (p. 516). I have not observed this form of spicule in any species of the amended Lobophytum.

Some of the tuberculate spicules are curved, some are crescentic, kidney-shaped, or ridged so that they are triangular in cross section, as in Sc. durum (fig. 31). In many species they are branched and are $Y$ or $K$ shaped, or have several forks as in Sc. capitale (fig. 16). They are sornetimes irregularly dumb-bell shaped (fig. $32 f$ ), but this form of spicule is rare. The tubercles are often arranged in more or less straight lines. Usually they are very numerous but in a few cases are sparsely scattered over the surface of a spicule. In Sc. durum and other species the tubercles are so closely set that a mosaic is formed (fig. $31 b$ ).

In every species of the genus, which I have examined, minute clubs and spindles are more or less crowded near the surface, but they form a much thinner crust than in Alcyonium or Acrophytum. These clubs often vary in shape to a considerable extent in a single specimen (fig. $32 a, b, c, d, e$ ). In some cases, the head is simply a knotted prolongation of the handle, but many of the clubs are bi- or tri-ramous. In all cases tuberculate warts are scattered in varying numbers over their surface. The spindles near the surface are usually very small, and dotted with a few simple spines (fig. $32 \mathrm{~g}$ ). Small spindles or rods generally occur in the outer walls and tentacles of the autozooids, and form a protective, calcareous, more or less conical cap which covers the aperture when the autozooid is partially retracted as in Sarcophytum.

Zooids. Of the eight species represented in the collection, four are dimorphic, but in all these the siphonozooids show unmistakable signs of degeneration. In two species the latter has proceeded further, and only vestiges of siphonozooids are present. In the remaining two species siphonozooids are absent.

In some of the species slight signs of degeneration are discernible in the autozooids.

The autozooids on the whole are smaller in this genus than they are in either Sarcophytum or Lobophytum. They are usually most numerous on the tips of the lobes. 
Throughout the genus the tentacles are short, blunt, and stumpy, compared with other genera. They vary slightly in size in different species (Table, p. 531) and in some cases are extremely small. They are only slightly pinnate, and in Sc. gardineri the pinnules are extremely rudimentary. Owing to the contracted condition of many of the specimens it was found impossible to determine the actual length and pinnate character of the tentacles of some of the species. In Sc. capitale and Sc. palmatum, which have comparatively large tentacles, some of the autozooids are expanded. In both of these species a double row of very small pinnules was seen on each side of the tentacles (figs. 17 and 27); in this respect this species approaches the genus Xenia.

The stomodaeum is comparatively long and has a well-marked siphonoglyph in every species of the genus. The mesenteries differ in size, in Sc. palmatum, Sc. hirtum, and Sc. capitale being well marked, in Sc. densum, Sc. polydactylum, Sc. durum and Sc. querciforme long and slender, but in Sc. gardineri only the dorsal ones well marked. The dorsal mesenterial filaments are long, broad, grooved and ciliated in every species, but the ventral and lateral vary in size in different species. 'These filaments are often very short and feebly developed and are never long or well marked (Table, p. 531); in Sc. gardineri they are apparently absent. The small size or entire absence of ventral or lateral mesenterial filaments is probably correlated with the presence of numerous zoochlorellae, for they are most numerous in Sc. gardineri, which has no ventral or lateral filaments.

Reproductive cells are not present in all the specimens, and where they do occur they consist entirely of female cells. I have not been successful in obtaining a single specimen with male cells. The ova appear to be of the typical Alcyonarian type, but the occurrence of ova on the dorsal mesenteries of Sc. gardineri is interesting (pp. 527-8).

Siphonozooids are present and are numerous in many but not in all species of the genus. They are very small compared with those of Sarcophytum and Lobophytum and show unmistakable signs of degeneration. They are largest in Sc. capitale where they have an average length of $3 \mathrm{~mm}$. (figs. 17 and 19, si.), but they are not difficult to recognise in stained preparations or sections of Sc. densum, Sc. hirtum, and Sc. palmatum, in which they vary from $1 \mathrm{~mm},-17 \mathrm{~mm}$. in length. In all these species they have small stomodaea which usually open to the exterior (figs. 19, 21, 22, 25, m. ap.), but this is often difficult to see except in stained sections. Traces of mesenteries occur in many of the siphonozooids. As a rule a siphonozooid terminates posteriorly in a large transverse vessel of the superficial canal system.

In Sc. durum and Sc. polydactylum the degeneration of the siphonozooids has proceeded much further than in Sc. capitale, Sc. densum, Sc. hirtum, and Sc. palmatum. In these two species the siphonozooids are represented by very short vertical caeca from the superficial, transverse canals. Traces of a stomodaeum may often be seen in an aggregation of ectoderm cells between the terminal portion of the caeca and the surface of the colony, but I have not observed any apertures to the exterior, nor any traces of mesenteries. Sc. gardineri and Sc. querciforme are similar anatomically in many respects to other species of this genus, but are more degenerate in character, and have completely lost their siphonozooids. In Sc. gardineri the autozooids also exhibit slight signs of degeneration.

Canal-systems and formation of zooids by budding. 'The transverse superficial and the internal canal systems can be easily distinguished in decalcified moderately thin free-hand sections, mounted simply in glycerine jelly or stained with borax carmine or 
brazilin, but the superficial canal system is best observed in stained microtome sections about $20 \mu$ in thickness. These sections however are too thick for histological purposes. The transverse superficial canal system is extremely well-marked in most species. The principal vessels are comparatively broad channels, which run also immediately below but parallel with the surface (fig. 22 t.s.c.); these I have named the "transverse canals." The vessels of this system ramify and anastomose throughout the peripheral tissues, they communicate with the terminal portions of vessels of the internal system, and have numerous apertures into the coelenteric cavities of neighbouring autozooids (fig. 22 ap.c.). From these vessels buds arise towards the surface, which in Sc. gardineri and Sc. querciforme develop into autozooids. In all the other species in the collection buds are extremely numerous and are very regularly arranged near the capitular surface, and differ from autozooid buds (1) in that they are all arrested at a very early stage, which appears to be constant for the species, and (2) differ also to a certain extent in development. There can be no doubt that these buds are homologous to the siphonozooids of Sarcophytum and Lobophytum, from which they differ in that their growth and development are arrested at a much earlier stage. These rudimentary siphonozooids retain throughout life their intimate connection posteriorly with the transverse vessels from which they originated (fig. 22). In Sc. capitale, Sc. densum, Sc. palmatum, and Sc. hirtum development is not arrested until the rudiments of a stomodaeum with mouth aperture and rudiments of mesenteries have been formed. In Sc. durum and Sc. polydactylum development is arrested at an earlier stage, a few ectoderm cells representing the stomodaeum wander into the mesogloea about the terminal portion of a bud, but there is no mouth aperture, and the bud is simply a caecum from a transverse canal, with only traces of mesenteries. In dimorphic species the number of siphonozooids arising from a transverse canal varies, but in Sc. capitale seven or eight siphonozooids terminating in a single vessel may often be counted between two antozooids.

In the presence of a special superficial canal system this genus is completely separated from Lobophytum, Sarcophytum, and Alcyonium, but in this respect it approaches Xenia. Zoochlorellae are numerous in the endoderm of the superficial canals, and are present in varying numbers in the lumen of the canals.

The internal canal system is strongly marked and is very similar to that of Xenia. It differs from that of Sarcophytum and Lobophytum in that the siphonozooids do not terminate posteriorly in the longitudinal vessels of the system, but in the transverse ressels (fig. 19). The principal vessels run more or less parallel with the longitudinal direction of the autozooids and have numerous apertures into their coelenteric cavities (fig. 22 ap.c.). They ramify and anastomose throughout the internal and especially in the basal portions of the colony. Many vessels terminate near the periphery in the vessels of the superficial canal system. Zoochlorellae are only to be found in this system in those canals which lie near the surface.

Zoochlorellae are present in all the specimens of the genus in the collection, but they vary in number in different species. Their numbers, however, do not appear to be affected by bathymetric variations within certain limits, for they are fairly numerous in specimens which have been taken at a depth of from 24-34 fathoms (Table I. p. 531). 'They are most plentiful in Sc. gardineri and least in Sc. capitale, both of which species were taken only in shallow water.

I have suggested (p. 528) that their presence in enormous numbers in Sc. gardineri is 
correlated with the reduced size of the tentacles and the absence of ventral and lateral mesenterial filaments.

\section{Sclerophytum capitale sp. nov. (Pl. XXVIII, fig. 8, Pl, XXIX. figs. 15-17).}

Two specimens were obtained from the reef at Hulule, Male Atoll, from shallow water. One specimen is complete (fig. 8), the other has a portion of the stalk and capitulum missing. The complete specimen is attached basally to a fragment of hard coral.

The colony is fairly large, broad and laterally compressed, with a beautifully lobed convex capitulum. The lobes are numerous, many of them are laterally compressed; some are branched. The colony is $65 \mathrm{~mm}$. high, and $70 \times 35 \mathrm{~mm}$. broad. The stalk is irregular in outline at the base, but the sides are rounded unbroken, and granular to the touch. The height of the stalk is $27 \mathrm{~mm}$. and the breadth is $43 \times 29 \mathrm{~mm}$. The colour of both specimens in spirit is yellowish-grey.

Spicules. Clubs and slender spindles are crowded near the surface as in other species of Sclerophytum. Most of the clubs have small knotted heads (fig. 15) and are about $18 \mathrm{~mm}$. in length. A few clubs occur, which are bi- or tri-ramous; they are slightly longer and more slender than those of Sc. densum. The tuberculate spicules (fig. 16) are smaller and less numerous than in many species of the genus. In the capitulum they are $1-2.5 \mathrm{~mm}$. in length, but they are a little larger in the stalk, where some of them attain a length of $3 \mathrm{~mm}$. These spicules vary considerably in shape as well as size (fig. 16); regularly and irregularly curved spindles are numerous. Crescentic, $\mathbf{Y}$ and $\mathbf{K}$-shaped spicules also occur, as well as a few spicules irregularly forked at both ends.

The autozooids are larger in this than in many species (Table I. p. 531), an expanded zooid measuring about $1 \mathrm{~mm}$. across the crown. They are very regularly distributed over the surface of the capitulum, but they are slightly more numerous on the tips of the lobes, where growth is apparently most vigorous. In vertical sections they appear to be very long and slender, broadest at the surface and tapering gradually posteriorly.

The tentacles are apparently longer than in any species except Sc. palmatum, when fully expanded measuring about $45 \mathrm{~mm}$. in length by $2 \mathrm{~mm}$. in breadth. They are broadest at the tip and are not bluntly conical in the preserved condition as in other species. The tentacles like those of Sc. palmatum are interesting because they have a double row of pinnules down each side (fig. 17 tent.), in this respect approaching the genus Xenia.

The stomodaeum is long and convoluted, and the mesenteries are all well-marked. All have mesenterial filaments. The dorsal ones are similar to those of other species. The ventral and lateral mesenterial filaments are short but are clearly marked. A partially digested mass of food material containing a few zoochlorellae in the process of disintegration was observed in the coelenteric cavity of one of the autozooids.

Siphonozooids are present in this species (figs. 17 and 19, si.), but they are rudimentary. They are, however, larger in this than in any other species of the genus which I have examined. Many of them have an extremely small stomodaeum, which in sections is seen to open to the exterior. They terminate posteriorly in the transverse vessels of the superficial canal system. Zoochlorellae occur in the endoderm and the superficial canal system, but they are not numerous in the coelentera nor in the lumen of the canals. 
Canal systems. The superficial and internal canal systems are both extremely wellmarked. Near the surface the vessels are very large (fig. 17) compared with those of other species. They are much branched and form an intricate network. The large transverse vessels run immediately below the siphonozooids and their lumen is continuous with their coelenteric cavities (fig. 19). They also communicate with the vessels of the internal canal system and directly or otherwise with the coelenteric cavities of neighbouring autozooids. The breadth of the transverse vessels is $07-3 \mathrm{~mm}$.

The species is characterised by (1) the tough fleshy texture of the colony; (2) the small size of the tuberculate spicules; (3) the siphonozooids less degenerate than in other species; (4) the superficial and internal canal systems extremely well-marked; (5) zoochlorellae less numerous than in any other species in the collection.

9. Sclerophytum densum (=Lobophytum densum Whitelegge, 1897, p. 219, figs. 19-22), Pl. XXIX. fig. 18, Pl. XXX. figs. 20-22.

One complete specimen over the edge of a shoal from Addu Atoll, at a depth of 11 fathoms. Several fragmentary specimens from shallow water from the western reef of Hulule, Male Atoll. Two fragments from 25 fathoms, Miladumadulu Atoll. One complete young specimen (fig. 18) from 34 fathoms, Felidu Atoll (this specimen has not yet lost its mushroom-like form although lobes have grown out from the margin).

The specimens vary considerably in shape and size, are all hard and brittle, and their surfaces rough to the touch. The capitula of mature specimens have numerous lobes, which vary in size in specimens from different localities. In many cases the margin of the capitulum has no seam, so that but for the presence of zooid apertures on its surface, the capitulum passes almost imperceptibly into the stalk.

I have compared these specimens with others from Funafuti, China Seas, and British New Guinea and find them to agree fairly well in all essential particulars. The species is the commonest in the collection and appears to be the most widely distributed of the genus. Its bathymetric range from shallow to fairly deep water is very interesting. The colour in spirit varies in individual specimens, some are dark brown, some are dark yellow, while others are greyish-brown in colour. The spirit in which the specimens had been preserved had a distinct greenish tinge, which may be due to the solution of green colouring matter in the zoochlorellae, as they are very numerous in the canals and endodermal tissues near the surface of the colony.

The spicules of this species are described and figured by Whitelegge. As they do not differ in any important respect from those of other species, they may be regarded as being fairly typical of the genus (fig. 20) if we except Sc. durum which apparently has no branched tuberculate spicules. Minute clubs and spindles are crowded near the surface. The most common tuberculate spicules are $2-3 \mathrm{~mm}$. in length.

The mesogloea is of a dense tough nature, stains very readily, and is of a yellowishbrown colour in spirit specimens.

The autozooids are very numerous, regularly arranged on the lobes, and apparently just as abundant in the furrows between the lobes. The diameter of an autozooid cavity (fig. 22) is greatest just below the surface and averages $75 \mathrm{~mm}$, in the stalk being slightly reduced.

G. II. 
The tentacles (fig. 22 tent.) are very small but are slightly larger than those of Sc. durum, being about $4 \mathrm{~mm}$. long and bluntly conical. They are pinnate, but I have been unable to see more than a single row of pinnules down each side.

The stomodaeum (fig. $22 \mathrm{~s}$.) is long, and somewhat convoluted and is $6-.85 \mathrm{~mm}$. in length. The siphonoglyph is clearly shown in transverse sections.

The mesenteries are long and slender (fig. 22); the ventral and lateral mesenterial filaments are short and broad and measure about $18 \mathrm{~mm}$. in length (fig. 22 v. m. f., l. m. f.). The dorsal mesenteries are much longer and are broader than the others, have broad grooved ciliated filaments (fig. 22) and are similar to those of other Alcyonaria.

Ova in all stages of development are present in the mesenteries of one of the fragmentary specimens from shallow water. They are of the typical Alcyonarian character and are of a yellowish-brown colour. The largest are easily seen with the naked eye.

Siphonozooids. Whitelegge $(1897$, p. 220) says of this species, "The Siphonozooids are minute and the orifices difficult to distinguish even with a lens."

If a thin strip of tissue be taken from the surface of the colony and examined under the microscope the siphonozooids are seen to occupy minute rounded areas surrounded by a spicular tissue containing minute clubs and spindles, as in Sc. capitale (fig. 17). It is only after decalcification and staining (borax-carmine answers very well) that the stomodaea and their apertures can be distinguished (fig. 21). The aperture is often rounded, but it is occasionally keyhole-shaped ${ }^{1}$. As in other dimorphic species the siphonozooids terminate posteriorly in the transverse vessels of the superficial canal system (fig. 22). As these vessels lie very near the surface of the colony the siphonozooids are necessarily very short, averaging $\cdot 17 \mathrm{~mm}$. long.

The stomodaeum is usually a tiny tube one cell in thickness and one or two cells in length. Sometimes it is a solid cord of cells without lumen so that the siphonozooids have no aperture to the exterior. Traces of mesenteries are not difficult to perceive in some of the siphonozooids.

Canal Systems. Both superficial and internal canal systems are clearly marked (fig. 22), and may be regarded as being typical of the genus (pp. 518-19). The vessels ramify and anastomose in all directions, so that a complete circulation of fluids is ensured throughout the colony. The vessels near the surface are crowded with zoochlorellae. The transverse vessels lie very near the surface, they are not so broad as the transverse ressels of Sc. capitale, their average diameter being $08 \mathrm{~mm}$.

10. Sclerophytum hirtum sp. nov. (Pl. XXX. figs. 23-25).

A single well-preserved specimen from Naifaro reef, Fadifolu Atoll, having a portion of the stalk with basal attachment missing (fig. 23), $46 \mathrm{~mm}$. high and $66 \times 35 \mathrm{~mm}$, broad.

The stalk is short, broad, laterally compressed, and is much wrinkled vertically, its surface is granular and it yields slightly to pressure. Its height (incomplete) is $22 \mathrm{~mm}$. and breadth $45 \times 25 \mathrm{~mm}$. The capitulum is irregularly divided into numerous and slightly flexible lobes. The primary lobes or branches vary to a considerable extent in height, breadth, and number of secondary lobes. The mode of branching is irregular; di- or tri-chotomy is frequent, but here and there lateral branches are given off from a common stem, some of these branches

\footnotetext{
1 These apertures should not be confused with the lobes left by spicules after decalcification.
} 
ramify dichotomously. The primary branches are $10-22 \mathrm{~mm}$. high and $10-17 \times 7-8 \mathrm{~mm}$. broad. In spirit the specimen is of a dull brownish-grey colour. The specimen is firmer in consistency and less fleshy than Sc. capitale, but not so hard and brittle as Sc. densum, Sc. durum, Sc. querciforme, etc.

The spicules are very numerous, clubs are closely packed near the surface, and most of the tuberculate spicules are very densely set with warts (fig. 24). The clubs have slender handles, but vary considerably in shape and size. They may have from one to four tuberculate heads. They are $1-33 \mathrm{~mm}$. in length and $02-12 \mathrm{~mm}$. in diameter through the head. Very slender clubs and spindles are present in the tentacles. In a partially retracted condition of the autozooid, they form an outer protecting conical wall to the soft fleshy tissues of the autozooid. The tuberculate spicules show great diversity in form and size (fig. 24 $a, b, c, d$ ), they are $1.1-4 \mathrm{~mm}$. in length and $18-1 \mathrm{~mm}$. in breadth. Forked, curved, and branched spicules are present similar to those of Sc. capitale (fig. 16). Irregular spindles constricted in the middle (fig. 24d ) also occur, but they are not common. Some of the spindles have few warts with very small tubercles, so that they seem to be beset with small spines.

The autozooids are very regularly arranged over the whole of the capitular surface, and are 1-1.5 mm. apart. Many of them are expanded, measuring about $8 \mathrm{~mm}$. across the crown. The tentacles are short, broad, and bluntly conical, there are indications of a double row of small pinnules down each side. Spicules in the form of slender clubs and spindles are regularly arranged on the outer walls. The stomodaeum is long and convoluted, and the siphonoglyph is strongly marked. The mesenteries are larger and stouter structures than in many species of the genus. The ventral and lateral mesenterial filaments are longer and broader than in Sc. densum and Sc. durum. The dorsal mesenterial filaments are similar to those of other species. Reproductive cells were not observed in the specimen.

Siphonozooids (fig. 25). The siphonozooids are very rudimentary, and are so minute that they cannot be distinguished without the aid of a microscope. Their average length is $1 \mathrm{~mm}$. and breadth $045 \mathrm{~mm}$. If a thin strip of tissue be carefully removed from the surface of the colony and stained with borax-carmine, the siphonozooids are seen to occupy more or less hexagonal or rounded areas, and are separated from each other by a spicular tissue containing minute clubs and slender spindles as in Sc. capitale (fig. 17). The siphonozooids appear to be devoid of spicules, but with high powers there may be seen a few extremely minute ones imbedded in the ectoderm cells. The rudimentary stomodaeum with its aperture to the exterior (fig. 25) is seen in surface view to be keyhole-shaped, in a few cases rounded, but sometimes the aperture cannot be distinguished even in sections. Traces of mesenteries are to be found in some of the siphonozooids.

Canal systems. As in other species, the transverse superficial canal system is wellmarked, the average diameter of the large transverse vessels being $07 \mathrm{~mm}$. If allowance be made for the great amount of space taken up by the numerous tuberculate spicules the internal canal system may also be said to be well-marked. The average diameter of the longituainal canals near the surface is $04 \mathrm{~mm}$. near the base of the colony, the canals are broader and have an average diameter of $07 \mathrm{~mm}$.

Zoochlorellae are numerous in that portion of the endoderm of the canals which lies nearest to the surface of the colony. They are not numerous in the lumen of the canals. 
The species approaches Sc. capitale and Sc. densum in that the siphonozooids are less degenerate than in the other species of the genus which I have examined. They are smaller than those of Sc. capitale, but agree with that species in having indications of a double row of pinnules on the tentacles and in that the mesenteries and mesenterial filaments are fairly well-marked, and are longer and broader than those of Sc. densum.

11. Sclerophytum polydactylum (= Alcyonium polydactylun Dana, = Lobularia polydactylum Ehrenberg).

A single complete and excellently preserved specimen, attached basally to a piece of hard coral, was taken at 25 fathoms, Miladumadulu Atoll. The colony has a marked lateral compression and is $48 \mathrm{~mm}$. high. The capitulum is $80 \times 34 \mathrm{~mm}$. broad. The base of the stalk is irregular in outline, the greatest height of the stalk is $26 \mathrm{~mm}$., its breadth is $58 \times 31 \mathrm{~mm}$. The specimen is of a tough fleshy consistency yielding slightly to pressure. The lobes are long and slender compared with other species, and are slightly flexible. The colour in spirit is a pale brownish-grey.

The appearance of the colony is very similar to the specimen figured by Klunzinger, 1879 (p. 26, Taf. 1, fig. 6) with which it also agrees in the form and character of the spicules. For many years the species has been included in the genus Alcyonium. A study of its anatomy however reveals its generic identity with the newly established genus Sclerophytum.

The spicules are described and figured by Klunzinger, many of them are of the tuberculated warted type. The spindles average $2 \mathrm{~mm}$. in length and $45 \mathrm{~mm}$. in breadth. Crosses, $\mathrm{K}$ and $\mathrm{Y}$-shaped spicules, and a few spiny spindles occur. Clubs are closely packed near the surface as in other species.

There are no true siphonozooids in the species.

The autozooids are very numerous and are regularly arranged on the many lobes. In the furrows between the lobes they are less numerous. The autozooids are very small, their cavities averaging $5 \mathrm{~mm}$. in diameter near the surface. When partially retracted, they are conical in surface view, the tentacles bending over towards the middle. Regularly arranged minute spicules in the form of slender spindles are imbedded in their outer walls, forming conical shields which effectively protect the soft delicate tissues within. Young autozooids arising from endodermal canals are numerous on the tips of the lobes. The tentacles are pinnate but they are all more or less retracted so that it is impossible to count the rows of pinnules.

The stomodaeum and siphonoglyph are similar to those of other species. The mesenteries are all long and slender, but the dorsal ones are the most prominent. The ventral and lateral mesenteries have short, feebly-marked mesenterial filaments, but the dorsal mesenterial filaments are broad, grooved, and of considerable length. I have been unable to find male or female cells in the specimen.

Canal Systems. The transverse superficial canal system is extremely well-marked. Short, broad, vertical caeca are given off from the large vessels of this system towards the surface, but do not communicate directly with the exterior. There can be no doubt that these caeca are identical in origin and to a certain extent in structure with the degenerate siphonozooids of Sc. capitale, densum, hirtum, and palmatum, but in this species degeneration has proceeded so far that the siphonozooids have no stomodaeal apertures. Traces of stomodaea 
may, however, in many cases be seen as aggregations of ectoderm cells about the upper terminal portions of the caeca. The average diameter of the transverse vessels is $16 \mathrm{~mm}$.

The internal canal system does not differ in any important respect from that of other species. The vessels of this system gradually become larger as they approach the surface. Many of the longitudinal vessels terminate in the superficial canals.

Zoochlorellae are present in considerable numbers in the endoderm and lumen of the superficial canals, but they are not so numerous as in Sc. gardineri.

This species is interesting because in many respects it forms an important link between Sc. capitale, densum, hirtum, and palmatum, which have clearly marked but degenerate siphonozooids, and Sc. gardineri which has no siphonozooids. In Sc. polydactylum the autozooids are small and appear to be slightly degenerate in the small size of the tentacles, and in the feebly-marked ventral and lateral mesenterial filaments. There are no siphonozooids which are functional as such, but traces of these individuals remain as the vertical caeca from the transverse vessels of the superficial canal system. Zoochlorellae are abundant in the endoderm and lumen of the superficial canals, and to a certain extent in the endodermal tissues of the zooids, but they are not nearly so numerous as in the more degenerate Sc. gardineri.

12. Sclerophytum palmatum sp. nov. (Pl. XXX. fig. 26 and Pl. XXXI. fig. 27).

A single well-preserved specimen was taken in shallow water from Hulule, Male Atoll (fig. 26).

The colony is erect, branched, and shows a marked lateral compression. It is $95 \mathrm{~mm}$. high and the capitulum is $35 \times 17 \mathrm{~mm}$. in diameter. The stalk is $53 \mathrm{~mm}$. in length and is $19 \times 8.5 \mathrm{~mm}$. in diameter. The capitulum is divided near its base into two large primary branches, one of which is $36 \mathrm{~mm}$. in length, and $10 \times 11 \mathrm{~mm}$. in diameter, the other is $33 \mathrm{~mm}$. in length and $14 \times 11 \mathrm{~mm}$. in diameter. These branches give off numerous secondary branches which vary in length and thickness. The stalk, the capitulum, and all the fairly large lobes exhibit the same lateral compression. The specimen is tough and fleshy in consistency. The lobes are soft and flexible.

The colour in spirit is bluish-green, with irregular brown patches on the stalk and about the base of the lobes. The bluish-green colour is confined to the surface of the colony and is only to be observed between the autozooids. The colour is not affected by dilute borax-carmine, but takes up Delafield's haematoxylin and alum, iron brazilin, and strong borax-carmine stains fairly readily.

The spicules are similar in form and size to those of other species of the genus (fig. 20). Immediately below the surface there is a thin layer of clubs averaging $13 \mathrm{~mm}$. in length by $.003 \mathrm{~mm}$. in breadth, and slender spindles averaging $07 \times 003 \mathrm{~mm}$. The spicules of the coenenchym are not numerous and are all of the tuberculate warted type characteristic of the genus. The spindles average $3 \mathrm{~mm}$, in length and $4 \mathrm{~mm}$. in breadth; a few are irregularly branched. The spicules of the stalk are similar to those of the capitulum.

The autozooids are of a pale brown colour, and are almost uniformly scattered over the whole of the capitular surface (fig. 26). There are usually from $7-8$ to $10 \mathrm{~mm}$. Many of the autozooids are almost fully expanded, and are situated on small raised rounded areas, which are not indicated in the drawing. 
The autozooids are slightly larger than those of many species. The anthocodial portion in the preserved state is very short, being only about $6 \mathrm{~mm}$. in length, so that the crown with its eight radiating tentacles appears to be apposed to the surface of the capitulum. The average diameter of a fully expanded crown is $1.5 \mathrm{~mm}$. Below the surface the diameter of an autozooid gradually diminishes posteriorly.

The tentacles are long compared with those of other species, and are about $7 \mathrm{~mm}$. in length when extended. They are blunt at the tip and are almost of uniform breadth. When carefully examined microscopically a double row of rudimentary pinnules may be seen down each side (fig. 27). In this respect this form resembles Sc. capitale and approaches Xenia.

The stomodaeum is long and convoluted, and the siphonoglyph is provided with long cilia. The mesenteries are larger and stouter in this form than in any other species in the collection. The dorsal mesenteries have large and broad, grooved mesenterial filaments, and the ventral and lateral mesenteries have longer and broader filaments than those of other species. The coelenteric cavities of neighbouring autozooids are often connected by means of short transverse ressels as in Sarcophytum (fig. 3). I have been unable to find male or female cells in the specimen of this species.

Siphonozooids are present but are clearly degenerate in this species, being represented by minute caeca from the large transverse vessels of the superficial canal system. They are regularly distributed in the peripheral portions of the capitulum between the autozooids. They apparently have no aperture to the exterior and therefore cannot be functional as true siphonozooids. In decalcified stained slips of tissue from the surface of the colony the caeca may be clearly seen in surface view through the ectodermal tissues, and average $07 \mathrm{~mm}$. in diameter. There is little doubt that the caeca are really very degenerate siphonozooids, for they are identical in origin with the less degenerate siphonozooids of Sc. capitale, Sc. densum, and Sc. hirtum, in which species the siphonozooids possess a small stomodaeum and traces of mesenteries.

Canal systems. The transverse vessels of the superficial canal system are very pronounced but they are not quite so broad as in Sc. capitale, averaging $1 \mathrm{~mm}$. and lying about $15 \mathrm{~mm}$. below the surface. The ressels of the internal system are fairly numerous, and are very broad near the surface, where as in other species they usually terminate in the transverse ressels of the superficial canal system.

Zoochlorellae are very numerous in that portion of the endoderm of the transverse vessels which lies near the surface. It is so distended by their presence as to almost obliterate the lumen of the canals. They are not numerous in the ressels of the internal canal system, except where they approach the surface. They are also present in considerable numbers in the endoderm of the autozooids, but they are not so numerous in any part of the colony as they are in Sc. gardineri.

The mesogloea is diffuse and does not stain very readily with borax-carmine or haematoxylin owing to the sparcity of spicules in the lobes, it is more abundant there than in many other species.

The interesting features of this species are (1) the colony is tough and fleshy in texture; (2) the spicules are not very numerous, and are small compared with those of many other species; (3) the autozooids are fairly large. The tentacles are longer than those of any other species in the collection, and have a double row of minute pinnules down each side. 
The mesenteries and mesenterial filaments are more pronounced in this than in any other species; (4) the siphonozooids are extremely degenerate and have no apertures to the exterior. They are represented by rertical caeca from the transverse vessels of the superficial canal system; (5) the transverse and internal canal systems are well-marked; (6) zoochlorellae are fairly numerous.

This species resembles Sc. capitale in certain respects: the tough fleshy texture of the colony; the fairly large autozooids; and the presence of a double row of rudimentary pinnules on the tentacles. It differs from that species, however, in that the mesenteries and mesenterial filaments are more strongly marked, the siphonozooids are more degenerate, and the canal system is not so clearly defined.

13. Sclerophytum gardineri sp. nov. (Pl. XXXI. fig. 28).

A single complete and well-preserved specimen was taken in shallow water from Hulule, Male Atoll.

The colony is $40 \mathrm{~mm}$. high and is $48 \times 26 \mathrm{~mm}$. broad, irregularly cup-shaped and laterally compressed (fig. 28). The stalk is $20 \mathrm{~mm}$. high and is $39 \times 20 \mathrm{~mm}$. broad, its surface is somewhat wrinkled and is hard, granular and unyielding to slight pressure. The capitulum is irregularly cup-shaped with irregular long and slender lobes, arising from the middle and edges of the cup. The cup is $40 \times 31 \mathrm{~mm}$. in diameter and in the middle is $20 \mathrm{~mm}$. deep; there are two clefts in the sides of the cup. The lobes are brittle and are often branched. The largest lobe $(l$.$) arises slightly obliquely from the middle of the cup and is 28 \mathrm{~mm}$. high and $9 \times 6.5 \mathrm{~mm}$. in diameter near the base. It gires off numerous digitate branches which vary in length from 2 to $7 \mathrm{~mm}$, but having an almost uniform breadth of $3 \mathrm{~mm}$. Owing to the presence of numerous spicules the surface of the capitulum like that of the stalk is hard and granular. In spirit the specimen is of a dark cream colour.

spicules. The hard and brittle nature of the coral is due to the presence of innumerable spicules. Clubs and slender spindles, similar to those of other species and measuring $\cdot 1-2 \mathrm{~mm}$, in length and $.05-06 \mathrm{~mm}$. in breadth, are crowded near the surface. The tuberculate spicules are similar to those of other species, the majority are spindles about $3 \mathrm{~mm}$. long and 8-1 mm. broad. A few are slightly forked as in Sc. densum and Sc. hirtum. The outer walls of the anthocodiae are studded with minute spindles as in many other species.

Autozooids only are present and the species may be regarded as haring lost its siphonozooids. The autozooids are very small, and as many of them are almost completely retracted only a few can be distinguished on the surface of the capitulum (fig. 28). A fairly expanded autozooid measures $4-5 \mathrm{~mm}$. across the crown. The tentacles are very minute, and when extended average only $3 \mathrm{~mm}$. in length. The pinnules are represented by very slight indentations of the lateral walls and are not easy to distinguish. The stomodaeum is fairly long, with much convoluted walls; its siphonoglyph is large and is provided with long cilia.

Mesenteries. The dorsal mesenteries are clearly marked and are very long; they are provided with long, broad grooved and ciliated mesenterial filaments, which are much convoluted at the beginning of their course. Ventral and lateral mesenteries are present but below the stomodaeum diminish rapidly in size, and consequently have a very short free edge with no filaments. Ova in all stages of development are present, and are frequently to be found on the dorsal mesenteries. In this respect this species is interesting, for ora 
are usually only found on the ventral and lateral mesenteries, and I believe have not been observed hitherto on the dorsal mesenteries in any species of the Alcyonaria.

Zoochlorellae are very numerous in the endoderm of the tentacles, and are present, but less abundant, in the endoderm of the mesenteries and in the coelenteric cavity of the zooids.

Canal Systems. The vessels of the superficial canal system are broad and fairly numerous. The transverse vessels lie in the mesogloea about $.07 \mathrm{~mm}$. below the surface and are about $1 \mathrm{~mm}$. in diameter. Both endoderm and lumen of these canals are densely crowded with zoochlorellae, which are also present but are not so numerous in the vessels near the surface of the internal system, which is similar to that of other species.

A study of the anatomy of this species reveals many interesting features, which may be briefly summarised. The autozooids are very small and are less numerous than in many other species. In certain respects they show unmistakable signs of degeneration:-(1) the tentacles are very short, blunt, inflexible, and are only very slightly pinnate; (2) the ventral and lateral mesenteries are very feebly marked, and (3) have no mesenterial filaments. On the other hand the siphonoglyph of the stomodaeum, the dorsal mesenteries and their filaments are all strongly marked. The occurrence of ova on the dorsal mesenteries is also interesting, but is probably an aberrant feature, as they have not to my knowledge been previously observed on the dorsal mesenteries in any species of the Alcyonaria.

The degenerate character of the food-capturing and digestive portions of the zooids is doubtless correlated with the presence of vast numbers of zoochlorellae in the endoderm and lumen of the superficial canals and in the endoderm of the zooids, for in no other species are the zoochlorellae so numerous nor the degeneration of the zooids so marked. It is possible that the absence of siphonozooids may also be correlated with the strongly marked character of the ciliated portions of the autozooids. In the absence of ventral and lateral mesenterial filaments, and of siphonozooids, and the presence of a well-marked superficial canal system this species resembles the genus Xenia.

\section{Sclerophytum durum sp. nov. (Pl. XXXI. figs. 29-32).}

Four specimens were taken. Three of them have a cup-shaped capitulum with marginal lappets; one of these has a rhizome-like outgrowth from the stalk which serves for additional fixation (fig. $30 r h$ ). The fourth specimen (fig. 29) is the largest and probably the oldest, for ova are present at an advanced stage of development. This specimen is not cup-shaped, but is proportionately shorter and stouter than the others and has a much lobed capitulum, so that the specific identity of the four specimens was not easy to recognise. Careful and minute examination, however, shows the difference to be one of facies only, for the anatomy of all the specimens proved to be identical. All the specimens are extremely hard and brittle. Enormous spicules (fig. $31 s p$ ) can be seen lying parallel to the surface through the ectodermal tissues.

One cup-shaped specimen creamy-white in colour (in spirit) was taken near Nilandu at a depth of 24 fathoms. Two cup-shaped specimens, one of which has a double cup, dirty yellow in colour (in spirit), were taken on the Mahlos Atoll in shallow water. The lobed specimen of a pale brownish-grey colour in spirit was taken on Addu Atoll, also in shallow water. The specimens vary from 30 to $50 \mathrm{~mm}$. in height, their capitula from 27 to $45 \mathrm{~mm}$. in diameter. Two of the specimens have slender, and two have broad stalks, the stalk of the lobed specimen being proportionately shorter and broader than that of the rest. 
Spicules. The species is characterised by the enormous spicules which occur throughout the colony and can be seen with ease through the ectodermal tissues (figs. 29 and $30 \mathrm{sp}$ ). The largest are all spindles of the tuberculate type (fig. 31). These spicules have an important bearing upon the form of the colony in that they materially affect its outline. Small clubs are numerous near the surface as in other species. The tuberculate spindles vary in size from $1.5 \times .5 \mathrm{~mm}$. to $7 \times 1.7 \mathrm{~mm}$. (fig. 31). They are often somewhat irregular in form; they may be sharply pointed or blunt at each end, many are ridged and are three-sided, some are crescentic, many are curved. All the large spicules are unbranched, in this respect the species differing from any other in the collection.

When a spicule is seen with the naked eye the general outline appears smooth and umbroken, when examined with a lens the surface appears granular (fig. 31), but when subjected to higher magnifications the granules are seen to be tiny tuberculate warts regularly arranged (fig. $31 \mathrm{~b}$, and $c$ ), averaging $09 \mathrm{~mm}$, across. A few spindles occur here and there with a few tubercles.

Packed closely near the surface are the small clubs and a few minute spindles with few tubercles, and a very few irregular tuberculate dumb-bells about $1 \mathrm{~mm}$. in length and $.08 \mathrm{~mm}$. in breadth. The clubs are knotted and of varied shape, $12-24 \mathrm{~mm}$. long and about $02 \mathrm{~mm}$. broad (fig. $32 a, b, c, d, e$ ). They are apparently the only branched spicules in the species.

The autozooids, most of which are completely retracted in all the specimens, are more numerous on the lobed (fig. 29) than the cup-shaped specimens, but are proportionately fewer in this than in any other species of the genus which $I$ have examined. This may, to a great extent, be due to the presence of numerous large spicules which run immediately below but parallel with the surface. The autozooids are very minute, and in the retracted state their apertures are difficult to distinguish even with a lens. In the cup-shaped specimens the polyps appear to be most numerous on the margin of the capitulum. The diameter of a polyp cavity when the polyp is completely retracted is $.25-5 \mathrm{~mm}$. The tentacles are extremely short and stumpy, and only very slightly pinnate. They possess spicules in the form of extremely small spindles. The stomodaeum is long, measuring about $.85 \mathrm{~mm}$. It is slightly convoluted in the preserved state; the siphonoglyph is fairly well-marked. The 8 mesenteries are very slender, but are clearly marked. All of them have mesenterial filaments.

The two dorsal mesenterial filaments are of considerable length and are grooved and ciliated as in other Alcyonaria. The ventral and lateral mesenterial filaments are extremely short and are confined to that portion of the autozooid immediately below the stomodaeum. They are similar in form and anatomy to those of other Alcyonaria. Typical Alcyonarian ova, $3-5 \mathrm{~mm}$. in diameter, are present in the mesenteries.

The siphonozooids are extremely degenerate in this species, and are represented by small creca from the superficial transverse canals.

Canal Systems. The superficial canal system is strongly marked. The large transverse vessels run in a sinuous course immediately below the ectodermal tissues. Many of the canals are closely apposed on their internal side to the enormous spicules which in this species lie so near the surface. These canals have very short vertical caeca towards the surface but they are shorter than Sc. polydactylum and are homologous to the degenerate siphonozooids in other species. The superficial canal system has numerous communications with the internal canal system, which is not so strongly marked as in other species. 
Zoochlorellae are present in that portion of the endoderm of the transverse canals which lies nearest to the surface, but they are not numerous, few are to be found in the lumen of the canals.

Owing to the great amount of space occupied by the spicules the supply of mesogloea is less abundant than in other species, but it is of a very dense nature and stains very readily.

\section{Sclerophytum querciforme sp. nov. (PI. XXXI. fig. 33).}

Two complete colonies were taken in shallow water on Hulule, Male Atoll. Both specimens are arborescent and are very similar in their manner of growth. Each is comparatively tall and slender, with a much branched capitulum, many of the branches having long and slender lobes. From near the base of the larger specimen a second stalk grows out bearing a small branched capitulum (fig. 33).

The larger colony is $46 \mathrm{~mm}$. high. The stalk is cylindrical above the junction of the secondary stalk and elliptical in cross section below. At the top the stalk is branched and passes almost imperceptibly into the capitulum, which is $20 \mathrm{~mm}$. high and $25 \times 18 \mathrm{~mm}$. in diameter, being slightly compressed laterally. The branches vary very considerably in size, but the two principal branches are 10 and $12.5 \mathrm{~mm}$. long and about $4 \mathrm{~mm}$. broad. The lobes are very slightly flexible. The surface of the capitulum and stalk is granular and fairly hard to the touch, but yields to slight pressure. The specimens in spirit were of a pale greenish-grey which gradually changed to a deep cream colour.

The spicules are very similar in form and structure to those of other species. Clubs are very numerous near the surface, $2-26 \mathrm{~mm}$. long by about $008 \mathrm{~mm}$. in greatest breadth. The tuberculate spicules vary in size, the largest being fully $6 \mathrm{~mm}$. long by $1 \mathrm{~mm}$. broad. A few forked spicules occur but are not numerous.

There are no siphonozooids in this species.

The autozooids are fairly numerous and are all of one kind. Most of them are completely retracted. An autozooid cavity is $4-.5 \mathrm{~mm}$. in diameter just below the surface. The tentacles are very short and pinnate. The pinnules are proportionately longer in this than in any other species in the collection.

The stomodaeum is long; the siphonoglyph is well-marked and is provided with very long cilia. The mesenteries are all strongly marked and are all provided with mesenterial filaments; the dorsal mesenterial filaments are long, grooved and ciliated as in other species. The ventral and lateral mesenterial filaments are not so long nor so broad as the dorsal filaments; they are more or less rounded in cross section and are similar in form and structure to those of Sc. palmutum, capitale, lirtum, and of many other Alcyonaria, but both mesenteries and filaments are longer and broader than in many species of the genus.

Canal Systems. The vessels of the superficial system are not so large nor so numerous as in other species in the collection. The transverse vessels lie about $25 \mathrm{~mm}$. below the surface and have no vertical caeca, but follow a course almost parallel with the surface. As in other species, these vessels communicate with the coelenteric cavities of the autozooids and with many vessels of the internal system, which is very similar to that of other species, but less strongly marked.

Zoochlorellae are fairly numerous in the endoderm and lumen of the canals and in the endodermal tissues of the autozooids. 


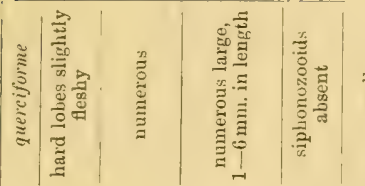

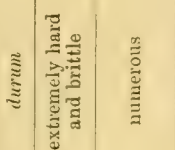

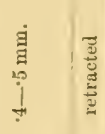

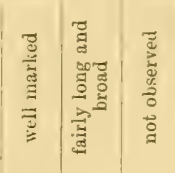

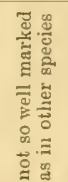

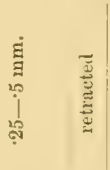

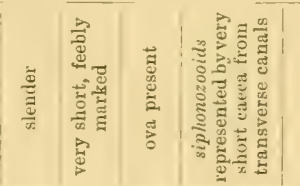

$\mid$

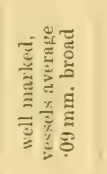

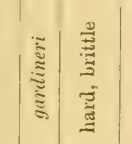
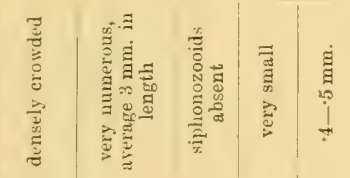

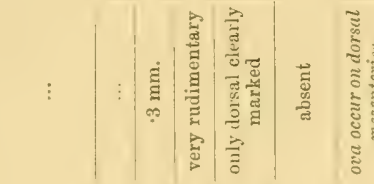
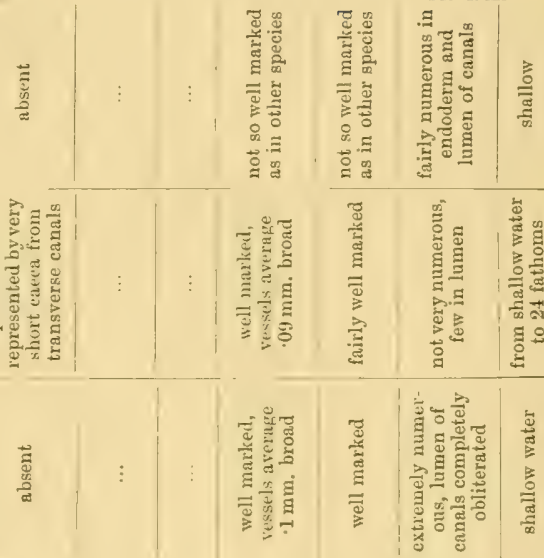

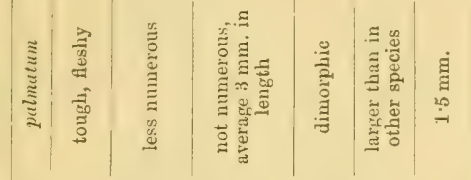

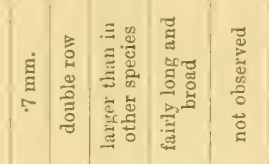

$\frac{\sqrt{1}}{\sqrt{1}}$

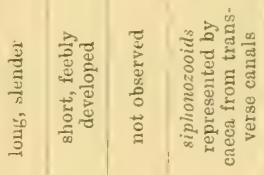

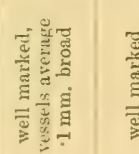

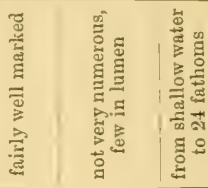

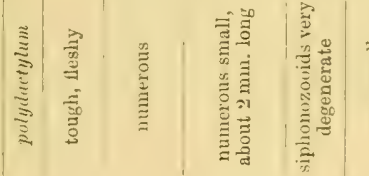

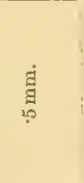

拿

焉

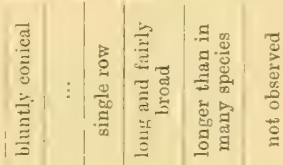

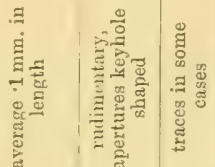

要

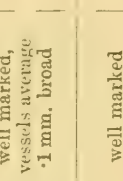

표

ํㅗㄹ

몀의

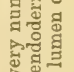

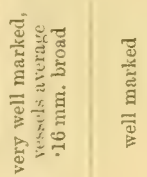

हूँ

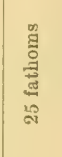

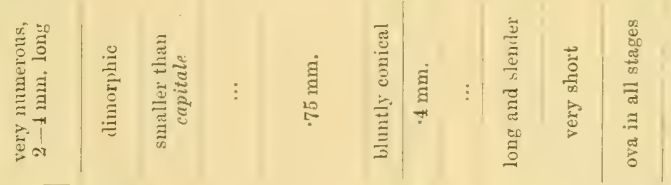

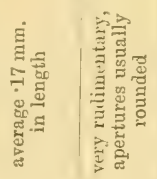

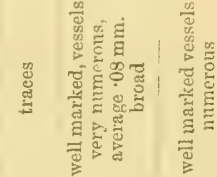

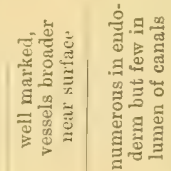

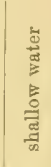

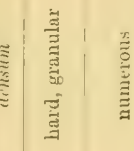

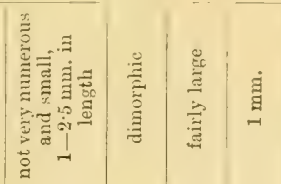

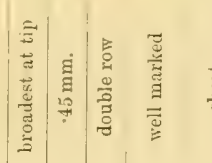

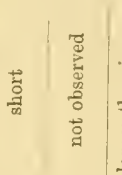

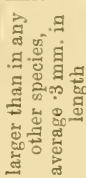

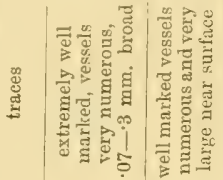

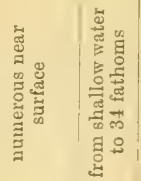

空

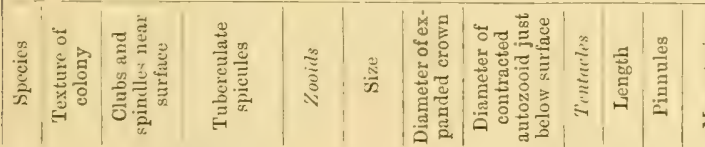

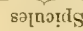

spı̣oozozny

sp!oozououdis

sumsis [ยนej 
The mesogloea is fairly dense owing to the presence of numerous large spicules, it is less abundant than in the soft, fleshy species.

The interesting features of the species are: (1) the erect arborescent form of the colony (fig. 33); (2) the presence of numerous very large tuberculate spicules; (3) the absence of siphonozooids; (4) the well-marked character of the zooids, the mesenteries and their filaments large compared with many other species; (5) the comparatively feeble development of the superficial and internal canal systems; (6) zoochlorellae present but not in considerable numbers.

\section{THE RELATIONS OF THE ABOVE GENERA.}

Sclerophytum differs from Alcyonium in (1) the form and size of the spicules; (2) the small size of the zooids; (3) the occurrence of dimorphism in many species; (4) the presence of a special superficial canal system; (5) the small size or complete absence of ventral and lateral mesenterial filaments. These important points of difference indicate a very distant relationship between Sclerophytum and Alcyonium.

A study of Table II. shows that while specimens of Sclerophytum and Lobophytum may be similar in outward form, yet there are many striking points of difference in their internal anatomy. The general anatomy of Lobophytum, however, is very similar in many respects to that of Sarcophytum, with which it appears to be closely allied.

Some of the important anatomical points of difference between Sclerophytum and the two genera Sarcoplytum and Lobophytum are: (1) the presence in Sclerophytum of more than one row of pinnules on the tentacles; (2) the ventral and lateral mesenterial filaments are always very feebly marked (but are absent in Sc.gardineri); (3) the presence of a special superficial canal system; (4) the absence of dimorphism in some of the species. In all these respects Sclerophytum approaches the genus Xenia. The following diagram suggests the probable relationship between the four genera and Alcyonium.

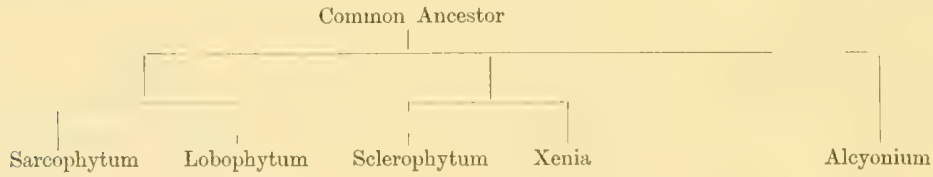

Mr Gardiner has given me the following note of the distribution of the genera Sarcophytum, Lobophytum, and Sclerophytum in the Maldives:-"They are found on nearly every reef in the Maldives but are most common on the reefs which fringe the passages into atolls. Under no circumstances are they ever found covering great areas, as Saville Kent says is the case with Sarcophytum on the Great Barrier Reef of Australia. 'They do not generally occur on shoals in the lagoonlets of secondary atolls (velu of faro), nor are they found on any reef more than $100-150 \mathrm{yds}$. from its outer edge. In the more enclosed atolls such as Goifurfehendu, Addu, Kolumadulu, and Haddumati, these genera are scarce, only small colonies being found on the reefs arising within their lagoons.

"The genera are common on the reefs of Hulule faro, Male Atoll. They live very abundantly on the outside part of the west reef and form large spreading masses. On the 
THE ALCYONARIA OF THE MALDIVES.

Table II. Comparison of the General Anatomy of the three Genera.

\begin{tabular}{|c|c|c|c|}
\hline Genus & Sarcophytum & Lobophytum & Sclerophytum \\
\hline Form of Colony & $\begin{array}{l}\text { usually mushroom-shaped } \\
\text { throughout life (fig. 1) }\end{array}$ & $\begin{array}{l}\text { young colonies may be mush- } \\
\text { room-shaped (fig. 12), older } \\
\text { forms have a much lobed } \\
\text { capitulum (fig. } 7 \text { ) }\end{array}$ & $\begin{array}{l}\text { as in Lobophytum } \\
\text { (tigs. } 18 \text { and 23) }\end{array}$ \\
\hline Spicules & $\begin{array}{l}\text { clubs, rods, and spiny spindles } \\
\text { usually not zoned }\end{array}$ & small zoned spindles, few clubs & $\begin{array}{l}\text { usually large tuberculate spicules } \\
\text { of varied form; may not be } \\
\text { zoned, clubs usually numerous } \\
\text { near surface }\end{array}$ \\
\hline Zooids & dimorphic & dimorphic & often dimorphic \\
\hline $\begin{array}{l}\text { Growth of colony } \\
\text { by formation of } \\
\text { new autozooids }\end{array}$ & $\begin{array}{l}\text { most vigorous on the margin, } \\
\text { hence mushroom-shape }\end{array}$ & $\begin{array}{c}\text { may take place from any part } \\
\text { of capitular surface, gives } \\
\text { lobed form }\end{array}$ & as in Lobophytum \\
\hline $\begin{array}{l}\text { Distribution : } \\
\text { (1) of autozooids }\end{array}$ & $\begin{array}{l}\text { most numerous on margin, } \\
\text { fewest in middle of } \\
\text { capitulum (fig. } 9 \text { ) }\end{array}$ & $\begin{array}{l}\text { more or less regularly on } \\
\text { surface of capitulum, least } \\
\text { numerous on margin }\end{array}$ & as in Lobophytum \\
\hline $\begin{array}{l}\text { (2) of siphono- } \\
\text { zooids }\end{array}$ & $\begin{array}{l}\text { least numerous on margin, } \\
\text { elsewhere regularly } \\
\text { arranged (fig. 9) }\end{array}$ & $\begin{array}{l}\text { usually most numerous on } \\
\text { margin, elsewhere regularly } \\
\text { arranged (fig. 7) }\end{array}$ & imperceptible to naked eye \\
\hline Adrozooins: & $\begin{array}{l}\text { fairly large, pinnate, only } \\
\text { one row of pinnules }\end{array}$ & similar to Sarcophytum & $\begin{array}{l}\text { very small, in some cases } \\
\text { slightly degenerate }\end{array}$ \\
\hline Tentacles & $"$ & $"$ & $\begin{array}{l}\text { short, stumpy, in some cases a } \\
\text { double row of very small pinnules }\end{array}$ \\
\hline Stomodaeum & long, convoluted & " & comparatively long \\
\hline Siphonoglyph & not well marked & " & very well marked \\
\hline Mesenteries & all well marked & all well marked & $\begin{array}{l}\text { in some cases ventral and } \\
\text { lateral feebly marked }\end{array}$ \\
\hline $\begin{array}{l}\text { Dorsal mesenterial } \\
\text { flaments }\end{array}$ & well marked & , & well marked \\
\hline $\begin{array}{l}\text { Ventral and lateral } \\
\text { mesenterial } \\
\text { filaments }\end{array}$ & fairly large & $\begin{array}{l}\text { as in Sarcophytum, differ } \\
\text { slightly in size }\end{array}$ & $\begin{array}{l}\text { very short and feebly marked } \\
\text { or absent }\end{array}$ \\
\hline Sipнохоzоoшs: & comparatively large & $\begin{array}{l}\text { as in Sarcophytum, differ } \\
\text { slightly in size }\end{array}$ & $\begin{array}{l}\text { very small and rudimentary } \\
\text { or absent }\end{array}$ \\
\hline Canal Systems & $\begin{array}{l}\text { eiliated channels between auto- } \\
\text { zooids numerous (tig. } 3 \text { ) }\end{array}$ & $\begin{array}{l}\text { ciliated channels as in Sarco- } \\
\text { phytum but not so numerous }\end{array}$ & $\begin{array}{l}\text { two } \\
\text { internal, well marked, and a } \\
\text { Special Superficial Canul System } \\
\text { intimately connected with } \\
\text { rudimentary siphonozooids } \\
\text { few ciliated channels between } \\
\text { autozooids }\end{array}$ \\
\hline Zoocblorellae & $\begin{array}{l}\text { fairly numerous in endoderm of } \\
\text { siphonozooids and autozooids }\end{array}$ & not numerous & $\begin{array}{l}\text { extremely numerous in super. } \\
\text { ficial canals and endoderm } \\
\text { where there are no ventral and } \\
\text { lateral mesenterial filaments, } \\
\text { less numerous where they } \\
\text { are present }\end{array}$ \\
\hline
\end{tabular}


boulder zone W. and S.W. small elumps occur, but it is obvious that the best position of growth is a little further out towards the atoll lagoon, where even at the lowest tide there is $3-6$ feet of water. Everywhere colonies are scarce within the boulder zone and are never found on the sand. A brilliant green species (Sarcophytum glaucum) alone inhabits the east and south sides of the faro; it ranges from the more external parts of the sandflat even to the extreme edge of the reef-flat where the waves break.

"Exposed to the air and sun colonies will continue to live so long as portions of them are bathed by the water, even for 3-4 hours. Torn off their support they may be kept alive for an hour or so in a bag or any receptacle which will prevent evaporation. In a mixed bucket of animals from any reef (enamelled bucket) the colonies will rarely live beyond an hour or two, but separate colonies can be kept alive for several days. Anaesthetisation with cocaine is useless, the chemical encouraging disintegration of the tissues; alcohol sometimes yields good results, as also does chloral hydrate."

\section{GENUS ALCYONIUM.}

Wright and Studer distinguish between Alcyonium and Lobularia on the ground that Alcyonium is restricted to temperate seas, while Lobularia occurs only in tropical waters. This distinction cannot be maintained, for in the collection is a single but excellently preserved specimen which appears to be identical with Klunzinger's Alcyonium pachyclados (1879, p. 24, Taf. 1, fig. 5) from the Red Sea. Hickson (1900, p. 72) records from the Cape of Good Hope the occurrence of a form similar in so many respects that he refers it to this species. I have been able to compare these specimens with the one from the Maldives and with another tropical form taken by Willey in New Britain. All the specimens agree in the character and form of the spicules and apparently in their general and minute anatomy, but differ in form and colour, so that it is very probable that they are different facies of the same species. The generic identity of these forms from temperate and tropical waters is indisputable, so that Alcyonium can no longer be regarded as an extra-tropical genus. The vague definition of Lobularia has led to much confusion among systematists, some writers including it with Alcyonium and not regarding it as a true genus.

Alcyonium is well known to be a monomorphic genus. Whitelegge $(1897$, p. 220) describes a lobed form with well-marked dimorphism from Funafuti which he doubtfully refers to Lobularia as L. ? viridis (Quoy et Gaim.). His description of this form, and his drawings of the spicules indicate it to be a species of the genus Lobophytum which I have attempted to revise in the present paper (p. 514). It is probable that other species of Lobularic which have not been attributed to Alcyonium will eventually be included in the new genus Sclerophytum (p. 516). The vague, confusing, and useless diagnosis of Lobularia makes it imperative that it should be deleted as a genus from the family of the Alcyonidae.

16. Alcyonium pachyclados $\mathrm{Klz}$.

A single well-preserved specimen agreeing with Klunzinger's description (1879, p. 24, 'Taf. 1, fig. 5) was taken from the reef of Naifaro, Fadifolu Atoll.

The colony from which the stalk is missing grows irregularly, and the bluntly digitate lobes with their short, blunt, closely set branches vary considerably in length. This specimen 
differs from the Cape specimens in form and colour. The Cape specimens are all more arborescent with longer and more slender branches.

The Maldive Island specimen in spirit is of a pale brownish-grey colour, paler on the tops of the lobes than in the furrows between. The specimens from the Cape, three in number, are all different in colour, one white, one red, and the third yellow. This difference is due to the difference in colour of the spicules. The form and character of the spicules in all cases is identical. The elliptical and opaque spicules described by Klunzinger were present in the Maldive Island specimen, but I have not been able to find them in the Cape specimens.

The general and minute anatomy of all the specimens is very similar to that of Alcyonium. Ova are very numerous on the mesenteries, the largest being $45 \mathrm{~mm}$. in diameter. The nutritive canal system differs from that of Sclerophytum in the absence of a special transverse superficial canal system.

The research in connection with this paper has been carried out in the Zoological Laboratories of the Owens College, under the supervision of Professor Hickson, to whom I am greatly indebted for much valuable assistance and advice.

My thanks are also due to Professor Herdman in allowing me to examine his valuable collection of Alcyonidae from Ceylon.

\section{LITERATURE.}

1833. Quoy et Gaimard. Voyage de l'Astrolabe, Tome IV. (Zoologie), Paris.

1834. Ehrenberg, C. G. Die Corallthiere des Rothen Meeres.

1848. Dana, J. D. "Zoophytes"” Unit. St. Expl. Exped.

1877. Klunzinger, C. B. Die Korallthiere des Rothen Meeres; erster Theil, "Die Alcyonarien und Malacodermen." Berlin, 1877.

1881. Moseley, H. N. Challenger Reports. Zoology. Vol. II. Corals ("Heliopora and Sarcophyton").

1883. Hickson, S. J. "On the Ciliated Groove (Siphonoglyph) in the Stomodaeum of the Alcyonarians." Phil. Trans. Part III.

1884. Wilson, E. B. "The Mesenterial Filaments of the Alcyonaria." Mitt. Zool. Stat. Neap. v.

1886. Marenzeller, C. von. "Ueber die Sarcophytum bennanten Alcyoniiden." Zool. Jahrb. I., Jena, 1886.

1889. Wright, C. P., AND Studer, T. H. Challenger Reports. Zoology. Vol. xxxi. Alcyonaria.

1889. Famintzin, A. "Beitrag zur Symbiose von Algen und Thieren." Mém. de l'Acad. Imp. des Sci. St Pétersbourg, Ser. viI. 
1895. Hickson, S. J. "The Anatomy of Alcyonium digitatum." Quart. Journ. Micro. Sci. Vol. xxxvir. Pt. 4, 1895.

1896. Schenk, A. "Clavulariiden, Xeniiden, und Alcyoniiden von Ternate." Frankfurt-a-M. 1896.

1897. Whitelegge, T. "Alcyonaria of Funafuti." Mem. Austral. Mus. Pt. III. 1897.

1898. Asнworth, J. H. "The Stomodaeum, Mesenterial Filaments, and Endoderm of Xenia." Proc. Roy. Soc. Vol. LxiII. 1898.

1899. MaY WaLther. "Beiträge zur Systematik und Chorologie der Alcyonaceen." Jena Zeitsch. Naturw. Bd. xxxmI. N. F. Xxvi.

1900. Bourne, Gilbert C. "On the genus Lemnalia," also "Branching Systems of Alcyonacea." Trans, Linn. Soc. London (Zool.), Vol. VII. Pt. 10.

1900. Hickson, S. J., ANd Hiles, Isa L. "Stolonifera and Alcyonacea from New Britain." Willey's Zool. Results, Pt. IV. Camb. Univ. Press.

1900. Hickson, S. J. "Alcyonaria and Hydrocorallinae of Cape of Good Hope." Marine Investigations in South Africa, Cape Town, 1900.

1901. Hickson, S. J. Alcyonium. Liverpool Marine Biolog. Committee, London, 1901.

\section{EXPLANATION OF PLATES XXVIII-XXXI.}
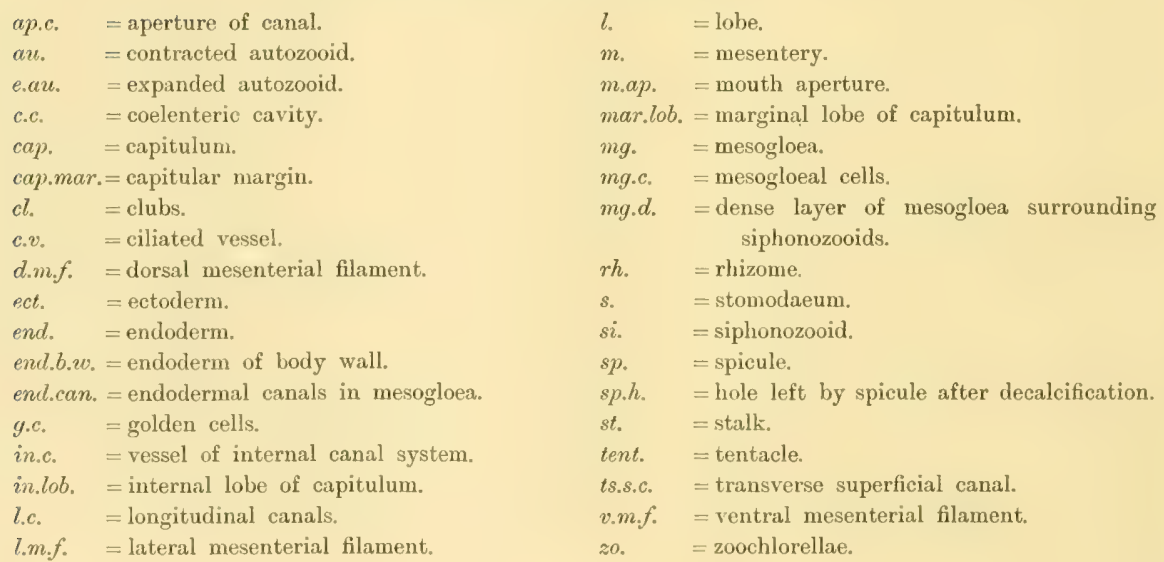

Fig. 1. Sarcophytum elrenbergi. $\times 2$. The mushroom-like form is characteristic of the genus. The autozooids are most numerous on the margin of the capitulum where the siphonozooids are few in number. The downward and inward eurve of the margin is shown. Many of the autozooids are almost completely retracted, but a few partially expanded ones are to be seen on the margin and upper part of the capitulum. 
Fig. 2. Surface riew of a portion of the capitulum of the same species showing two autozooids, one expanded, the other contracted. Small spicules are seen imbedded in their walls. Spicules are also numerous in superficial tissues between the zooids and are seen by transparency of the ectoderm. The mesenteries of the siphonozooids may be seen through the ectodermal tissues. $\times 20$.

FIG. 3. Sarcophytum glaucum. A ciliated canal connecting the coelenteric cavity of an autozooid with that of a siphonozooid. $\times 300$. Running at right angles to the ciliated canal is a longitudinal canal of the internal canal system, which in the preserved condition appears to be unciliated; this canal also opens into the coelenteric eavity of the autozooid.

FIG. 4. Group of rounded golden cells in same species with granular yellow contents in internal canal system. $\times 620$.

Fig. 5. Sarcophytum plicatum. Spicules, $\times 60$. (This species was not in the collection, but the drawing is inserted because the spicules are tuberculate and approach Sclerophytum in form.)

FIG. 6. Sarcophytum tenuis sp. nov. Spicules. $\times 120 . a=a$ slender spindle to be found in the coenenchym and on the anthocodia of the autozooids. $b$ =slender clubs from the coenenchym. $c=$ small club to be found in the periphery of the capitulum and in the stalk.

FIG. 7. Lobophytum pauciflorum. A colony characteristic of the genus. $\times 2$. As all the specimens in the collection of fairly large colonies are fragmentary, a drawing was therefore made of a complete specimen from New Britain, which agrees with the specimens from the Maldives in all essential details. The lobed appearance of the capitulum is due chiefly to the formation by budding of new autozooids at any portion of the capitular surface. In this genus the siphonozooids are most numerous on the marginal seam of the capitulum. The marginal lobes differ from the inner lobes in the proportionately greater number of siphonozooids compared with the number of autozooids on their surface.

Fia. S. Sclerophytum capitale sp. nov. A complete colony. $\times 2$. Many of the autozooids are fairly expanded.

Fig. 9. Sarcophytum tenuis sp. nov. $\times 1 \frac{1}{3}$. Only the upper surface of the slightly concave capitulum is shown. Autozooids are very numerous round the margin forming a thick fringe. In the middle of the capitulum they are much ferver in number. Siphonozooids are indicated as dots between the autozooids, they are much more numerous in the actual specimen.

FIG. 10. Sarcophytum roseum sp. nov. Spicules. $\times 120$. The spicules are slightly zonate, and in this respect approach Lobophytum. I, II, III are taken from near the surface of the capitulum, IV, V, VI and vir from the coenenchym of the capitulum.

FIG. 11. A portion of the capitulum of the same species. $\times 1 \frac{1}{3}$. All the autozooids are contracted. The capitulum is thickest in the middle and thins out towards the margin, and therefore has no capitular fold as in "ehrenbergi" (fig. 1). Siphonozooids are indicated as small dots between the autozooids.

FIc. 12. Lobophytum panciflorum. Young mushroom-shaped colony. $\times 2$.

Fic. 13. Surface view of tip of lobe of capitulum of same species, showing three autozooids and surrounding siphonozooids. $\times 30$. One autozooid is fairly expanded.

G. II. 
Fig. 14. Longitudinal section through four siphonozooids of the same species $\left(S i_{1}, S i_{2}, S i_{3}, S i_{4}\right)$, showing ciliated vessels connecting the coelenteric eavities. The section passes through the siphonoglyph of the first siphonozooid. Only the left half of the fourth siphonozooid is indicater.

FIg. 15. Sclerophytum capitale. Clubbed spicule. These are very abundant near the surface of the colony. $\times 219$.

Fig. 16. Different forms of the tuberculate spicules to be found in a single colony of the same species. $\times 20$. (Regular spindles, similar to those of other species, are also numerous, but they are not figured.)

FIG. 17. Surface view of a portion of the capitulum of the same species, showing arrangement of siphonozooids between two autozooids. $\times 45$. One of the autozooids is partially contracted, the other is fairly well expanded. The tentacles have a double row of small pinnules down each side.

FIG. 18. Selerophytum densum. Young colony, showing formation of primary lobes from the margin of the capitulum. The colony has not yet lost its mushroom-like form. The surface of the capitulum is slightly concave. The siphonozooids are very minute and are not indicated in the drawing. $\times 1 \frac{1}{3}$.

FIG. 19. Sclerophytum capitale (sp. nov.). Drawing of a fairly thick free-liand section through a lobe of the capitulum of the same species. $\times 65$ (Cam. Lucida). The drawing shows the rudimentary siphonozooids which terminate posteriorly in the transverse vessels of the superficial canal system. The vessels of this system communicate with those of the internal canal system, and directly or otherwise with the coelenteric cavity of the neighbouring autozooid.

Fig. 20. Sclerophytum densum. $a, b, c, d, e$. Different forms of tuberculated spicules characteristic of the genus. $\times 10 . \quad f$. A forked spicule with irregular tubercles. $g, h$. Two tubercles seen laterally. $\times 300$ (Cam. Luc.).

FIG. 21. Longitudinal section through a single degenerate siphonozooid of same species. $\times 730$. The section passes through the mouth aperture of the siphonozooid. The stomodaeum is extremely short in this specimen. A deeply staining layer of dense mesogloea surrounds the siphonozooid internally. The siphonozooid passes posteriorly (on the left) into a superficial transverse vessel. The endoderm lining the cuelenteric cavity is distorted by the presence of numerous zoochlorellae. An aggregation of endodermal cells near the stomodaeun is probably a degenerate mesentery.

Fic. 22. A partially retracted autozooid of same species. The drawing was made from a fairly thick freehand longitudinal section stained with borax carmine. The figure shows the intimate connection between the coelenteric cavity of the autozooid and the lumen of the canals, and also with the coelenteric cavity of the degenerate siphonozooids. The long stomodaeum is shown (dotted shading). The ventral and lateral mesenterial tilaments are very short. The dorsal mesenterial filament is long, ciliated, and grooved.

Fic. 23. Sclerophytum hirtum. Drawing of a colony to show lobation of capitulum, $\times 1 \frac{1}{3}$. Most of the autozooids are partially expanded.

Fig. 24. Spicules of same species. $a, b, c, d$, tuberculate spicules; $e, f$, clubs. 


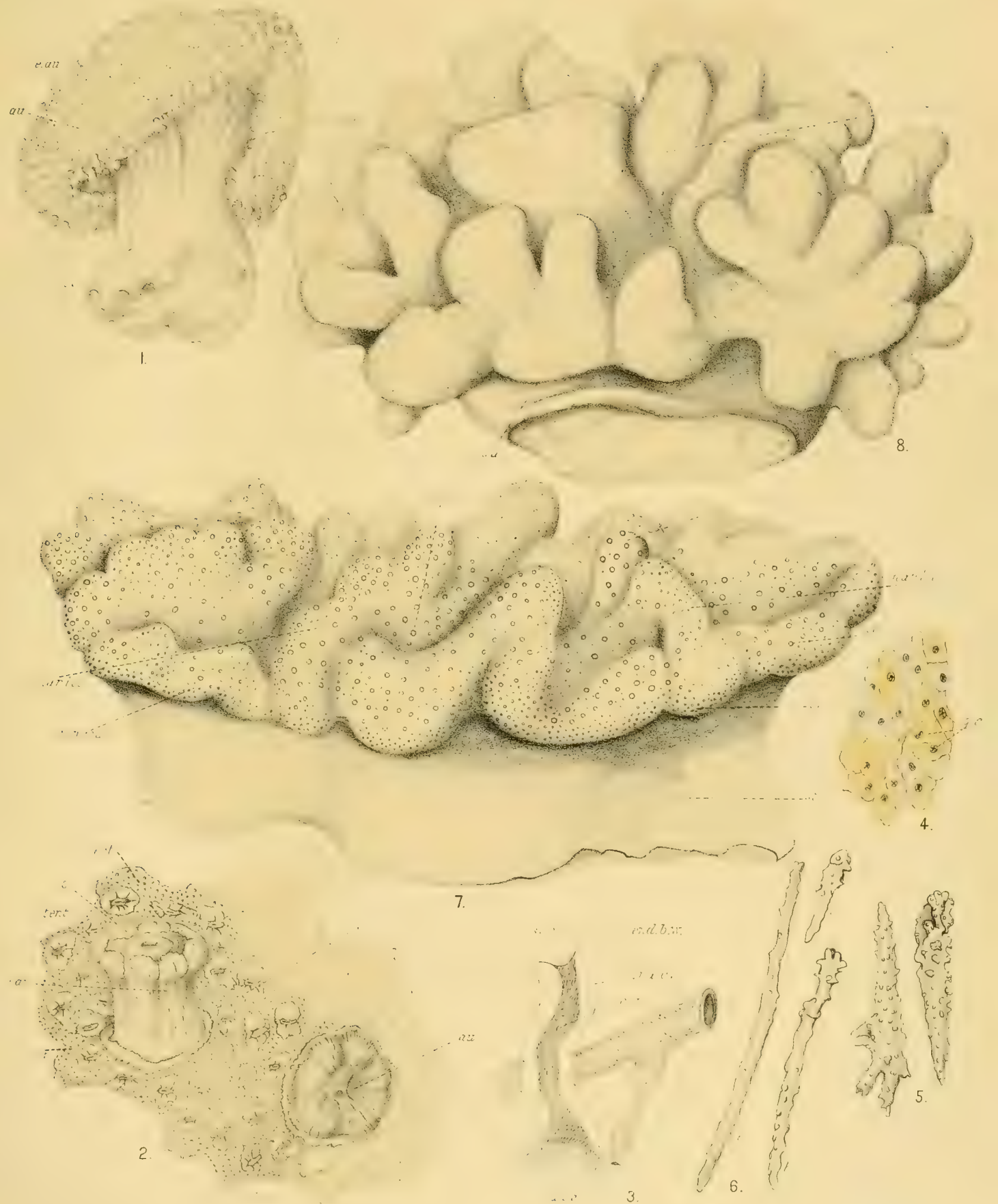





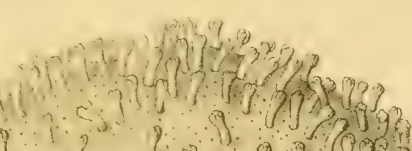

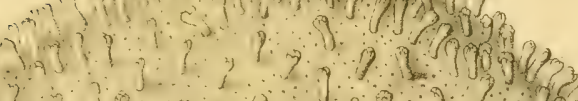

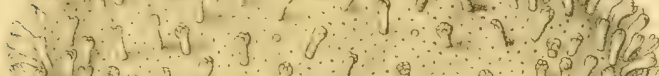

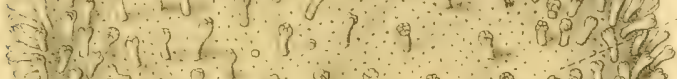

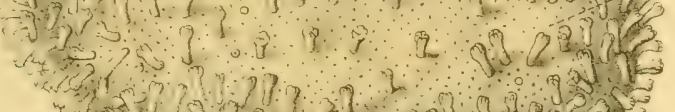

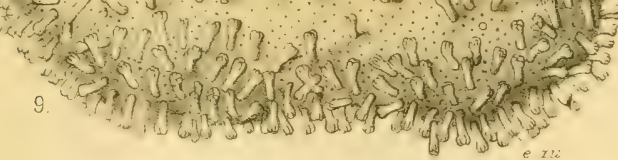
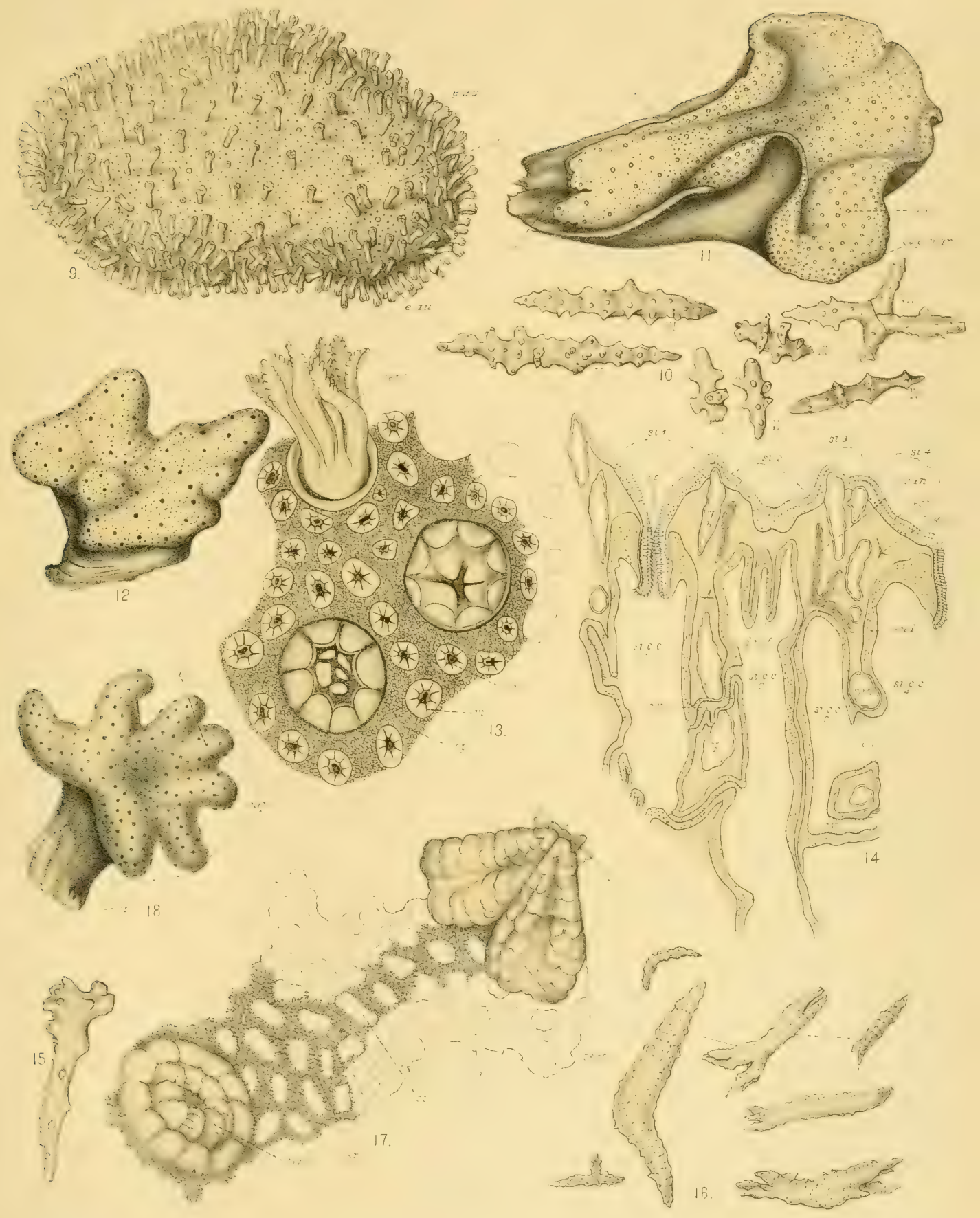


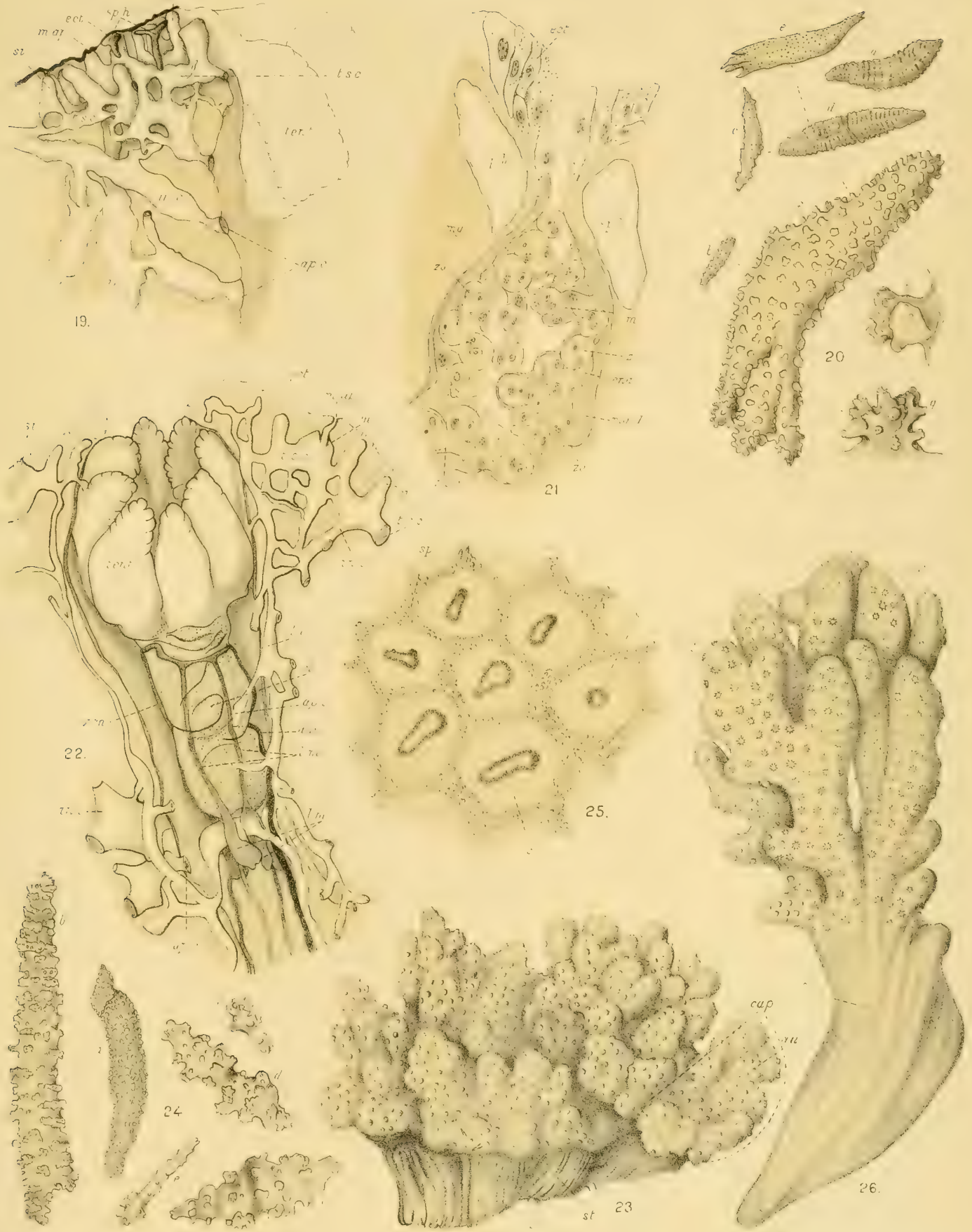



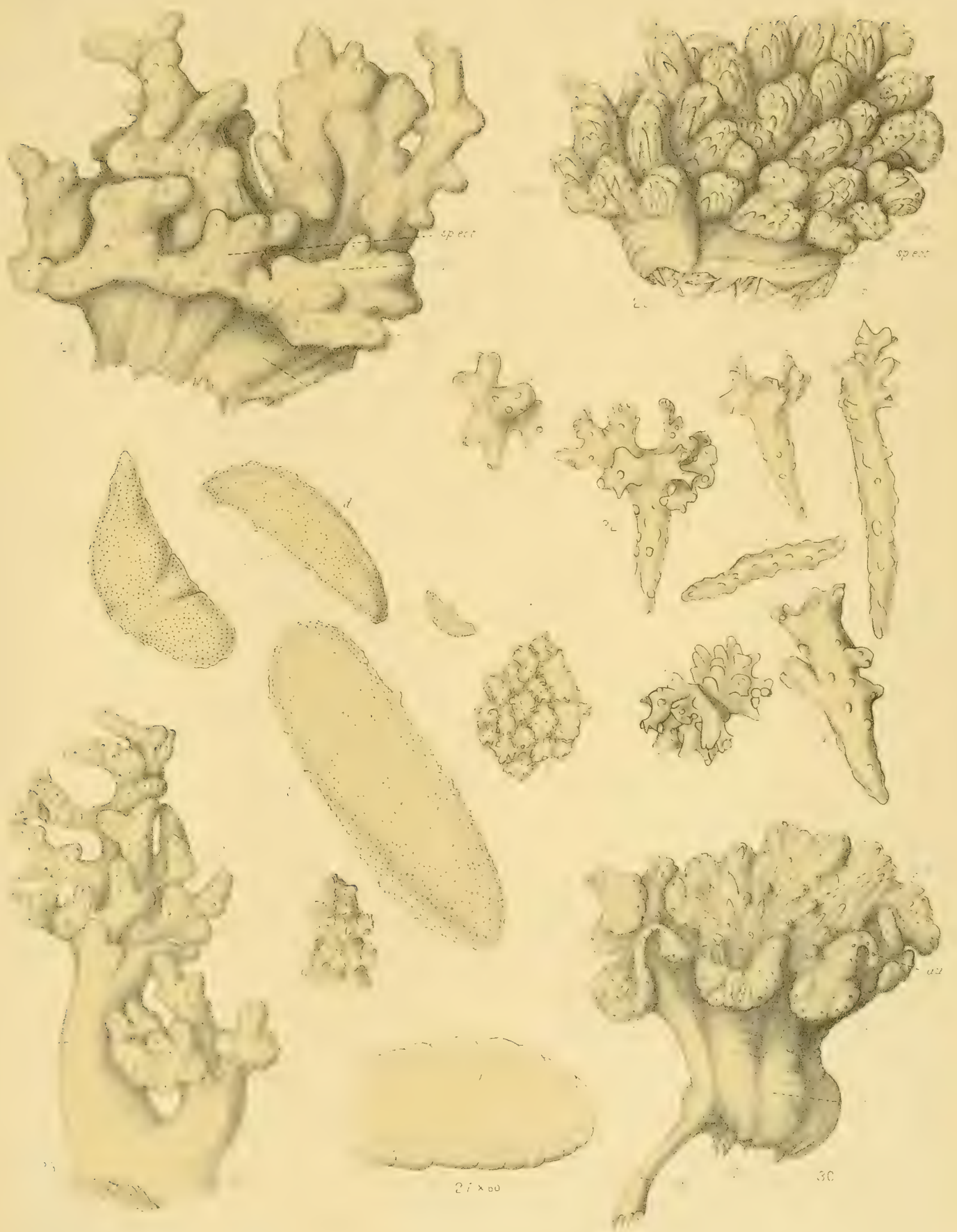



Fig. 25. Group of rudimentary siphonozooids of same species. Surface view of stained preparation. $\times 90$. The drawing shows the degenerate stomodaeum with mouth aperture (Cam. Luc.).

Fic. 26. Sclerophytum palmatum sp. nov. Drawing of a colony to show branching of capitulum. Many of the autozooids are expanded. Natural size.

FIG. 27. A tentacle of autozooid of same species, showing double row of rudimentary pinnules down each side. (× 60 Cam. Luc.)

FIG. 28. Sclerophytum gardineri sp. nov. Drawing of a colony. $\times 2$. The colony is laterally compressed and is irregularly cup-shaped, with lobes arising from the middle and edges of the cup. The autozooids are small and are not numerous. Siphonozooids are absent.

Fig. 29. Sclerophytum durum sp. nov. A lobed colony. $\times 1 \frac{1}{3}$. All the autozooids are retracted. The enormous spicules characteristic of this species can be seen through the ectodermal tissues of the capitulum. They are also shown protruding from the base of the stalk.

Fig. 30. A younger cup-shaped colony of same species with rhizome-like outgrowth from the stalk. $\times 2$. A few very small lobes are seen arising from the basin of the capitulum. The autozooids in this specimen are apparently most numerous round the margin of the capitulum.

Fig. 31. Tuberculate spicules of same species. a. A single tuberculate spindle. $\times 10 . \quad b . A$ portion of the tuberculate surface of the same spicule, more highly magnified. $\times 80$. c. Tip of a more pointed spindle showing tuberculate warts. $\times 8$, d. $\times 6$ (Cam. Luc.).

FIG. 32. Spicules of same species; numerous near surface of colony. $a, b, c, d, e$. Different forms of clubbed spicules. All these forms are common. $a, b, c, \times 290, d, \times 270, e, \times 250$. $f$. An irregular tuberculate dumb-bell (rare). $\times 270 . \quad$ g. An irregular spindle with small spines. $\times 250$.

Fig. 33. Sclerophytum querciforme sp. nov. A colony with a secondary stalk and capitulum. $\times 2$. The large tuberculate spicules are seen protruding from the base of the stalk. The stalk is branched at the top and passes almost imperceptibly into the capitulum. 


\title{
NUDIBRANCHIATA,
}

\section{WITH SOME REMARKS ON THE FAMILIES AND GENERA AND DESCRIPTION OF A NEW GENUS, DORIDOMORPHA².}

\author{
By Sir Charles Eliot, M.A., K.C.M.G., \\ Commissioner of the British East Afirica Protectorate.
}

(With Plate XXXII.)

THE Nudibranchs described in the present paper represent the collections made by Mr J. Stanley Gardiner in the Maldive and Laccadive Islands (1899-1900). I have added descriptions of two other remarkable specimens with which he has furnished me, one (Doridomorpha Gardineri) obtained by himself at Rotuma in 1896, and the other (Pleuroleura striata) by the Skeat Expedition from Pulan Bidang in the Malay Peninsula (1899). The specimens from Hinikoi (Laccadive Islands) were all reef forms: those from the other localities were largely dredged. In only a few cases are there any notes as to the colour or appearance of the living animals: as preserved they have, with a few conspicuous exceptions, lost entirely their original colour and assumed the dirty yellowish tinge common in alcoholic specimens. They have also in many eases been strongly contracted and distorted by the action of the preserving medium. I have therefore felt very diffident in creating new species, and have perhaps erred on the side of identifying specimens with the most similar forms already described. But I think it useless to create new species of Nudibranchs unless it is possible to formulate the specific characters. The fact that an alcoholic specimen does not seem quite the same as those already deseribed is not sufficient to give it specific rank.

Besides forms common in the Indo-Pacific region, the present collections contain a number which confirm the deseriptions by previous authors of species established on the strength of one or a few specimens, and also offer some novelties. Of these the most interesting is Doridomorpha, a small Dorid without gills, related to Doridoxa Bgh. There are also a large and well-preserved Notodoris, which appears specifically distinct from $N$. citrina, for which Bergh established the genus: a new species of Dictyodoris: a form 
to which I hesitate to give generic rank and somewhat doubtfully refer to Staurodoris, liberally interpreted: and a remarkable specimen of the Hexabranchidae, which has been greatly distorted, but seems at least specifically distinct. The rediscovery of Pleuroleura striata, v. Hass, is also interesting.

The list of genera and species is as follows:

\section{HOLOHEPATICA.}

1. MIarionia arborescens B.

2. *Doridomorpha gardineri nov. gen., nov. sp.

3. Hexabranchus faustus B.

$4 . \quad$ digitatus nov. sp.

5. Notodoris gardineri nov. sp.

6. Trevelyana crocea B.

7. Nembrotha nigerrima B. ? var.

8. Chromodoris elizabethina B.

$9 . \quad$, rosans B.

10. $" \quad$ pustulans B.

11. Ceratosoma trilobatum Gray.

12. ", gracillimum Semper.

13. Discodoris concinna (A. and H.).

14. " pardalis (A, and $\mathrm{H}_{\text {. }) \text { ? }}$
15. Discodoris meta $\mathrm{B}$.

16. Platydoris eurychlamys B.

17.,$\quad$ scabra (Q. and G.).

18. $\quad$ sp.

19. Dictyodoris maculata nov. $\mathrm{sp}$.

20. Staurodoris pecten nov. sp.

21. Trippa ornata B.

22. Doridopsis nigra Stimpson, var. nigerrima B.

23.,$\quad$ apicalis B.?

24. Phyllidia varicosa Lam.

25. $\quad$ elegans B.

26. Fryeria rïppelii B.

27. Phyllidiopsis striata B.?

\section{CLADOHEPATICA.}

28. Pleurophyllidia gracilis $\mathbf{B}$.

29. *Pleuroleura striata (van Hass.).

30. Doto indica B?

31. Phidiana unilineata (A. and $\mathbf{H}$.)?

Of these nos. 2 and 29 (Doridomorpha and Pleuroleura), both starred, are not from the Maldive or Laccadive Islands.

I have left undescribed eleven specimens which were too much injured to admit of identification. Six were Dorids of soft consistency, without jaws, and with simply hamate teeth: the remaining five were a small species of Chromodoris, possibly scurra, though, if so, all trace of the characteristic coloration had disappeared.

Though one of the best works ever published on the Nudibranchiata (Alder and Hancock's Monograph of British Nudibranchiate Mollusca) is in English, little has been written in our language on the group, and the exotic forms have received scant attention from our naturalists, the greater part of what is known of them being due to the fruitful labours of Prof. Bergh ${ }^{1}$.

1 The reference letters S.R. stand for Prof. Bergh's "Malacologische Untersuchungen," published in Semper's Reisen im Archipel der Philippinen. 
I have therefore given somewhat full deseriptions of the family and generic characteristics which I trust will not be considered out of place. In classification I have adopted Bergh's division into Holohepatica and Cladohepatica in preference to Pelseneer's four tribes Tritonioidea, Doridioidea, Aeolidioidea, Elysioidea. There is probably no group of comparatively well-known animals in which we may look forward to as many additions to our knowledge as in the Nudibranchiata, and to the discovery of forms which are not merely new but of morphological and systematic importance. Such are Doridoxa, Atthila and Hedyle discovered in the last few years, and as few seas have been thoroughly investigated and the fauna of many large marine areas (such as the tropical and southern Atlantic) remain as far as Nudibranchs are concerned practically unknown, many more finds may be anticipated. It is therefore better to have as elastic a system as possible, and to arrange the group in a series into which new members can be easily inserted, than to cut it up into rigid subdivisions whose definitions may require alteration. Pelseneer's Tritonioidea contain a somewhat miscellaneous assemblage, and it is not clear what is the distinction between them and the less typical Aeolidioidea. Why, for instance, does Dendronotus belong to the former and Doto to the latter class? I have, however, departed from Bergh's arrangement in two respects. Firstly, I classify Tritonia among the Holohepatica, and not as he does among the Cladohepatica. It is true that its general anatomy allies it rather to the Cladohepatica, but it is clearly a connecting link between the two tribes, and as the distinction between them is the entire or divided condition of the liver, and as the liver of Tritonia is entire, it seems more logical to regard it as a holohepatic form with affinities to the Cladohepatica than as a cladohepatic form (which it is not) with affinities to the Holohepatica. Secondly, I have included among the Cladohepatica the Elysioidea or Ascoglossa, which cannot in my opinion be separated from the rest of the Nudibranchiata.

\section{HOLOHEPATICA.}

The Nudibranchiata Holohepatica are characterized by the liver being entire and not ramified. They may be divided into two sections, the first containing the Tritoniadae and the second all the other forms. As mentioned, the members of the first section are really intermediate between the Holo- and Cladohepatica: in virtue of their unbranched liver they belong to the former but in their other characters they bear more resemblance to the latter. The other section, often conveniently called Dorids, are characterized by possessing two spermatothecas and a blood gland. Further, in all except a few abnormal genera the branchiae are dorsal and arranged round the vent.

\section{Fam. Tritoniadae ${ }^{1}$.}

The characters of the family may be defined as follows. Animals of moderate or even large size with an elongate and somervhat rectangular body. A frontal veil, usually provided with appendages and two somewhat spoon-shaped tentacles are present. Rhinophores

1 For the study of this family the following may be consulted. Alder and Hancock, British Nudibr. Mollusca, 1855, pt. vir. Vayssière, "Description du Marionia Berghii," Jour. de Conchyl. 3. S. xix. 1879. Pelseneer, Recherches sur divers Opisthobranches, Bruxelles, 1893, and especially the following papers of Bergh. (1) Semper's Reisen, Hefte xv., xvi. and xvir. (2) Nudibr. Mollusca of North Pacific (in Dale's Results of Exploration of Alaska). (3) Beitr. zur Kenntniss der Japanischen Nudibr. II. (4) Report on the Nudibranchiata of the Challenger, 1881. (5) Opisthobranchier der Sammlung, Plate. (6) Nudibranchiate Gasteropoda of the Ingolf Expedition, 1900 . 
retractile into sheaths. Branchiae consisting of arborescent tufts set in a single row along the pallial margin. Buccal mass very large; mandibles powerful. Radula wide, with a broad central tooth, the first lateral larger than the rest. Liver not at all ramified. Vent lateral. No blood-gland. One spermatotheca. Reproductive system unarmed.

Setting aside the disputed genus Hancochia Gosse, the family may be considered to comprise three genera, Tritonia Cuv., Marionia Vayssière, and Atthila Bergh. Although the creator of the last named considers it sufficiently distinct to form a new family, it has clearly great aftinities to Tritonia. The characters of the latter genus are as follows. The frontal veil bears papillae and there are two spoon-shaped tentacles. The rhinophores are not laminate but have a single club, surrounded by pinnate filaments. There are no dorsal appendages except the branchiae and no stomach plates. Most authors recognize as a subgenus Candiella Gray (Figures of Moll. Animals, IV. 1850) distinguished by haring only a few digitate processes on the frontal veil and a somewhat narrower radula. The genus Marionia Vayssière resembles Tritonia externally, but the stomach is armed with a series of horny plates. Generally but not always the appendages on the frontal veil are branched. The genus Atthila, instituted by Bergh for a single specimen obtained by the Ingolf expedition in the northern Atlantic, has the frontal veil entire, and rhinophores of the ordinary lamellate type. On the back are three rows of appendages, probably all simple, but the specimen was somewhat damaged. In their general characters the branchiae and buecal parts resemble Tritonia.

The Tritoniadae are not numerous in collections, being inhabitants of fairly deep water and only obtainable by dredging, but seem to be cosmopolitan in their distribution. They are recorded from the Mediterranean, the Northern and Arctic Atlantic, Brazil, the Pacific coast of Patagonia, California, the Aretic Pacific, Hawaii, the Cape, the Red Sea, and the Malay Archipelago. Marionia is recorded from a less wide range than Tritonia, but it is probable that several species described under the name Tritonia should really be referred to the latter genus.

The Tritoniadae are sluggish but voracious animals, living largely on Alcyonium, large chunks of which are often found in their stomachs. The spawn is a simple string-like coil deposited on seaweeds or corallines.

The present collection contains only a single representative of the family belonging to the genus Marionia, created by Vayssière, and characterized by the presence of a girdle of horny plates set round the stomach.

\section{Marionia Vayssière'.}

1. Marionia arborescens B. (S.R. Heft xvII. pp. 890-894, Pl. LXXXVIII).

One specimen from Fadifolu Atoll, Maldives, 12-25 $f$. (fathoms). The species was established by Bergh for four specimens captured by Brock at Amboina. The specimen contained in the present collection agrees well with his description but is somewhat smaller, being only $3.5 \mathrm{~cm}$. long and 1.3 broad.

\footnotetext{
1 Vayssière, "Sur un nouveau genre de la famille des Tritoniadés," Comptes rendus de l'ac. des sc. Lxxv. 1877, pp. 299-301. Id. "Description de la Marionia Berghii,"

Journ. de Conchyl. 3. S, xIx. 1879, pp. 106-118. Bergh, "Beit. zu einer Monogr. der Gattung Marionia, V." JIittheil. aus der Zool. Stat. zu Neapel 1v. 2. 1883, pp. 303-326.
} 
The form is as usual in the genus. The colour uniform dirty yellow. From Bergh's specimens it appears that the living animal is yellow with green branchiae. Frontal veil with 10 simple papillae arranged in three groups, four in the middle and three on each side: outside the latter are the tentacles with a deep groove on the under side. The dorsal surface is covered with minute knobs. The dorsal margin is fairly prominent and bears 11 branchiae on each side, of which the first, tenth and eleventh are rudimentary and the fourth, fifth and sixth the largest. The branchiae are long, arborescent and mostly bipinnate. The rhinophore sheaths are distinctly raised and the rim is irregularly scalloped: the rhinophores as usual, with five pectinated filaments and a simple club. The buccal mass, as usual in this family, is enormous for the size of the animal: the jaws are large and strong and the cutting edge bears a single row of large denticles. The radula also as usual, consisting of about fifty rows of yellow teeth: the formula for each row about $45+1+1+1+45$. The shape of the median tooth and first side tooth as usual: the laterals diminishing towards the outside. The first stomach lamellated: the second with a girdle of yellow horny plates. There are about 30 large plates and numerous small ones of varying sizes between them. The other internal organs were not well preserved, but did not indicate any deviation from the generic characters. The species is characterized by the appendages on the frontal veil being simple and not branched and by the single row of large denticles on the jaw.

\section{Fam. Doridoxidae.}

This family was created by Bergh in 1900 (The Danish Ingolf Expedition-Nudibranchiate Gasteropoda-Copenhagen, 1900) to contain a remarkable molluse dredged at a depth of $55 \mathrm{f}$. in the North Atlantic. Doridoxa is externally similar to the Dorids in its general shape and rhinophores, but has no external gills whatever and the vent is lateral, not dorsal. The jaws are large and strong: the radula is somewhat as in Tritonia and Bathydoris and consists of a large central tooth with several laterals, of which the innermost differ somewhat in form from the rest. A blood-gland is present and there are two spermatothecas. It is most interesting to find that Mr Gardiner has captured a somewhat similar form at Rotuma in the southern Pacific. The specimen is unfortunately small and the internal organs are hardened into an indistinguishable mass. It is therefore impossible to state whether the animal possesses a blood-gland and a second spermatotheca. If those organs are really absent, it would probably be necessary to make it the type of a new family, but meanwhile its other characters, and in particular the buceal parts, show a close resemblance to Doridoxa. It is however in any case generically distinct from that animal, from which it differs in its round form, smooth back, absence of tentacles and its toothed mandibles. A third gill-less Dorid is the Heterodoris of Verrill, which has the general shape of Triopa, a lateral vent but no mandibles or central tooth. In its external characters it appears to form a good connecting link between Tritonia and the Polyceradae, but in its buccal organs it varies from the former family much more than do the Doridoxidae.

2. Doridomorpha Gardineri nov. gen., nov. sp.

One specimen from Rotuma. In the tank received by me this animal was concealed within the epipodia of an Aplysia but the position was no doubt accidental and does not indicate any natural association. The form (fig. 1) is oval and much rounder than Doridoxa, 
the length being $0.65 \mathrm{~cm}$. and the breadth 0.55 . Though the back is arched, the height is small compared to the length and breadth, and the general appearance is flat. The colour is a uniform yellowish brown. The back is perfectly smooth and the mantle edge ample all round. The foot (fig. 2) is however not small: in the preserved specimen its edges are turned inwards, but when extended it must be of a considerable breadth. Its anterior margin is not grooved. The visceral mass is much narrower than either the mantle or the foot. The rhinophores (fig. 3) are yellowish and perfoliate: they appear to be retractile into simple holes without any rim, but in the preserved specimen both were exserted. Above the foot and clearly divided from it is a sort of snout without any trace of tentacles. Considering the size of the animal the buccal mass is large and strong. The edge of the powerful mandibles (figs. 4 and 5 ) is denticulate, and at the base of the denticulations is a row of blunt knobs. The radula (fig. 6) was somewhat injured in extraction but appeared to be short and to contain about 13 teeth in each row. The character of the teeth was, however, clear. The central tooth consists of a basal plate with a strong cusp: the laterals of a basal portion and a hook: towards the ends of the row the teeth grow more slender and elongate and the hook smaller. Owing to the bad preservation of the interior and the small size of the animal it was not possible to satisfactorily determine the character of the digestive tract and other organs, but it was quite plain that the anal papilla was under the mantle and latero-posterior (fig. 2). A careful examination failed to discover a blood-gland, but its absence cannot be regarded as certain. In the central nervous system all that could be clearly made out was that the optic nerve was long and the eyes, which were large and black, situated unusually deep. At the right anterior corner of the foot was situated the large genital papilla with two distinct orifices (fig. 2). It was unfortunately impossible to ascertain the character of the internal genital organs, but the hermaphrodite gland appeared to be large and to cover the liver. There were no signs whatever of internal or external gills.

\section{Fam. Hexabranchidae.}

The family as at present known is composed of the single genus Hexubranchus, with the following characters. Large animals of a flattish shape and with ample and undulated pallial margin. Back soft and smooth. Foot broad. Tentacles foliaceous. Rhinophores perfoliate, retractile. Labial armature very strong. Radula composed of numerous simply hamate laterals, without a central tooth. Branchial apparatus consisting of $6-8$ arborescent tufts, separate from one another, not retractile into a common cavity, but each capable of contracting into a small hollow at the base, which does not however amount to a permanent pocket and does not hide the branchia. Anal papilla within the circle of branchial tufts, central or subcentral. Reproductive organs unarmed. Verge exceedingly long. Nervous system much concentrated, so that it is difficult to distinguish the ganglia. Blood-gland single but large. Near the renal pore there is another small orifice of unknown function.

The Hexabranchidae differ remarkably from most Dorids in their habits. They are large, active animals, capable of swimming as well as of crawling. I have generally found them in pools left by the high tide, but think that on these occasions they are merely stranded and naturally prefer deep water. I have also found them swimming on the surface about a quarter of a mile from the coast. Their coloration is generally red and exceedingly conspicuous, in no way resembling their surroundings, but, when at rest, they fold the sides of

G. II. 
the mantle over the back (almost like Placobranchus) and conceal their gorgeous colours, thus entirely altering their appearance. When swimming, they flap the sides of the mantle and bring the two edges of the foot together so as to form a sharp keel. When in captivity I have often observed them adopt an almost vertical position, standing on their heads and walking, or at least feeling their way with their large tentacles. They are very voracious and browse freely on sponges, sertularias, polyzoa, etc.

Bergh has justly observed that it is very difficult to determine the species of Hexabranchus without, or even with, an anatomical examination. Perhaps most of the so-called species are merely varieties. Most of them are very imperfectly described, and even in those cases where the description is adequate it is not always plain what are the specific characteristics beyond colour. There are unfortunately no notes as to the colour of the animals in the present collection when living. As preserved they are of an almost uniform dirty yellow. The family is recorded only from the Indo-Pacific (E. Africa, India, Philippines, Polynesia, Red Sea).

The peculiar arrangement of branchiae displayed in this genus is also found in the Bathydorididae and Kalinga. The former are deep-sea forms, with strong jaws and a radula provided with a median tooth, and are thus allied to Doridoxa and Tritonia. The buccal parts of Hexabranchus, though unusually powerful, show a near approach to the ordinary type of the cryptobranchiate Dorids. The affinities of Kalinga are very uncertain. Bergh places it among the Polyceradae.

\section{Gen. Hexabranchus ${ }^{1}$ Ehr.}

\section{Hexabranchus faustus B.}

I somewhat doubtfully refer to this species a specimen from the S.W. reef of Hulule, Maldives. It is $14 \mathrm{~cm}$. long, and considerably broader across the gills $(7 \cdot 3)$ than across the head $(54)$. The mantle is crinkled at the sides, but quite straight and simple in front. It is compressed against the sides of the body, but the free edge when pulled out and extended measures $2.5 \mathrm{~cm}$. The rhinophore sheaths are slightly raised and quite smooth. The groups of branchiae are set rather close together, and are not always distinct. They appear to be usually 8, but might perhaps be divided differently. Each group consists of several, generally 4 , tripinnate tufts ${ }^{2}$. The anal papilla is central, wide, but not very prominent. Near it are the renal pore and the other orifice alluded to. The labial armature and radula are both strong and dark brown, the former consisting of two furrowed plates composed of a cumpact mass of small and slightly bent rods. The latter contains about 45 rows of simply hamate teeth, there being about 70 teeth on each side of the rhachis in every row. The tentacles are large, foliaceous, furrowed down the middle, and with crinkled edges. Reproductive organs as usual.

\section{Hexabranchus digitatus $\mathrm{n}$. sp.}

One individual from Hulule S. reef, $7.8 \mathrm{~cm}$. long and 5.2 broad, the breadth being much the same in front and behind. The specimen is very much retracted and corrugated

\footnotetext{
1 Bergh in S. R. Hefte XII., xvI, and Supp. I. and in Ergebnisse einer Reise nach d. Pacific, Schauinsland, Opisthobranchien, 1896-7. Several species are described in the voyages of the Bonite, Astrolabe, and the United States
} 
owing to the action of alcohol, but the following characters seem certain and sufficient to establish a new species. The mantle is extremely ample and much crinkled, recalling in this respect Tridachia; when extended from the body, the free edge measures $3.4 \mathrm{cms}$. Over the head are three digitate processes, which are not due to undulations but are distinct and permanent projections from the mantle edge. The rhinophores are not much bent back. The tentacles are almost arborescent; they arise from short stalks, and are deeply indented and subdivided. The buccal parts, nervous system, and reproductive organs are as usual in the genus. The radula and labial armature are strong and reddish-brown in colour. Both the head and the branchiae are withdrawn to an unusual degree into the body. The latter are partly covered by an anterior flap of skin and are crowded together, so that the usual division into groups is not clear. The sections are however divided from one another by eight membranous septa. If this arrangement could be considered with certainty as structural it would afford an interesting link between the ordinary branchial arrangement of Hexabranchus and that of the cryptobranchiate Dorids, but in view of the generally wrinkled and contracted state of the specimen I do not think it safe to regard this configuration as more than a distortion, and should define the species by the following characters-mantle edge extremely ample with digitate processes over the head: tentacles much subdivided and almost arborescent. But it must be remembered that specimens of Hexabranchus which seem to be mere varieties exhibit great differences in the extent to which the mantle and tentacles are developed.

\section{Fam. Dorididae phanerobranchiatae.}

A number of Dorids are conveniently grouped together as Phanerobranchiata, that is to say, they have no distinct and permanent dorsal cavity into which the branchiae can be retracted, though when touched the branchiae may contract so strongly as to almost disappear. Bergh divides them into the Goniodorididae, which possess a buccal gizzard (ingluvies buccalis), and the Polyceradae, which do not, an arrangement which brings together forms of such different appearance as Lamellidoris and Ancula. It seems to me that it would be more natural to subdivide the group into Polyceradae with limaciform bodies, sometimes bearing appendages, and Pseudodorididae, flat Dorid-like forms. It would appear that in other groups closely related genera may either possess or not possess this buccal crop. Thus it is present in Placobranchus and Tridachia, but absent in Elysia. The Pseudodorididae seem to be confined mainly if not entirely to northern seas.

The radula of the Phanerobranchiata is usually narrow and with differentiated teeth. They show a greater variety of form than the Cryptobranchiata, but are far less numerous in species.

\section{Gen. Notodoris B.}

Body limaciform, with no clear distinction between the back and sides: hard, rough, and rugose; surface filled with spiculae. Frontal veil large. Rhinophores smooth, protected by valves. Gills protected by a large valve, which is sometimes elaborately subdivided. No labial armature. Radula without central tooth but with numerous hamate uniform laterals, having a rudimentary secondary denticle below the main hook.

1 Bergh, "Neve Nacktschnecken d. Siidsee, III." Journal d. Mus. Godeffroy, viI. 1875. 
This genus was instituted by Bergh for a single specimen ( $N$. citrina) from Rarotonga. I have obtained another ( $N$. minor) at Zanzibar, which seems specifically distinct, and the present collection contains a third. All three forms are identical in their anatomy, and are also all of a yellow colour, but they differ externally in the contour of the body and the subdivisions of the branchial valve. It may perhaps be proved that they represent merely varieties or different ages, but provisionally they must be classed as separate species. $N$. citrina appears to have a single median ridge from the rhinophores to the branchiae, a branchial valve with about 8 lobes, and a fairly distinct tail. In $N$. minor the tail is not distinctly marked off from the rest of the body, and the whole animal seen dorsally somewhat resembles Phyllidia. The inconspicuous branchial valve is three-lobed, and though the surface of the back is somewhat irregular there are no distinct longitudinal ridges. The colour is lemon-yellow, with black lines, not spots. In $N$. gardineri the long tail is plainly distinguished from the body: there are four dorsal ridges: the branchial valve consists of three lobes, each of which is elaborately subdivided: the colour is yellowish, with a few round black spots.

Notodoris is evidently allied to Aegirus (found on the British and E. European coasts) and to the little known Triopella, both of which are of hard consistence, and have the branchiae and rhinophores protected by tubercles. This little group of three genera seems to stand near the cryptobranchiate Dorids, inasmuch as the teeth are not differentiated but uniform, and the branchiae capable of being concealed. They are not retractile into a pocket, but the same result is produced by the protecting valve, which shuts down over them. Nothing is known of the habits of these animals. In captivity $N$. minor was quite inert, and did not make any movement. With Mr Gardiner's specimen is a piece of hard, yellow sponge. There is no note, but as the colour and consistency of the sponge closely resemble those of the nudibranch it is highly probable that the latter frequent it.

\section{N. gardineri n. sp. (fig. 7).}

One specimen from Hulule, Maldive Islands. Length $335 \mathrm{~cm}$.: breadth at widest part 9 : height at highest part 1.2. Colour, uniform dirty yellow, with a few vivid black spots on the upper but not on the under surface. Frontal veil large and rounded. The flat sole occupies the whole under surface of the body. There is no distinct mantle edge, but a ridge runs from each end of the frontal veil to the branchial valves. Between these are two more ridges, which are again connected by smaller ridges, shaped like the letter $\mathrm{Y}$. The depressions between the ridges are smooth, but the tail and other parts of the body covered with rough and rather large tubercles. The radula (as in the other species) consists of numerous uniform hamate teeth, with a rudimentary additional denticle. Their form is exactly that given in Bergh's plate ( $l$. c. Pl. IX. 39). The visceral mass and reproductive organs were too much hardened to admit of any examination, but in $N$. minor the verge appeared to be trifid at the extremity and covered with rows of small tubercles. The rhinophore openings are closed by their valves. The large branchial valve (fig. 8) is composed of three lobes, each elaborately divided and furnished with numerous spatulate processes. In order to preserve the specimen the internal parts were taken out through the foot and the frontal veil and branchial valve not removed. Hence the gills were not examined. 
Gen. Trevelyana Kelaart?.

The shape of Trevelyana is limaciform, there being no mantle margin or distinction between the back and sides and no appendages. The rhinophores are retractile and perfoliate. The branchiae, which are generally placed about the middle of the back, vary in number (7-32), but are usually numerous, simply pinnate or compound. The tentacles are small. There is no labial armature or rhachidian tooth. The radula is short and narrow: the first and sometimes also the second tooth differs in shape from the others. There are two or three distinct hermaphrodite glands not attached to the liver. The verge is armed.

Trevelyana is only recorded from the Indo-Pacific area, but within it is one of the commonest of polycerids, and is frequent under stones in the littoral zone, e.g. in East Africa. It is generally found in pairs.

6. $T r$. crocea B.

Two specimens from Hulule. Length $2.4 \mathrm{~cm}$ : : breadth $1 \cdot 2$. Body rather square and stout: well preserved, but the colour lost, the whole animal being of a uniform greyish-white. Rhinophores small, with about 12 perfoliations, and retractile into simple pits without raised margin. Branchiae 20 in both individuals, forming a circle open behind, which is completed by the anal papilla. The gills are bent inwards, and on their inner side are simple lamellae. The tentacles very small: the radula is composed of about 15 rows: the two teeth next to the rhachis are bicuspid, consisting of a basal portion, from which two hooks arise: the others have a single hook, which is much reduced in the outermost. The nervous system is rather large, and shows the various ganglia very distinctly divided. There are two distinct hermaphrodite glands close together, and not spread over the liver. The verge is armed with small spines. Prostate large.

Though there is no record of the colour of the living animal the specimens seem referable to Trevelyana crocea on account of the number of the branchiae and the shape of the teeth.

Gen. Nembrotha Bergh?

Externally this genus closely resembles Trevelyana, and differs only in the gills, which instead of being numerous and small are few in number, but very stout and strong. Internally it differs in the structure of the radula and generative organs. There is a squarish central tooth, with a large hamate lateral at the side. The remaining teeth, which vary in number from 3 to 12, are also generally squarish plates without hooks. The hermaphrodite gland is spread over the liver, and not separated into distinct masses. There is no prostate. As a rule there is no labial armature, but a weak one exists in $N$. nigerrima.

7. Nembrotha nigerrima ? variety.

One specimen from Minikoi, much bent and contracted. Length $3.4 \mathrm{~cm}$., breadth 1.6, height 2.4. Colour, a uniform dirty yellow: the gills and rhinophores are much redder, and there are a few raised reddish spots, particularly near the gills. The rhinophores small, with about 30 perfoliations: the skin round the rhinophore openings is much contracted, but no raised edges were discernible. The gills large, 5: two on each side and one in front. As in other species of Nembrotha which I have seen the rhachis is very hard and strong, so

1 A. and H., Notes on a Coll. of Nudib. made in India, 1863. Bergh in S. R. Hefte XI. and xvr. Id. Beitr. zur Kenntn. der Japanischen Nudibr. 1880. Id. Beitr. zu einer Monographie der Polyceraden, 1883.

2 Bergh in S. $R$. Hefte xI., xvir., and in Harvard Bull. of Comp. Zoology, 1894. 
that when the gills are contracted it almost covers the branchial lamellae, like the valve in Notodoris. No tentacles were discernible: the inner lip is brown, and bears a weak armature of small rods: the formula of the radula appears to be $11+1+1+1+11$. The central tooth is squarish: its front edge is turned upwards, and bears four or five denticles. The first lateral is large and sickle-shaped: the rest squarish without hooks, and decreasing in size outwards. Blood-gland large. The hermaphrodite gland spread over the liver. Verge armed with small hooks.

The typical Nembrotha nigerrima appears to be black, with bluish-green spots, red gills, and a red mantle border. Several species of Nembrotha which I have preserved in spirits have kept their colour well, and I do not think it likely that the ground colour of the present specimen was ever black. I am very doubtful if this individual should be referred to $N$. nigerrima, as both its shape and coloration seem different, but I cannot formulate any separate specific characters.

\section{Fam. Dorididae cryptobranchiatae.}

The cryptobranchiate Dorids are characterized by the possession of a distinct and permanent dorsal pocket, into which the branchiae can be entirely withdrawn. The rhinophores are invariably perfoliate and retractile. There is never a buccal gizzard. A labial armature is present or absent. The radula is broad, and the teeth either uniform or only slightly differentiated, A central tooth is rare.

In number of species this is the richest family of all the Nudibranchiata. Though cosmopolitan in distribution it is particularly abundant in the Tropics.

\section{Gen. Chromodoris A. and $\mathrm{H}^{1}{ }^{1}$}

The form of this genus is generally high, narrow, and limaciform, the mantle being somewhat small at the sides, but expanding into a fairly ample frontal and caudal veil. The coloration is brilliant. The foot usually projects behind the mantle. The branchiae are simply pinnate, but are sometimes bifid and vary considerably in their arrangement. The tentacles are retractile. The labial disk has a strong armature of minute hooks. The rhachis of the radula is either naked or bears thickenings, very rarely true teeth. The laterals are numerous and hamate: the first is denticulate on both sides, those which succeed it on the external sides only, the outermost at the extremity only.

Chromodoris is the largest genus of the Cryptobranchiatae, comprising over a hundred species. Many of these resemble one unother closely in structure, but some show remarkable variations such as Chr. scabriuscula, which has a hard tuberculate back and rhachidian teeth, peculiarities which almost entitle it to generic rank. Also the shape is somewhat variable. Typically, it is as described above, but some species are flatter with an ample mantle margin, and present a quite different appearance. Many tropical Chromodorids have considerable powers of altering their form, and alternate between a high narrow condition and a flat condition

${ }_{1}^{1}$ Bergh in S. R. xI. Supp. Heft I., Hefte $\mathrm{x} \nabla$. , xvI., xvIr. Bergh, "Neue Nacktschnecken der Südsee," Journal des Mus. Godeffroy, Heft virı. 1875 and Heft xiv. 1878. "Untersuchung der Chr, elegans u. Villafranca," Mal. Blätter, xxxv. 1878.
Challenger Report on Nudibranchiata, 1881. von Jhering, "Beit. zur Kennt, Nudibr, Mittelmeeres," Mal. Blätter, N. F. Bd. Ix. 1880. Collingwood, On some Nero Nudibr. Mollusca from the Eastern Seas, 1878. 
in which the mantle is extended. Thorunna, Bgh., closely resembles Chromodoris, but lacks the labial armature.

The Chromodorids are confined to the warmer seas, and are most abundant in the Tropics, but there are some ten species in the Mediterranean, and the genus is represented on the coasts of Japan and California. They are common on coral reefs and in pools filled with seaweed. Their brilliant coloration, which is often dazzlingly gorgeous in the living animal, does not appear to in any way harmonize with their environment. On the other hand some of the most striking species are commonly found under stones where their hues can be neither "protective" nor "warning."

The species of Chromodoris are distinguished largely by their colour, though other characters are not wanting, such as the details of the teeth and labial armature, the presence of rhachidian thickenings, glands on the mantle edge, and the arrangement of the gills. The number of gills however is not constant in the same species, and even the arrangement seems to vary. The colour of Nudibranchs as a rule is very variable, but in this genus the general pattern and ground colour, though they may differ in elaboration or intensity, are mostly constant. Unfortunately there are no notes as to the living colours of the specimens in this collection, and in only two are they recognisable, so that it is exceedingly difficult to make any certain identifications.

\section{Chr. elizabethina Bgh.}

Two specimens from S. Nilandu Atoll, Maldives, $30 f$. One was dissected. The animal was much bent, but if straightened out would have been about $2.5 \mathrm{~cm}$. long by 6 broad. Colour in alcohol brownish-yellow, margin of mantle whiter. From a black patch between the rhinophores rise three broad black lines, two of which run down the sides and meet behind the gills, while the third runs from the rhinophores to the anterior edge of the branchial pocket. Round the sides of the body are other black lines, in one specimen three, in the other two. In this latter specimen the lines are only on one side, having disappeared on the other. Branchiae twelve, two being free in the middle, and the rest united at their bases into two groups of five, one on each side. Three gills on one side and two on the other were bifid. The radula with thickenings on the rhachis: the innermost teeth with 4 small denticles on each side. The outermost with from 2 to 4 points.

\section{Chr. rosans B. (? Chr. Bullockii Coll.).}

One small specimen from Minikoi. $1.3 \mathrm{~cm}$. long and 5 broad. Colour a uniform reddishpurple, with traces of a white border. Rhinophores and branchiae grey. It would appear that the living animal is rose-coloured, with a brilliant white border and yellow rhinophores and branchiae. Gills nine, apparently set in a horseshoe open behind, decreasing in size as they go backwards. No thickenings or rhachis of radula: teeth as usual, outermost with several largish denticles.

This seems to me to be a young individual of $C h r$. rosans B., which is probably identical with the Chr. Bullockii described and figured by Collingwood (l.c.).

10. Chr. pustulans B.

Two specimens from Minikoi seem referable to this species. Length of largest $2 \cdot 1 \mathrm{~cm}$, breadth 1:2. The broad back is covered with low, round tubercles. The ground colour is dull yellowish-brown, but the gills and tubercles show traces of bright yellow pigment. The 
gills are 12 (eleven in Bergh's specimen), arranged in an incomplete circle, the vacant space in which is filled by the anal papilla. The two median gills are separate, the others connected into two groups, five on each side. A strongish labial armature of bifid hooks. Radula without thickenings or rhachis. Innermost teeth somewhat irregularly denticulate on both sides. Outermost very irregular in shape.

\section{Gen. Ceratosoma Ad, and Reeve'.}

This genus is easily recognized by its extraordinary shape. The body rises upwards from the head so that the branchiae are much higher than the rhinophores. Near the branchiae are two side lappets and behind them a long dorsal process. There is a round frontal veil, a narrow mantle edge and a narrow foot prolonged into a tail of nearly the same length as the body. In their essential characters these animals resemble Chromodoris ${ }^{2}$. There is a labial armature of hooks: the radula has no central tooth but numerous hamate laterals which are sometimes denticulate. The tentacles are retractile: the branchiae simply pinnate: the reproductive system unarmed, and as in Chromodoris there is no true stomach.

I have seen numerous specimens of Ceratosoma polyomma alive in East African waters. They are sluggish and generally found among seaweed, where they make no attempt to hide themselves. They have a strong, disagreeable odour. The colour varies from green to chestnut-red and there is also some variety in the shape; one specimen had neither the lateral nor the dorsal lobes.

\section{C. trilobatum Gray.}

Two specimens from S. Nilandu Atoll, Maldives, $30 \mathrm{f}$. The animals as preserved are quite white, except for a slight bluish tinge at the end of the dorsal process. They are hard and of a peculiar waxy appearance. This is not the coloration of the specimens previously described, but the species seems to be really characterized by the back being relatively less steeply inclined than in others, by the thick mantle edge and frontal veil and by the thick, rounded and somewhat indistinct lateral lobes. They resemble fairly well Gray's figure (Figures of Molluscous Animals, Pl. 67, fig. 14) of Doris trilobata. The largest specimen is $5.7 \mathrm{~cm}$. in length and 1.5 in breadth across the lateral lobes. The strong rounded tail is $3.2 \mathrm{~cm}$. long and the dorsal process $1 \mathrm{~cm}$. The foot is a long narrow groove. The mantle edge, lateral lobes and frontal veil are all thick and indistinctly marked off from the body. The tentacles are retracted: the mouth is a narrow vertical slit between them. The labial armature consists of two light yellow plates, rather soft and composed of little hooks. The radula contains about 70 rows: in each row were numerous hamate teeth bearing a single denticle on each side of the naked rhachis. The back is quite smooth; immediately below the dorsal process lies the small branchial opening, which contracts even further within. The rim is smooth and hardly raised. The branchial apparatus, which is retracted into the lowest depths of the cavity, is rather large and it is a wonder how it can even emerge from so small an opening. The branchiae appear to be 14 in number. In front are two, quite separate. At the sides are six united together and sometimes bifid so that it is hard to say how they should be counted. The posterior ends of these two lateral groups turn inwards.

\footnotetext{
${ }_{1}$ Bergh, S. $R$. Heft x., xvir., and Supp. Heft $1_{v}$, and in Nudibranchiata of Challenger.
}

2 Some species of Chromodoris (e.g. Ch. Semperi) bave a dorsal prominence behind the gills which recalls Ceratosoma. 


\section{C. gracillimum Semper.}

One specimen from Kolumadulu Atoll, Maldives, $33 f_{\text {. }}$, of a uniform dirty yellowish-brown. It is easily distinguished by its very slender dimensions. The length from the head to the tip of the tail is $2.7 \mathrm{~cm}$., the body being somewhat bent. The tail is very long $(1.6 \mathrm{~cm}$.) and compressed, being only $2 \mathrm{~mm}$. thick. The breadth across the back is $7 \mathrm{~mm}$., and the height of the dorsal process also $7 \mathrm{~mm}$. The mantle and frontal veil are far more distinct than in the last species and the free mantle edge measures $2 \mathrm{~mm}$. The apertures for the rhinophores and branchiae are very small. The specimen was not dissected.

Two small specimens about a centimetre long from $\mathrm{N}$. Male Atoll, Maldives, $27 \mathrm{f}$, are perhaps referable to the same species though proportionally less elongate and slender than the larger individual.

\section{Gen. Discodoris ${ }^{1}$ B.}

The Discodorids are soft, flat animals, of an oval or oval-elongate form. The back is granulated or finely tuberculate, and in the known species generally yellow or brown with darker mottlings. The mantle edge is ample but the foot fairly wide, grooved and more or less notched on the upper lip in front. The tentacles are digitiform, the branchial aperture round, crenulate or stellate. There is a labial armature formed of two plates (or a continuous ring) composed of minute rods. The radula consists of simple hamate laterals, without a central tooth. The reproductive organs are unarmed but there are large prostates.

Discodoris is distinguished from Platydoris externally by its softer texture and internally by the presence of a labial and the absence of a genital armature. Separate genera have been ereated by Bergh for several allied forms with a labial armature but showing various peculiarities in the reproductive system.

Discodorids are recorded from the Pacific, Indian Ocean, E. Africa, Philippines, Mediterranean, and West Indies. They are therefore in all probability cosmopolitan. Like Platydoris they are frequently found under stones between tides on coral reefs. They are lethargic in their movements and several species have an extraordinary power of self-mutilation. When handled, or apparently when feeling uncomfortable, they slowly detach part of the mantle, or even the whole mantle edge in a complete ring. The remaining part of the animal seems uninjured and lives at least several days. This self-mutilation is generally explained as an attempt to escape from a foe who has seized hold of the mantle, but considering how slowly it is effected and that it takes place when the animal is in captivity and is not attacked, though perhaps suffering from the effects of bad water, it may equally well be regarded as a sign of weakness, due to unfavourable physical conditions².

\section{D. concinna (A. and H.).}

One specimen from Minikoi. Length $4.2 \mathrm{~cm}$., breadth $2.2 \mathrm{~cm}$, foot $1.3 \mathrm{~cm}$. wide. The back is minutely tuberculate, yellowish-brown in colour with blackish spots. The tips of

\footnotetext{
1 Bergh, S. $R$, Hefte xII., xy., xrII., Supp. Heft I., and Challenger Report on Nudibranchs. Alder and Hancock, Notes on a Coll. of Nud. Moll. made in India, 1863.

2 This self-mutilation is particularly frequent in a species of Gena common at Zanzibar. I have collected about 30 specimens and found that they invariably threw off their tail, at least half the bulk of the entire body, within three
}

G. II. hours after capture. This was the case when they were put in a vessel quite alone without any other animal or object which could alarm them. The division always took place at exactly the same point, just in front of the last pair of dorsal processes. The rejected half bore an extraordinary resemblance to a nudibranch. The foot was able to adhere and the dorsal processes looked like rhinophores. 
the tubercles, both in the yellowish and in the blackish parts, are of a lighter colour than the bases, which gives a curious effect well rendered in Alder and Hancock's plate $l$. c. The foot and under edge of the mantle are spotted with purplish-brown. The rhinophore sheaths are raised and tuberculate. The branchial opening is large and crenulate and contains six tripinnate gills. The labial armature consists of two narrow yellowish plates, which form an almost continuous ring. The radula is as usual in the genus and family broad, the teeth being smaller but not denticulate at the outside.

I think this specimen may be safely referred to $\mathbf{A}$. and $\mathrm{H}$.'s species concinna.

\section{D. pardalis, var. (A. and $\mathrm{H}$.).}

One specimen from $\mathrm{N}$. Male Atoll, Maldives, $25 \mathrm{f}$. Length $4.4 \mathrm{~cm}$., breadth $2.1 \mathrm{~cm}$. Dorsal surface finely tuberculate, yellowish, with traces of orange-coloured spots. Under surface yellowish, without spots. Foot grooved at the anterior end but the notch in the upper lamina is hardly perceptible. Branchial opening raised, so as to be almost a papilla, round and not notched. Branchiae six, long and slender, tripinnate. Labial armature circular and very strong, consisting of a compact mass of yellowish rods. Radula unusually narrow: teeth simply hamate, large and coarse and not materially diminishing at the inside or outside of the row. Formula 13 (or 14). O. (14 or) 13. Reproductive system unarmed. Prostates large.

I doubtfully register this specimen as $D$. pardalis (A. and H. l. c.) because it has obvious resemblances to that species as described and the points of certain difference do not seem sufficient to constitute a new species. The coloration, the slender branchiae, and the absence or inconspicuousness of the notch on the upper lamina of the foot are all points of resemblance. But the branchial opening though raised is distinctly round and not stellate as in A. and H.'s specimen, and though they give no details as to the radula it is noticeable that they do not allude to its narrowness or the great size of the separate teeth.

\section{D. meta B.}

A single specimen from $\mathrm{N}$. Male $\Lambda$ toll, Maldives, $30 \mathrm{f}$, seems referable to this species with tolerable certainty. The animal is oval in shape, $2.3 \mathrm{~cm}$. long by $1.7 \mathrm{~cm}$. wide: the texture is soft and the back covered with fairly large papillae. The ground colour is yellowish with the remains of brown and purple blotches in the middle. From between the rhinophores to the gill opening runs a somewhat indistinet dorsal ridge. The mantle margin is ample and undulated. The rhinophore sheaths are projecting, with jagged edges, which in the preserved specimen have closed over the opening. The branchial opening consists of a transverse slit, the upper end of which overhangs the lower. Gills, 6, tripinnate. Foot deeply grooved and notched in front. Labial tentacles reddish-yellow. Labial armature bright blue, formed of minute rods. The radula consists of simply hamate teeth. Both the innermost and outermost, especially the former, are smaller than the median teeth, but none were rudimentary. The cerebral ganglia were rather far apart.

The colour of the labial armature is unusual. In the two specimens examined by Bergh (l.c. Heft XII.) it was olive-grey. 
Gen. Platydoris B. ${ }^{1}$

Flat, oval animals of a fair size and peculiar hard, leathery texture. The back is finely granulated and rough to the touch: the mantle margin ample: the foot grooved in front and the upper lamina deeply notched. The branchial opening is generally stellate: the branchiae are tripinnate and usually five, six or seven in number. There is no labial armature or rhachidian tooth. The radula consists of numerous hamate laterals, the outermost of which are sometimes finely serrulate. The reproductive organs have an armature of hard scales, bearing hooks.

The Platydorids are recorded from the Indian Ocean, E. Africa, the Pacific (including the W. coast of America), the Mediterranean, Great Britain (Pl. planata), the West Indies, and the Canaries. They may therefore be considered as cosmopolitan. They are frequent on coral reefs under stones at low tide. They are exceedingly lethargic and are often found wedged into the crevices of stones, the mantle having grown into the shape of the hollow in a way which suggests that the animal has not moved for a considerable period. Several of the species show the same phenomenon of self-mutilation as Discodoris.

\section{Pl. eurychlamys B.}

One specimen from the Kolumadulu Atoll, Maldives, $33 f$. The animal as preserved is $7 \mathrm{~cm}$. long and $4 \mathrm{~cm}$. broad. The back, which is as usual flat and leathery, is blackishbrown, with white spots, which are particularly numerous near the margin. The underside dirty white, with black spots on the foot. The rim of the branchial pocket white; the branchiae six, whitish with black rhachis. The numerous teeth are of the ordinary hamate type; the outermost are very irregular in shape but not serrulate.

From Bergh's descriptions of various specimens the colour appears to be very variable.

17. Pl, scabra Q. and G.

One small specimen from Minikoi $3.5 \mathrm{~cm}$. long by $1.7 \mathrm{~cm}$. broad. Not dissected. This species, which I have frequently seen alive in the South Seas, is hard and leathery and grows to be three or four inches long. The mantle is wavy and indented. The labial tentacles small, white and tapering. The rhinophore sheaths somewhat projecting. The colour of the back is white with irregular blotches of brown formed by aggregations of minute spots. The under surface yellowish-white. The branchial aperture has six lobes and presents a star-like appearance. The branchiae are six, yellowish, very voluminous and delieate?

\section{Platydoris sp.}

Two specimens from the Maldives, Hedufuri, Mahlos Atoll. The largest is $2.2 \mathrm{~cm}$. long by $9 \mathrm{~cm}$. broad, the form being somewhat elongate. The back is finely granulated, bluishwhite, with traces of yellowish-brown mottlings in the centre. Round the mantle margin

1 Bergh in S. R. Hefte xII., xvI., xviI., and Supp. Heit I., and Sammlung, Plate, Opisthobranchiata.

"As there seems to be no description of this species except Quoy and Gaimard's brief notes, I add the following particulars taken from specimens examined in East Africa. The living animal is as much as $10 \mathrm{~cm}$. long, very stiff, sellowishwhite, with irregular violet mottlings of varying intensity, formed mostly by minute rings of the same colour with yellowish centres or by spots. The under side is a elear yellowish-white, with no markings except at the sides of the

foot which are mottled like the back. The branchiae are light yellow with grey axes: the rhinophores, buccal mass and viscera all bright, light yellow. The foot small and narrow, grooved in front and notched, but not deeply: the upper lamina thick. No trace of labial armature. Radula about $48 \times 60.0 .60$. Teeth simply hamate: innermost smaller, two or three outermost irregular. Male branch of reproductive organs with the characteristic hook-bearing scales apparently set in four rows: female branch with strong folds. 
is a row of purplish spots and the sole and sides of the foot are streaked with the same colour. The margin of the mantle is undulated. The rhinophore sheaths not much raised and with smooth margins. The branchial opening roundish with indistinct lobes and containing five small tripinnate branchiae. No labial armature. The radula consists of simply hamate teeth, smaller towards the outside but not denticulate. The verge is armed with hamiferons dises.

Not having access to the descriptions of some recorded species of Platydoris, I cannot give an opinion as to whether this form is new or not. I lay no stress on the branchial opening being roundish. This is not unfrequently the case in alcoholic specimens, although the opening may be typically stellate.

\section{Gen. Dictyodoris Bergh ${ }^{1}$.}

The texture of the body is leathery, the dorsal skin smooth. Foot not grooved in front or only slightly. Branchial aperture round: branchiae few, bipinnate. Tentacles digitiform. No labial armature. Radula of simply hamate teeth with naked rhachis. Reproductive system unarmed. The two known species have reticulate figures on the back and only four branchiae. In $D$. tesselata the outermost teeth are pectinate, in $D$. maculata not.

\section{D. maculata n. sp.}

One specimen from the Fainu-Inguradu Channel, N. Mahlos, Maldive Islands, $26 f$. Nearly round in form: length $8 \mathrm{~mm}$., breadth $6 \mathrm{~mm}$. Colour bluish-white, with blackish spots which seem to be under the skin. There are several black spots of a more ordinary appearance on the under edge of the mantle and a black rim running round at the junction of the foot and body. On the dorsal surface is a reticulate pattern formed by ridges, but their conspicuousness is due rather to a difference of colour than to their real prominence, which is small. I could not distinguish any groove in the anterior part of the foot. Branchial aperture small and round: 4 bipinnate whitish gills, the posterior pair being smaller than the others: the main and secondary axes are marked by a broad black line. Tentacles digitate: no labial armature: radula fairly broad: no central tooth: laterals simply hamate, the innermost small, the outermost irregular, sometimes bifid or trifid but not consistently pectinate. Central nervous system somewhat concentrated, though not as in Asteronotus, two pairs of ganglia being distinguishable.

This specimen bears a striking resemblance to Alder's drawing of Doris Incii (reproduced in Gray's Figures of Molluscous Animals, 1850, Tab. 226, figs. $1 a, b, c)$, which, as Bergh points out, may represent either a Dictyodoris or Sphaerodoris. As however we have no account of the anatomy of this animal, it can never be possible to certainly attribute it to either genus. In spite of the strong external similarity of the present Dorid to Alder's drawing I do not propose to call it $D$. Incii because the figure has (1) indistinct but apparently simply pinnate branchize, (2) no tentacles, (3) starlike apertures for the rhinophores, (4) no spots or dark rim on the under surface. The genus Dictyodoris appears to be closely related to Halgerda, Bergh.

1 Bergh, S. R. Sup. Heft x. 1880. 


\section{Gen. Staurodoris Bergh}

This genus was established by Bergh for the Doris verrucosa which is common in the Mediterranean and is characterized by him as follows. The body is flat and tuberculate: the retractile rhinophores and branchiae are protected by valve-like tubercles. The branchiae are simply pinnate. There is no labial armature or median tooth: the radula consists of numerous simply hamate teeth and the reproductive system is unarmed. If this definition of the genus is rigidly adhered to, the form described below must be made a new genus, as the rhinophores and branchiae are not protected by valves and the branchial opening is crescent-shaped and very peculiar. Von Jhering however describes under the name of Stuurodoris pseudovernucosa an animal obtained at Naples in which there were no valves round the gill cavity? ${ }^{2}$. It seems therefore simpler to somewhat enlarge the definition of the genus than to create a new one. We may therefore characterize Staurodoris as belonging to the large class of Dorids which have no labial armature or median tooth but a simply hamate radula and as distinguished from the other genera by its tuberculate back and simply pinnate branchiae. Perhaps to these characters may be added the shape of the tentacles, which appear as two ridges above the mouth ${ }^{3}$.

\section{Staurodoris pecten nov. sp.}

Two specimens from N. Male Atoll, Maldives, $27 \mathrm{f}$. The animals are nearly round, the larger specimen being $1.3 \mathrm{~cm}$. by $1 \mathrm{~cm}$, and flat. The dorsal integument is full of rod-like spicules and studded with small conical warts or papillae, which are not connected or confluent. The colour is quite uniform, in the one specimen yellowish-brown, in the other faded yellow. The foot is broad $(1 \mathrm{~cm}$. by $0.7 \mathrm{~cm}$.) and slightly grooved in front, the upper lamina being notched. The rhinophores emerge in the middle of a wart, but can hardly be said to be protected by distinct valves. The gill opening is in the shape of a crescent, the horns pointing anteriorly. The crescent itself acts as one large valve, but its lips are not protected by any special tubercles, and when it is closed and the branchiae completely withdrawn it is hardly distinguishable from the rest of the dorsal surface. The branchiae are disposed in three groups. The anterior one consists of a single simply pinnate leaflet: those to the right and left consist each of six similar leaflets, united at the base so that they might be regarded as bipinnate. The central nervous system is much concentrated and the commissures very short. The tentacles seem to be ridges above the mouth, very slightly grooved externally. There is no labial armature. The radula consists of simply hamate teeth, not denticulate, and uniform except that the innermost and outermost are somewhat smaller than the rest. There is no central tooth. The reproductive system is unarmed.

It is very doubtful whether this species should be regarded as a Staurodoris or the type of a new genus. Probably new forms belonging to this group will be discovered and have to be distributed between the genera Staurodoris and Echinodoris. The latter though strongly characterized externally by its greatly elongate papillae is really closely allied to

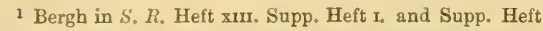
II, and in Bull. of Mus. of Comp. Zool. Harvard, 1894, pp. 160-2. Also von Jhering, Jahrbücher der Deutschen Malak. Gesellschaft, 1886, Heft ur. pp. 230-233.

2 It had the further peculiarity of having bipinnate gills.
${ }^{3}$ Since writing the above more than a year ago, I have examined in East Africa several forms referable or allied to Staurodoris, which may necessitate a further modification of this definition. I postpone the discussion of their affinities to another paper. 
Staurodoris, from which it differs chiefly in its denticulate teeth, penial armature and bipinnate gills. But as seen from the present specimens it is not always easy to say whether gills are simple or bipinnate.

Collingwood (On some New Species of Nudibranchiate Mollusca from the Eastern Seas) gives notes on a Doris pecten from Formosa. His deseription is not sufficiently full to decide to what genus the animal should be referred but, as it has a crescent-shaped row of simply pinnate branchiae and the other characters are not inconsistent with those of the present specimens, I have indicated its possible identity in the proposed specific name. No species of Staurodoris is recorded with certainty from the Indo-Pacific, but Abraham's Doris pustulata seems closely related, though it has bipinnate branchiae.

\section{Gen. Trippa Bergh"1.}

This genus, which seems identical with Phlegmodoris Bergh"2, comprises a few tropical cryptobranchiate Dorids with a soft tuberculous body and no jaws. The characters are as follows. Body flattish, soft, sometimes gelatinous: the dorsal surface covered with tubercles, which are generally compound and support smaller projections. Tentacles small. Foot broadish with a shallow groove in front, the upper part united to the head. The branchial rosette far back at the end of the body composed of five or six tripinnate plumes. No labial armature: radula composed of uniform simply hamate teeth: a number of glandular bodies (? glandulae ptyalinae) are inserted in a circle round the posterior extremity of the oral tube. The reproductive system is unarmed. In the Opisthobranchier d. Sammlung Plate (p. 527) Bergh apparently drops the character of the foot being connected with the head.

\section{T. ornata B.}

Recorded hitherto from the Philippines and the Malay Archipelago. The present collection contains two specimens from Minikoi marked "mottled yellowish-brown and white," which agrees fairly well with Brock's coloured sketch of the animal. The preserved specimens are of a purplish grey; the dorsal tubercles somewhat darker, though some on the other hand are quite white. The foot somewhat lighter. They are both about $3.5 \mathrm{~cm}$. long and $2 \mathrm{~cm}$. broad. The back is flattish and covered with numerous small tubercles, which when closely examined are seen to be covered with little lumps. The mantle fairly wide at the sides and over the head, with an irregularly marked dark border. The rhinophores completely retracted, but as far as can be judged bent backwards in the living animal. The branchial orifice set far back, shallow, the branchiae being exposed in both specimens. They are five in number and tripinnate, the secondary pinnae being long and the tertiary short. The anal papilla is central, large and long. The radula is small and white and consists of twenty rows (only one specimen examined), each of which contained from 32 to 37 teeth on each side of the rhachis. The other characters are as for the genus. Except for some small differences in the radula the specimens correspond very well with Bergh's description.

\footnotetext{
1 S. R. Heft xix. 1877, Heft xvr. 1890, Opisthobranchier der Samml., Plate, p. 527.
}

2. S. R. loc. cit. Heft xim. Bull. of Mus. of Comp. Zool. Harvard, 1894. 


\section{Fam. Doridopsidae ${ }^{\text {. }}$}

The Doridopsidae externally much resemble the cryptobranchiate Dorididae but differ in their internal structure, particularly in the buccal parts. The body is soft, often gelatinous: the back either smooth or covered with soft warts and tubercles. The rhinophores perfoliate and retractile. The branchiae retractile into a common pocket, generally rather large, few in number and tri- or quadripinnate. The foot broad, grooved in front with a notch in the upper lamina, not extending behind the mantle. Tentacles small, not projecting freely and resembling two folds, sometimes hardly distinguishable. The mouth is a fine pore, usually situated in the anterior cleft of the foot: there is no trace of jaws, radula, or labial armature and the buccal organs consist of a slender suctorial tube which can be protruded as a proboscis through the mouth pore. Beneath the anterior part of this tube are two large folliculate glands called ptyaline. The true salivary glands appear to be represented by two nodules at the commencement of the oesophagus. The stomach is surrounded by the liver, which is bifid behind. The nervous system is extremely concentrated. On the interior dorsal wall of the pericardium are a number of folds, sometimes called the pericardial gill, though their respiratory functions are not clear. The hermaphrodite duct is spread over the liver and there are two spermatothecas. There is an armature of minute hooks on the spermatic duet and the glans.

The Doridopsidae are clearly allied to the cryptobranchiate Dorids by their retractile gills and general structure, but can usually be distinguished externally by their soft consistency and pore-like mouth in the anterior pedal groove. The suctorial mouth allies them to the Phyllidiadae, especially Phyllidiopsis, and the details of their anatomy (the concentrated nervous system, the pericardial lamellae and the penial armature) present remarkable resemblances to that family. Whether they are phylogenetically more akin to the Dorids or the Phyllidiadae can only be proved, if ever, by the discovery of connecting links, but the present evidence seems to bring them nearer to the former than to the latter group. They differ from the Dorids mainly in the buccal parts, which may be easily modified by diet, but from the Phyllidiadae in their general shape, texture and respiratory organs. The concentrated nervous system and reproductive armature are found in several Dorids and it is not clear that the pericardial lamellae are a character of importance.

The family contains more than 60 species arranged by Bergh in two genera, Doriopsis and Doriopsilla. The latter, which contain only one certain species, is characterized by the body being hard and by the buccal ganglia being situated at the anterior not the posterior part of the buccal tube. The genus Doriopsis (or Doridopsis), though apparently not found in the colder seas is probably cosmopolitan in warm waters, being recorded from the Mediterranean, the West Indies, and most parts of the Pacific and Indian Oceans. The animals are generally abundant under stones on coral reefs. Their food is unknown. In captivity I have never seen them take nourishment, though they crawl over. stones and sponges as if seeking for something to eat.

1 Pease, Proc. Zool. Soc. London, 1860, Amer. Journal Conchol. v1. 1871. Hancock, On the Anatomy of Doridopsis, 1865. AIder and Hancock, Notes on a Coll. of Nud. Moll. from Madras, 1863. Bergh, "Neue Nacktschnecken der Südsee," Journal Mus. Godeffroy, Heft virm. 1875, Heft xIv. 1878. Id. "Die Doriopsen des Atl. Meeres," Jahr. der

Deutschen Malac. Gesell. v1. 1879. Id. Die Doriopsen des Mittelmeeres, ib. vIr. 1880. Id. Challenger Report on Nudi. branchs, 1881. Id. in S. R. Heft x. Supp. Heft I., Heft xv., xvi., xvII. Id, Die Nudibranchiata holohepatica Porostomata, Wien, 1892. 
22. D. nigra Stimpson, var. nigerrima B.

Three specimens from the Maldives, Mulaku Atoll $40 \mathrm{f}$., and Mahlos Atoll $20 \mathrm{f}$. The largest is $1.7 \mathrm{cms}$. long and $8 \mathrm{~cm}$. broad. The colour is a deep bluish-black; the foot, especially the margin, is somewhat lighter and on the back are some inconspicuous spots of bluish-grey, looking as if the black pigment had been rubbed off. But there are no signs of white spots, a coloured border or of white on the rhinophores or gills. The latter are six and tripinnate. The internal organs are as usual, but even here the black tint prevails.

This species shows great variety of coloration and in my experience the pure black form is the rarest. At Zanzibar I have found in considerable abundance (1) a black form with large white spots and no border, (2) a purplish form with numerous small spots and a border of the same colour but lighter, (3) a black form with or without white spots and with a bright red border, (4) a greyish-white form without markings; found in the company of (3) and apparently differing only in coloration.

\section{D. apicalis? B.}

One specimen from the Suvadiva Atoll, Maldives, $42 f$. Length $5.4 \mathrm{~cm}$, breadth across the rhinophores $1 \cdot 1 \mathrm{~cm}$, across the gills $2 \cdot 3 \mathrm{~cm}$. The form is thus unusually long and tapering. The back is smooth and the mantle edge narrow. The colour uniform dirty grey with some whitish mottlings on the back but no dark spots or markings. Foot, dirty yellow, smaller before than behind. Rhinophores small, straight with about 20 perfoliations. Gills six, tripinnate. The blood-gland appears to be double and the intestine gives off a small diverticulum near the pylorus. This last character and the elongate tapering shape of the animal incline me to identify it with $D$. apicalis B., recorded from Amboina. But the colour is not quite the same, the shape is not peculiar to this species but found elsewhere (e.g. in $D$. vidua) and it remains to be seen whether the diverticulum is a consistent specific character.

\section{Fam. Phyllidiadae ${ }^{1}$.}

The genus Phyllidia was created by Cuvier and Fryeria by Gray. Our knowledge of the group is however mainly due to the writings of Bergh ${ }^{2}$. The members of the family are perhaps the most easily recognizable of Nudibranchs and can at once be identified by their curious leathery consistency and the brightly coloured lumps or ridges which usually adorn their dorsal surface. They may be more accurately characterized as follows:

The texture of the animals is coriaceous and the form flattish, elongate oval. The margin of the mantle covers the foot all round, though the latter is fairly broad. There is no distinct head but merely a minute oral pore beneath two small digitate tentacles which are united at the base so as to form a rudimentary veil, and are slightly furrowed on the outer side. Seen from above, the shape of the anterior and posterior extremities is much the same. The dorsal surface bears tubercles or ridges, which are generally brightly

\footnotetext{
1 Bergh: (1) "Bidr, til en Monogr, af Phyllidierne," Naturhist. Tidsskr. 3 R. 1869.

(2) "Neue Nacktsch. der Südsee," Journal des Mus. Godefiroy, Heft i1. 1873.

(4) Neue Beitrüge zur Kenntniss der Phyllidiaden, Wien, 1876 (aus den Verhandl. der $k$. $k$. zoologisch-botanischen Gesellschaft in Wien besonders abgedruckt).

(5) Die Nudibranchiata holohepatica Porostomata, Wien,

(3) Malacol, Untersuch, in Semper's Reisen, Heft x. 1892 (do. do.).
} 1876, Heft xvi. 1889 and Heft xv1r. 1890. 
coloured. The rhinophores are perfoliate and completely retractile. They usually emerge from two of the anterior tubercles. Under the mantle edge are a large number of branchial lamellae which form a more or less complete circuit interrupted only by the mouth and genital orifice and in Fryeria by the vent. The mouth parts consist of a minute poriform aperture leading into a narrow tube, which passes into a large mass of glands that impart a thick conical appearance to the anterior portion of the digestive tract (except in Phyllidiopsis). Behind this glandular mass the pharynx reemerges as a thin tube, which subsequently dilates and enters the liver. There is no exsertile proboscis as in Doridopsis. The vent is usually dorsal and perforates one of the posterior tubercles. Only in Fryeria is it under the mantle rim. There are no jaws, radula or buccal armature of any kind. The liver is not divided posteriorly. The verge is armed with rows of hooks. As in the Doridopsidae the dorsal wall of the pericardium is furnished with a series of lamellae, and the nervous system is much concentrated. A single blood-gland is present.

The Phyllidiadae are Dorids in virtue of their unbranched liver, their two spermatothecas, their retractile rhinophores, and their usually dorsal vent. The suctorial mouth, the concentrated nervous system and the so-called pericardial gill ally them to the Doridopsidae, but still the group Porostomata proposed for the two families by Bergh seems, as he himself admits, somewhat artificial, for the absence of the ordinary branchial rosette and the position of the branchial lamellae under the pallial margin separate the Phyllidiadae decisively from all Dorids except the Corambidae. From that family however they are equally decisively separated by the structure of the mouth parts and the general habitus.

The family is divided by Bergh into four genera, Phyllidia, Phyllidiella, Fryeria and Phyllidiopsis. Fryeria is sharply distinguished from the others, the vent not being dorsal but terminal and under the mantle rim. Phyllidiopsis is also well characterized, as the mouth parts resemble those of Doridopsis and the anterior part of the oral tube is not surrounded by a large glandular mass as in the other genera. The distinction between Phyllidia and Phyllidiella is less satisfactory. The former is said to have the dorsal tubercles arranged in longitudinal rows and the latter in groups or quincunxes. But there is much variety in respect of this arrangement. I have seen specimens of Phyllidiella nobilis in which the tubercles appear to be arranged in rows, and the present collection contains a specimen which has all the characters of Phyllidia varicosa, but in which there are only seven tubercles scattered irregularly on the back and certainly not arranged in lines. In dissecting a considerable number of specimens $\mathbf{I}$ have not been able to observe the difference noted by Bergh in the mouth parts; in Phyllidia forma tubi oralis glandulâ ptyalinâ obtecti symmetrica and in Phyllidiella asymmetrica. The remarkable Phyllidiopsis papilligera ${ }^{1}$, which has elongated papillae on the back, seems worthy to be the type of a new genus.

The Phyllidiadae are abundant in the Red Sea, Indian Ocean, the Philippines and Malay Archipelago, Polynesia and East Africa. They are not recorded from the more northern or southern parts of the Pacific, from the West Coast of America, North or South, from the Mediterranean or Atlantic, except Phyllidiopsis papilligera from the Gulf of Mexico. They seem therefore to be tropical forms and so little is known of the Nudibranchs of the equatorial Atlantic that it is probable they will be found there. They appear to be mainly littoral and inhabitants of coral reefs. Hardly anything is known of their manner of life,

1 Bergh, Bull. of the Mus. of Comp. Zoology of Hartard Cullege, xix. 3. 1890. Since writing the above, I have pro-

G. II, posed the genus Ceratophyllidia to include this form and another which I have discovered in East Africa. 
but from the extreme narrowness of the mouth pore and the oral tube it may be concluded that they live by suction, probably on animal juices. Most authors repeat the statement of Quoy and Gaimard that they are extremely sluggish and almost motionless. I cannot support this from my own observations, as Phyllidia varicosa when kept in a basin crept continually round and round as actively as any Dorid. Collingwood (Nudibranchiate Mollusca from the Eastern Seas, 1878) describes the spawn as a long irregular narrow ribbon of a whitish colour. When touched the skin of most Phyllidiadae secretes a liquid with a disagreeable smell,

\section{Gen. Phyllidia Cuv.}

Vent dorsal: tentacles free. Tubercles in centre of back arranged in longitudinal lines: Phyllidia sensu stricto. Tubercles in centre of back not arranged in lines but in groups: Phyllidiella.

\section{Phyllidia varicosa Lamarck.}

Back with at least three median lines of tubercles, more or less confluent and forming united ridges. Lateral tubercles varying, but generally two or three form an irregular line or ridge running in from the mantle edge to the central dorsal area. Form somewhat elongate; foot broad, darkish in colour, with a distinct black line down the middle. Four specimens from N. Male and Hulule, Maldives.

The colour of this species, as well as the disposition of the tubercles, seem very variable. The living animals, which I have seen at Zanzibar, were of a slaty-blue with brilliant orange tubercles. The specimens preserved in the present collection ${ }^{1}$ show three distinct varieties. First, one magnificent specimen from the Maldive Islands, $6 \mathrm{~cm}$. long; the smooth parts of the back are of a brilliant black, the projections lilac, but considerably varying in intensity. The median tubercles are fused into three distinct ridges, not uniting anteriorly or posteriorly, the tubercles appearing merely as peaks on the ridge. Lateral tubercles more or less fused into ridges, but irregular. Secondly, three specimens from the Maldive Islands from 3 to $4 \mathrm{~cm}$. in length. Tubercles and ridges much as in the previous variety: colour black and dirty white, probably representing blue and yellow in life. Thirdly, six specimens from Rotuma with much the same coloration as the last variety. The tubercles are not fused into ridges, but are sometimes quite separate, sometimes connected by a low black elevation. Five of the specimens show a tendency to have the tubercles arranged in seven longitudinal lines, one median and three lateral on each side. In one specimen this arrangement is quite symmetrical and complete. In the others the outer lateral rows are confused and indistinct. The sixth specimen, as already mentioned, is quite abnormal and has merely seven large and indistinctly compound tubercles scattered over the back, though its other characters appear to be those of the species in every respect.

\section{Phyllidia elegans B.}

One specimen from Kolumadulu Atoll, Maldives, $40 \mathrm{f}$. Form elongate, $2 \mathrm{~cm}$. long. Tentacles short and thick. Foot grey, with a thick black line down the centre. The ground colour of the back appears to be black but there are eleven patches of a lighter colour (in the preserved specimen dirty white), two median, one anterior, one posterior, four on the right side and three on the left. They are studded with low confluent tubercles, of 
very irregular shape. Those on the median patches are arranged in three not very distinct lines.

Gen. Fryeria Gray.

The shape of the animal and arrangement of the tubercles much as in Phyllidia but the vent is terminal, beneath the mantle edge, interrupting the branchial circuit.

\section{Fryeria Rüppellii Bergh.}

One specimen from the W. side of Fadifolu Atoll, Maldives, $70 \mathrm{f}$., $1.5 \mathrm{~cm}$. long. The form and mouth parts are much as in $P h$. varicosa. There are three longitudinal lines of tubercles on the back, two of which are fused into ridges, while those of the left-hand line are mostly separate from one another. There are also twelve lateral groups of ridges, running inwards from the mantle edge, one anterior, one posterior, and five on each side. The ground colour is blackish, and the tubercles and ridges dirty white, perhaps representing blue and yellow in life. The foot and the rhinophores are yellowish. The animal is undoubtedly a Fryeria, and allowing for the variability of markings so common in this family corresponds fairly well with Bergh's description of $F r$. Rüppellii.

\section{Gen. Phyllidiopsis Bergh.}

External appearance much as in Phyllidia but the tentacles are not free but attached along their entire length. The buccal apparatus resembles that of Doridopsis, that is to say it is not involved in a glandular mass. The oral pore gives entrance to a fairly wide chamber with laminated walls, into which opens the anterior portion of the alimentary tube which is cylindrical and receives two small salivary glands. Beneath it is a single gland probably corresponding to the ptyaline gland of other Nudibranchs.

\section{Phyllidiopsis striata?}

One specimen from Haddumati Atoll, Maldives, $40 \mathrm{f}$. Mouth parts as described above. The upper surface of the preserved specimen is blackish, with three white lines down the centre and two white patches one at each extremity. Near the edge are some irregular white markings. There are no tubercles or ridges. The foot and branchiae are somewhat lighter than the back. The form is long and narrow, $1.4 \mathrm{~cm}$. by $5 \mathrm{~mm}$. broad and very flat.

The markings of this specimen do not entirely correspond with Bergh's figure (Semper's Reisen, xvi. Plate 84, fig. 23) of an individual captured by Moebius at the Ile aux Fouquets, Mauritius, but the differences do not seem sufficient to warrant the creation of a new species.

\section{CLADOHEPATICA.}

The Nudibranchiata Cladohepatica are characterized by the liver being ramified or at least divided. The dorsal surface generally bears appendages, into which the ramifications of the liver pass. As a rule, well-developed mandibles and a radula are present. In the more specialized forms the latter is frequently reduced to a single row of teeth. There is no blood-gland and only one spermatotheca.

The numerically largest family of the Cladohepatica, which also shows all the characteristics of the division in a typical form, is that of the Aeolididae, but there are a number 
of other families obviously related to Tritonia. These mostly show an advance in the direction of the Aeolid type, but do not seem capable of arrangement in a progressive series culminating in Aeolis, as most of them have marked peculiarities of their own which are not found in Aeolis or other families. Such are the Lomanotidae, Dendronotidae, Scyllaeidae, Bornellidae, Tethymelibidae, Phylliroidae, Hedylidae and Pleurophyllidiadae. The first six of these are not represented in the present collections, which is somewhat remarkable, as Melibe, Scyllaeu and Bornella are all common in the Indo-Pacific.

\section{Fam. Pleurophyllidiadae.}

These are animals of a remarkable external appearance, which it is easier to recognize than describe. The form is elongate-oval or tongue-shaped. The back is somewhat coriaceous and bounded by a distinct mantle rim which extends beyond the foot. The dorsal surface is marked with longitudinal stripes or tubercles. The head is distinct and divided from the body by a space which may be conveniently called the neck. In front of this neck is a tentacular shield, the corners of which are usually drawn out into points. Behind the neck and immediately under the anterior margin of the mantle are two small perfoliate rhinophores. In front of them are often a wart (caruncula nuchalis) or several papillae. Except in Pleuroleura there is a branchial apparatus. Behind the head and underneath the mantle a cleft runs inwards in which are set a number of branchial lamellae, and the sides of the body underneath the mantle edge also bear another series of lamellae. The vent, genital and renal openings are all on the right side. Jaws strong and denticulate. Radula with a strong median tooth, cusped and denticulate. Laterals varying in form, denticulate or not. Liver much ramified, sending branches to the back and sides, which penetrate into the lateral lamellae. On the margin of the mantle are cnidopores, often visible to the naked eye, from which cnidae can be emitted. The reproductive system is unarmed.

The family appears to be cosmopolitan, but is recorded in especial abundance of species from the Indian Ocean. The systematic position of the Pleurophyllidiadae has given rise to some discussion. The older naturalists created a division, Inferobranchiata, to contain this family, the Phyllidiadae and Hypobranchiata (=Corambe), but it is now generally admitted that this association of forms is artificial and untenable. The presence of cnidae and the ramification of the liver are points of connection with the Aeolids, and Pelseneer (Recherches sur divers Opisthobranches, 1893) actually places the Pleurophyllidiadae among the Aeolidioidea. But their dentition allies them to the Tritonids, and they have distinctive peculiarities which separate them from both Aeolids and Tritonids. No connecting links have yet been discovered which throw light on their relations to other groups.

\section{Gen. Pleurophyllidia Meckel'}

Pleurophyllidia possesses lamellae under the mantle both at the sides and in a cleft. It is distinguished from the other genera which possess them by the following characters.

1 Bergh, Bidrag til en Monogr. af Pleurophyllidierne, 1866. Id. S. R. vi. 1874. Id. Beitrüge zur Kenntniss der Japanischen Nudibranchien, 1880. Id. Weitere Beit. zur Kenntniss der Pleurophyllidien, 1890. von Jhering, "Zur
Kenntniss der Nudib, der brasilianischen Küste," Jahrb. d. Malaco. Gesel. xmI. 1886. Eydoux et Souleyet (under name Diphyllidia, Voyage de la Bonite, 1841). 
The body is elongate. The mantle edge is continuous in front: the rhinophores are placed close together: on the neck in front of the rhinophores is a tubercle (caruncula nuchalis) or a series of papillae. Cnidocysts are present. The genera Linguella Blv. (= Sancara Bgh.) and Camarga Bergh are closely related and are perhaps only subgenera.

About 20 species of Pleurophyllidia are recorded from the N. Atlantic, Brazil, Mediterranean, Indian Ocean, E. Africa, Malay Archipelago, Polynesia, and California. They generally inhabit mud or sand and their peculiar shape seems correlated with a burrowing habit. I have observed $\mathrm{Pl}$. californica in captivity on the West Coast of $\mathrm{N}$. America. It buried itself in the sand with the head and tail exposed and bent upwards, so that the body assumed a crescent-like shape. A continuous current of water was kept passing from the front backwards under the mantle, the edge of which was apparently applied to the sides so as to form a tube over the lamellae. At night however the animals became very lively and moved rapidly round and round the glass dish in which they were confined.

The species of Pleurophyllidia are more distinct than is common among Nudibranchs. A useful synopsis will be found in von Jhering's paper cited above. They may be divided into the species which have tubercles on the back ( $P l$. pustulosa and marmorata), and the larger number which have longitudinal stripes. This latter class may again be divided into those which have papillae on the neck and those which have merely one more or less welldeveloped tubercle before the rhinophores. The several species have usually a characteristic dentition. Another point of difference is that some species have numerous separate lamellae at the sides of the body, while others have these lamellae united into three (or in $P l$. pallida into only one) continuous bands.

\section{Pl. gracilis Bgh.}

One mutilated specimen from Minikoi seems referable to this species, which was instituted by Bergh for two individuals found at Bombay (S.R. VI. p. 250). There was a large rent which had carried away much of the back, most of the left side and nearly all the internal organs. The length is $2.3 \mathrm{~cm}$. but the body was somewhat bent: the breadth $.8 \mathrm{~cm}$. What remained of the dorsal surface was almost colourless, with the remains of numerous yellowish longitudinal bands and occasional traces of brownish pigment. The neck was thickly studded with conical colourless papillae. The gills were fairly numerous and of different sizes. The lamellae on the right side of the body formed three continuous crinkled and sometimes indented lines. The uppermost extended nearly the whole length of the body: the second was shorter, and the third shorter still. The jaws were strong, the cutting edge armed with numerous rows of minute serrulations. The rhachidian tooth of the radula was as usual squarish: there were $7-8$ denticles on each side of the central cusp and sometimes two more near its point. The first lateral was also squarish, denticulate on the outer and bearing traces of minute serrulations on the inner edge. The subsequent laterals are denticulate on the outer edge only, and these denticulations decrease as the teeth are further from the centre. The last 10 or 15 teeth are simply hamate and the outermost small and rudimentary.

It is risky to identify a mutilated specimen, but the essential characters of $P l$. gracilis seem to be (1) numerous nuchal papillae, (2) small outermost teeth, and the present animal possesses both. 


\section{Gen. Pleuroleura Bgh. (= Dermatobranchus van Hasselt).}

The genus Pleuroleura, which is practically Pleurophyllidia without gills or side lamellae, is made by Prof. Bergh the type of a separate family. But as it differs from Pleurophyllidia only in the point mentioned and agrees with it in numerous distinctive peculiarities, it seems better to include both in one family, like Tethys and Melibe, of which Tethys has gills while Melibe has none ${ }^{2}$.

The history of the genus is somewhat remarkable. Van Hasselt described three species of Dermatobranchus in 1824. In 1874. Bergh created the genus Pleuroleura for a fourth species (ornata) and held that there was not sufficient evidence to identify it with Dermatobranchus as van Hasselt's specimens were lost. He subsequently discovered them in the Leyden Museum and in 1888 (l.c.) expressed the opinion that the identity was practically certain, but maintained the name Pleuroleura all the same. By the rule of priority there can be little doubt that the genus should be called Dermatobranchus, but that rule is not an end in itself but a means to an end, namely to find one name for one genus or species. When two names have approximately equal claims the earliest ought certainly to be taken. But when hardly anything is known of the animal under the earlier name and practically all our knowledge comes from descriptions published under the later name, it appears to me that the principle at stake is not sufficiently important to outweigh the inconvenience of resuscitating the original designation, a reference to which would give an enquirer very little information.

Pleuroleura strongly resembles Pleurophyllidia in appearance, but the known species seem somewhat smaller and have no warts or papillae on the neck. The tentacular shield is perhaps not always so distinct as in the other genus. The rhinophores are set close together, but emerge from separate short sheaths and bear longitudinal folds. The sides of the body bear no appendages, and there are no branchial elefts. The jaws, radula, digestive and reproductive apparatus are all similar to those of Pleurophyllidia. The mantle margin is perforated by enidopores.

Bergh gives as a family character of the Pleuroleuridae, Notaeum antice in nuchum transiens. If $\mathbf{I}$ am right in supposing this to mean that the mantle margin is not continuous in front but interrupted and that the dorsal surface and neck are consequently continuous $^{3}$, the character is not possessed by the specimen here examined and apparently not by Pleuroleura fortunata (Bergh, l.c. 1888, Pl. X. figs. 1 and 3).

Pleuroleura is recorded hitherto only from the Philippines, the Malay Archipelago, East Africa, and Spitzbergen". Nothing whatever is known of its habits.

29. Pleuroleura striata (van Hasselt).

Mr Gardiner furnished me with a single specimen found by the Skeat Expedition in Pulau Bidang. It is externally well preserved but very hard and brittle. The form is rather

1 van Hasselt, Allg. Konst en letterbode, 1824, 2. 3. 4. Bergh, S. R. vi. p. 276 ff. 1874. Iu. "Die Pleuroleuriden," Zool. Jahrbïcher: Abth. für Systematik, 3 Band, 3 Heft, Jena, 1888.

2 I have since discotered in East Africa a form which I call Pleurophyllidiella and which seems to be a connecting link between Pleurophyllidia and Pleuroleura inasmuch as it

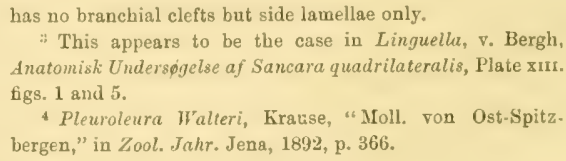
Anatomisk Underspgelse af Sancara quadrilateralis, Plste xir. figs. 1 and 5 .

4 Pleuroleura Walteri, Kracse, "Moll. von Ost-Spitzbergen," in Zool. Jchr. Jena, 1892, p. 366. 
short and broad, $95 \mathrm{~mm}$. long, $6 \mathrm{~mm}$. broad across the back: foot $3 \mathrm{~mm}$. broad. The colour of the dorsal surface and of the tentacular shield is blackish. Down the middle of the back runs one fairly straight line. On each side of it are eleven or twelve other lines, not parallel to it, but arising with it at a point behind the rhinophores and going off towards the mantle edge at various angles in a posterior direction. All these lines as well as the borders of the mantle of the tentacular shield are raised, very distinct, and of a whitish-yellow, which contrasts strongly with the ground colour. Numerous cnidopores were distinctly visible on the mantle edge. The anterior corners of the foot are produced. The anterior mantle edge is continuous, but deeply notched above the rhinophores.

The jaws are as usual in the genus, with several (at least six) rows of denticles on the cutting edge. The radula of about 20 fully developed rows. The rhachidian tooth of the usual shape with a long central cusp and about 6 denticles on each side. The first lateral squarish, with about 5 denticles on the outer side. The other laterals were $9-11$ in number in the various rows and, as far as I could see, not denticulate. The inner are broad and somewhat clumsily shaped hooks: the outer narrower and of the ordinary hamate type. The intestines were much hardened and little could be made out of them, but the ramifications of the liver seemed discernible.

Van Hasselt's description of his D. striatus is as follows". "Corpore nigro, tlavo fuscoque variegatissimo: dorso mucoso sulcato, sulcis simplicibus longitudinalibus, rectis parallelis: capitis et pedis margine flavo: tentaculis apice nigris: pallio antice emarginato. Long. pallii 0.011: lat. 0-003. Corporis totius 0-1. Hab. Anjer-baie (Sunda Strait) vulgaris." This description seems applicable to the present animal except that the dorsal stripes are not strictly speaking straight and parallel. A comparison of several specimens might show some variation in this respect, and as van Hasselt says the animal is common they may be found in the future. Meanwhile, I see no reason why this animal should not bear the name striata.

\section{Fam. Dotonidae ${ }^{2}$.}

The Dotonidae are closely allied to the Aeolididae in both external and internal structure. The rhinophores however are simple and retractile into wide cup-shaped sheaths. The cerata are arranged in two rows and as a rule are large, ovate, and at least some of them compound. They contain ample and many lobed hepatic ramifications. As a rule there are no anterior tentacles, but a rounded frontal veil. The vent is latero-dorsal. Cnidocysts are absent. The jaws are weak and not denticulate. The radula uniseriate (as a rule): the teeth with a central cusp and more or less distinct lateral denticles. The reproductive system is unarmed.

The Dotonidae as a family are distinguished from the Aeolididae by one character only-the rhinophore sheaths. The genus Doto is also marked by its ovate compound cerata and its frontal veil, but a formation of the head analogous to the latter is also found in Embletonia, and the nodules on the cerata of Capellinia and Proctonotus seem a step in the direction of the composite condition. The other genera of the family are less well known and differ from Doto chiefly in having some or all of the cerata simple and not compound.

1 I quote from Bergh's quotation S. R. vI. p. 277, not Porto di Genova, 1881. Vayssière, Recherches sur les 110 . having access here (East Africa) to the original work.

lusques Opisthobranches de Marseilles, 1888. Bergh, Beitr.

${ }^{2}$ A. and H., Brit. Nud. MLoll. Trinchese, deolididae del

z. Kenntniss der Aeolidiaden, VI. Id. S. R. xvI. 
The Dotonidae are mostly minute animals and the forms described come chiefly from the northern Atlantic and Mediterranean. At least one species however comes from East Africa, and the family is probably cosmopolitan.

30. Doto indica Bgh.?

One small specimen from Minikoi in the Laccadives. Length $7 \mathrm{~mm}$., breadth $3 \mathrm{~mm}$., colour uniform dirty yellow. There were apparently five pairs of cerata on the back, but all have fallen off. One, however, which doubtless belonged to this specimen, was found in the same bottle. It was fusiform and bore three rings of tubercles. The frontal veil was ample and expanded at the side into lappets. The rhinophore sheaths with an uneven indented margin: on the outside of each is an undulated membranous process. The foot rounded in front, the tail short. The jaws weak. The radula uniseriate. The teeth of the form usual in the genus. The central cusp not very prominent, with $3-5$ irregular lateral denticulations.

There is, strictly speaking, no proof that this specimen belongs to the genus Doto, since the cerata are not preserved, but I think it probable that it is Bergh's Doto indica (S. R. XVI. p. 795) recorded from Mauritius. The identification is supported by the shape of the rhinophore sheaths and the membranous process.

\section{Fam. Aeolididae.}

The Aeolids are limaciform animals with tentacles ${ }^{1}$, rhinophores either simple or perfoliate but always non-retractile and without sheaths, and simple dorsal cerata containing ramifications of the liver. Mandibles are always present, and the radula has never more than one or three teeth in a row.

The Aeolids are the largest family of the Cladohepatica and comprise about forty genera. It is therefore somewhat remarkable that they should be represented in the present collection by only one small specimen. It has often been noticed that they are far more abundant in Northern than in tropical waters-or at least in collections from the North than in those from the tropies-but still the proportion here is unusually small. My own experience after collecting continuously for a year in East Africa and Zanzibar is that the genera of Aeolids are numerous but the individuals few and hard to get. Dorids can be found under almost every stone on a coral reef, but Aeolids are obtained either in fairly deep water or among seaweed where they are not easily seen.

\section{Gen. Phidiana Gray²}

The characters of the genus are as follows. Body elongate and slender. Rhinophores perfoliate. Foot rounded or truncated in front. The masticatory edge bears a single row of denticles. Radula uniseriate. Verge armed with a hook.

Phidiana is one of the many genera of Aeolididae, which have an elongate body and perfoliate rhinophores. It is separated from most of them by the fact that the anterior

1 'The strange Pseudovermis Kovalewski (Mém. de l'Ac. de S. Pêt. Ser. vint. vol. xur. no, 4, 1901) is described as having neither tentacles, rhinophores, nor cerata.
${ }^{2}$ A. and H., Notes on a Coll. of Nudibr. Moll. made in India. Bergh, Beitr. $z$. Kenntniss der Aeolidiaden, $x$ and $\mathrm{vt.}$ Id. Opisthobranchier der Sammlung, Plate. 
margin of the foot is round or square and not produced into tentacular prolongations. In its external characters it closely approaches Speirilla but differs in the jaws, teeth, and reproductive organs. The genus is recorded from the Indian Ocean and several parts of the Pacific, including the West Coast of South America, and from the Atlantic.

31. Phidiana unilineata (A. and $\mathbf{H}$.)?

One small specimen from Fadifolu Atoll, Maldives, 25 f., imperfectly preserved. Length $9 \mathrm{~mm}$., breadth $2.5 \mathrm{~mm}$, Colour uniform yellowish-white. Cerata partly lost, but apparently arranged in seven indistinct oblique rows, leaving only a narrow space bare in the middle of the back. Foot rounded in front. Tentacles long: rhinophores much shorter. Jaws long and narrow, with a single row of rather distinct denticles. The radula consisting of about 25 teeth, bearing from 5 to 8 lateral denticles, two or three of which are not on the basal portion but on the sides of the cusp itself. The penial hook was small but appeared to be shaped as in Bergh's figures of $P h$. selencae.

This specimen perhaps belongs to A. and H.'s Ph. unilineata $\left(l . c_{0}\right)$ in view of the habitat and of the fact that there is nothing in its external or internal characters which conflicts with the identification. Still, the anatomical details given by $\mathrm{A}$. and $\mathrm{H}$. do not afford many specific characters, and all trace of the colour has disappeared in this specimen. It is therefore impossible to be sure of the identification.

\section{Fam. Janidae Bgh.}

The Janidae closely resemble the true Aeolids, but are distinguished externally by the cerata extending not only all round the sides and end of the back as usual but also in front of the rhinophores along the anterior mantle margin. This character is accompanied by a corresponding arrangement of the hepatic ramifications which supply the cerata. Further, in most members of the family the radula is multiseriate; there is a crest between the rhinophores (except in Proctonotus) and the vent is median and dorsal. The genus represented in the present collection, Madrella, does not possess these peculiarities and serves to connect such forms as Janus and Proctonotus with the ordinary Aeolids. The radula has only three teeth in a row, and the vent is lateral, not dorsal. In all the known genera the reproductive system is unarmed and there are no cnidocysts.

\section{Gen. Madrella A, and H.}

\section{Madrella ferruginosa $\mathrm{A}$. and $\mathrm{H}$.}

One small and immature specimen obtained off a large Antedon laevissima from S. Nilandu Atoll, Maldives, $30 \mathrm{f}$. Length $6 \mathrm{~mm}$, breadth $4 \mathrm{~mm}$. The animal is oval and flat, of a deep copper colour. Round the dorsal margin is set a not very thick band of cerata and on the central area of the notaeum are a few scattered papillae. Both the mantle edge and the foot are wide, but between them there is a deep groove. The vent is at the posterior and the generative opening at the anterior end of the right side. The form of the rhinophores is unusual: they are not perfoliate, but there is a circle of papillae

1 A. and H., Monograph of Brit. Nud. Moll. Id. Notice of a Coll. of Nud. Moll. made in India. Bergh, Beiträge z. G. II.
Kennt. d. deolidiaden, I. 1873. Id. Report on Challenger Nud. Trinchese, Aeolididae del porto di Genova, 1881. 
round the club much as in Tritonia. The mantle overhangs the head: there are no anterior tentacles, but the head is broad and crescent-shaped with produced ends. The mouth is ventral: the front of the foot square, without tentacular prolongations. The jaws are large and not denticulate. The middle tooth of the radula has a central cusp with $7-8$ denticles on either side, and the laterals are denticulate on the inner margin. The ganglia of the central nervous system are distinct.

This genus is recorded from the Indian Ocean (A. and H.) and Zanzibar, where I have captured many specimens. The external characters of the animal vary somewhat with the size, that is presumably with age. The smaller specimens are as described above. The larger have many more cerata, and the papillae in the centre of the back (which apparently do not contain hepatic ramifications) pass up between the rhinophores, forming a sort of rudimentary crest. They have also a white patch between the rhinophores, which is absent in the smaller individuals. When kept in eaptivity Madrella pours forth a peculiar ferruginous secretion, which discolours the water round. It appears to proceed from the whole surface of the body, not from any one gland, and is of much the same colour as the skin, so that the creature looks as if it were dissolving.

There are four more families of the Cladohepatica which are sometimes classed together as the tribe Elysioidea (Pelseneer) and sometimes united with Oxynoe and Lobiger as the Ascoglossa (Bergh) or Saccoglossa (v. Jhering). They are (1) Hermaeidae, much like Aeolids externally but without oral tentacles. (2) Phyllobranchidae, with peculiar flat leaf-like cerata. (3) Elysiadae (including Placobranchus), with no cerata, but lateral expansions or wings. (4) Limapontiadae, small forms with no cerata, wings or appendages, and often with neither tentacles nor rhinophores. All these families have a ramified liver and also the following anatomical characters. (1) There are no jaws. The radula consists of a single series of teeth, each fitting into the next. The front teeth instead of becoming worn away and destroyed fall into a peculiar pouch in which they are preserved. This form of radula may be conveniently termed "ascoglossan." (2) In the nervous system the cerebral and pleural ganglia are fused, the pedal ganglia are approximated and the visceral commissure bears three ganglia (but in Limapontia only two). (3) The reproductive organs, though imperfectly understood, are extremely complicated, provided with aecessory glands and ramified throughout the body. The male and female orifices are far apart, and there are generally two of the latter.

\section{Fam. Hermaeidae ${ }^{1}$.}

The Hermaeidae closely resemble Aeolids and can hardly be distinguished by any external character except that the oral tentacles are not developed. Stiliger Mariae was described by its discoverers, Meyer and Möbius, as an Embletonia. Internally, the family is distinguished from the Aeolids by the following characters: (1) Jaws are absent and the radula is ascoglossan, (2) the nervous system is formed of seven ganglia, (3) the hepatic system is somewhat as in Fiona, there being no posterior hepatic trunk: the lateral branches are often much ramified in the cerata and dorsal integuments. The vent as a rule is dorsal and anterior. (4) The genital apparatus is much complicated by the presence of accessory

1 Alder and Hancock, Brit. Nudibr. Mollusca. Bergh, Golfe de Marseille, 1888. Pelseneer, Recherches sur divers Beitr. zur Kennt. der deolidiaden, rv., v. and vin. Id. S. R. Opisthobranches, 1893:

Heft Ivr. Vayssière, Recherches sur les Moll. Opisth. du 
glands, which are often diffused and ramified throughout the body. But the details of structure seem to vary in the different genera and even species.

\section{Gen. Hermaea Lov.}

Small animals resembling Aeolids in shape but without oral tentacles. Foot long and narrow with round expanded anterior corners. Rhinophores canaliculate. Cerata elongate or slightly fusiform, arranged somewhat irregularly at the sides of the back. Hepatic trunks elaborately ramified in the cerata and dorsal integuments. Anal papilla large, medio-dorsal. Genital orifices distinct, at base of rhinophores. Albumen-gland diffused and in some species at least ramified in cerata. Verge generally armed with a spine ${ }^{1}$.

\section{Hermaea? minor B.}

One specimen from the Laccadives, Minikoi. Length $3 \mathrm{~mm}$.: breadth $4 \mathrm{~mm}$. On the label is written "Green nudibranch": the preserved specimen is of the usual dirty yellow. The centre of the back bears no cerata, but on the sides are about 20 rows containing 2 to 4 papillae each. The cerata are elongate, fusiform, and besides the hepatic ramifications contain other glands, the openings of which form tubercles on the exterior surface. The teeth appeared to be 11 in all, exclusive of those in the bag, transparent, and very narrow. I could not discover more than two genital openings, and there appears to be no hook or spine on the verge.

I think this specimen probably belongs to a species which I have found abundantly at Zanzibar, and which is perhaps identical with Bergh's $H$. minor from Mauritius. The colour does not quite correspond with the descriptions of Bergh's two specimens, which are said to have had the cerata tipped with red. My specimens varied from brown to white, and in captivity tended to assume the latter colour. The prevailing tint of the newlycaptured animals was however green, the body walls being pale translucent green, and the hepatic ramifications dark bright green. The eyes were distinct on a yellow spot. The cerata were not tipped with red, but some specimens had splashes of carmine on the back. I append a drawing made from life by Mr Crossland (fig. 9).

It is possible that these specimens may after all not be identical with $H$. minor, for they had never more than 4 cerata in a row, whereas the latter is said to have as many as 10 .

\section{Fam. Phyllobranchidae ${ }^{2}$.}

The animals belonging to this family can easily be recognised by their flat shape and leaf-like cerata.

There is a small frontal veil, above which rise two bifid canaliculate rhinophores. Small canaliculate oval tentacles are generally present. The sides of the back are covered with thick rows of large, flat, leaf-like cerata, which generally, if not always, contain hepatic diverticula. Anal papilla large, dorsal, or lateral. No cnidocysts. Genital apertures two: $\delta$ on

\footnotetext{
1 The genus has been subdivided as follows: (1) Hermaea sens. stric. Teeth smooth, liver ramified within cerata: vent median dorsal. (2) Hermaeina Trin. Teeth denticulate on lower edge. (3) Placida Trin. Hepatic lobes not ramified within cerata. (4) Hermaeopsis A. da Costa. Vent lateral.
}

Pelseneer has also pointed out remarkable differences between Hermaea dendritica and Hermaea bifida.

${ }^{2}$ A. and H., Notes on a Coll. of Nud. Moll. made in India. Bergh, S. R. II., xvi. Beitr. zur Kennt, der Aeolid, Iv. Pelseneer, Recherches sur divers Opisthobranches, p. 51. 
right side of head and $q$ behind it. No jaws: a gizzard attached to the buccal mass: radula ascoglossan: teeth generally denticulate: only a very few functional at a time. Genital apparatus exceedingly complicated.

There are three genera (1) Phyllobranchus A. and H. Foot undivided: teeth denticulate, forming a spiral in the radula bag. Gizzard long. Vent lateral. Verge unarmed. Recorded from the tropical parts of the Pacific and Indian Ocean and from the Caribbean Sea. (2) Cyerce B. Foot transversely divided: teeth denticulate, forming an irregular heap in bag. Gizzard short. Vent dorsal. Verge armed. Recorded from the tropical Pacific and Indian Ocean. (3) Caliphylla Da Costa. Foot undivided: no oral denticles: teeth not denticulate, forming a spiral in the bag. Vent latero-dorsal. Verge unarmed. Two species from the Mediterranean. It is possible that there may be really a fourth genus, since A. and $H$. describe their $P h$. orientalis as having cerata round the head, apparently like Janus. Bergh thinks this is merely a mistake.

The present collection contains two specimens referable to Cyerce. There is some doubt as to the relations of the cerata, and the liver in this genus. Pelseneer $(l . c$. speaking of Cyerce Jheringi, of which I have not seen a detailed description) states that the liver is entirely contained in the visceral mass, and does not extend into the cerata. Bergh (1871) seems satisfied that the papillae do contain hepatic ramifications, though he admits that the structure of the liver is obscure, and that the "hyaline folliculi" in the cerata can only doubtfully be homologised with the contents of the cerata of Phyllobranchus. The present specimens throw no light on the matter.

\section{Cyerce nigra $\mathrm{B}$.}

Two specimens from Minikoi, which had entirely lost their cerata, only one small detached leaflet being found with them. Apart from this the animals were well preserved externally, but the internal organs were hardened into a uniform mass, in which nothing could be distinguished. What remained of the colour was black with reddish-yellow spots, and lines consisting of a border round the foot, another round the mantle edge, and two lines behind the moderately large pericardial prominence. The body was very plump. The length of the largest specimen $2.1 \mathrm{~cm}$., the breadth $1 \mathrm{~cm}$., the height $9 \mathrm{~mm}$. The oval tentacles small, canaliculate and continuous with the ends of the moderately-large frontal veil, from which a sort of ridge runs down to the anterior margin of the foot. The foot is broad, and very deeply grooved in front. The transverse division of the under surface is quite distinct, but not very deep. The part of the foot before the division is $5 \mathrm{~mm}$. long. The anal papilla in front of the pericardium large and high. The rhinophores strong, bifid and canaliculate. Of the internal organs nothing could be ascertained except that the teeth are long and denticulate. The single small detached papilla, which was preserved, was black, with a reddish-yellow margin and spots of the same colour on both sides. It may therefore be concluded that at least one and probably both the specimens belonged to the variety ocellata $B$.

'This collection of Nudibranchs does not in any way indicate that the fauna of the Maldive and Laccadive Islands contains any element foreign to the rest of the Indo-Pacific. All the genera except the very doubtful Staurodoris are typical of this area, and all the species, which are not new, are more or less certainly recorded from it. Two points however are worthy of notice. Firstly, a large number of common and characteristic Indo-Pacific 



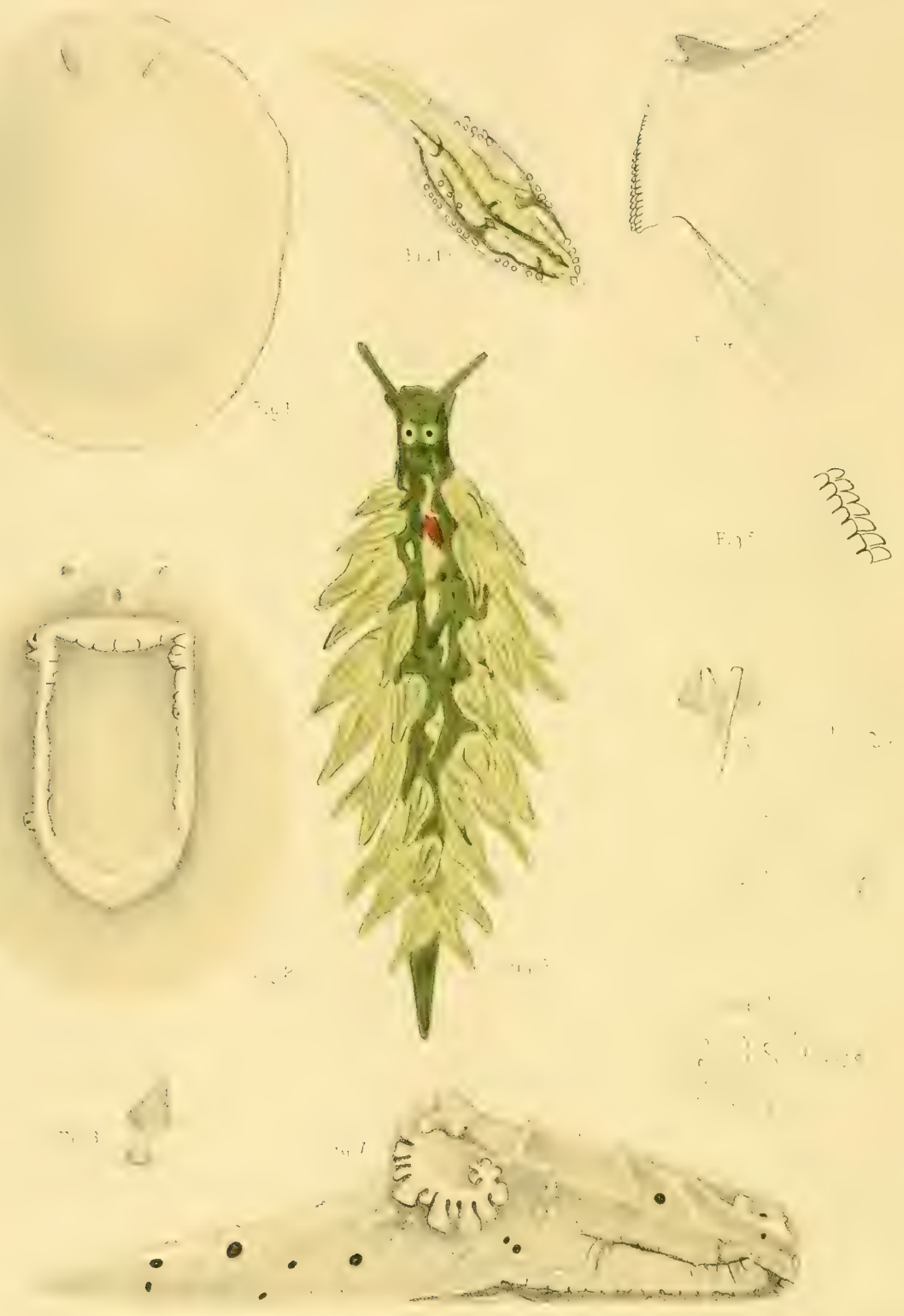


genera are absent, such as Asteronotus, Kentrodoris, Casella, Melibe, Bornella, and Placobranchus $^{1}$, and secondly, the specimens are on an average considerably smaller than those recorded from the Philippines, India, or East Africa. This latter feature is also noticeable in the Tectibranchs (particularly the Pleurobranchoids) collected by Mr Gardiner, and I have observed it in the specimens collected by myself at Samoa. It would seem as if the marine fauna of small islands which have never been connected with a continent is less both in number and size than that of the mainland and its adjacent islands. I am not however sure that a thorough examination of the Polynesian fauna would bear out this conclusion, particularly as regards the number of genera and species.

\section{EXPLANATION OF PLATE XXXII.}

Doridomorpha gardineri nov. gen., nov. sp.

1. Dorsal view of a preserved specimen. 2. Ventral riew of the same. 3. Rhinophore pulled out of its pocket after removal of mantle. 4. Mandible. 5. Edge of mandible more highly magnified. 6. Teeth $(a)$ central, $(b)$ first lateral, $(c)$ from centre of row, and $(d)$ outermost.

Notodoris gardineri nov. sp.

7. Animal preserved in spirit about twice the natural size. 8. One lobe of the branchial valve.

Hermaea minor Bergh.

9. Living animal. $\times 10.10$. One of the cerata. $\times 30$.

1 These genera are recorded from the Philippines, Indian Archipelago, and South Seas, and I have found them all abundantly on the East Coast of Africa. 


\title{
MARINE CRUSTACEANS.
}

\section{THE SPONGE-CRABS (DROMIACEA).}

\author{
By L. A. Borradaile, M.A., Lecturer in Natural Sciences at Selwyn \\ College, Cambridge.
}

(With Plate XXXIII.)

ThE members of the Dromiacea are separated from the other groups of Brachyura by a number of characters, most of which are primitive and show that they are nearer than the rest of the Crabs to the macrurous ancestors from which the tribe arose. The most important of these features are: the presence of a pair of vestigial limbs on the first abdominal segment of the female, and often on the sixth in both sexes ${ }^{1}$, the epipodites, which are often found on one or more of the pairs of legs, the number of gills, which is usually large, the more or less square shape of the mouth, the large, usually free, basal joint of the antennal stalk, and the often incomplete orbits. To these must be added a highly characteristic, but not primitive, feature-the small size, dorsal position, and usually prehensile shape of one or both of the hinder pairs of legs (Pl. XXXIII).

This conformation of the hinder legs is connected with the most characteristic peculiarity in the habits of the Dromiacea. Most of them are in the habit of holding over their backs masses of some sessile animal-usually a sponge, but at times an ascidian, an alcyonarian, or even half a bivalve shell, on which a sea-anemone is often seated-by means of which they are completely hidden?

The most important part of the prehensile apparatus by which this is accomplished is the last joint of the legs of the hinder two pairs. This joint is sharp and hooked in most genera, and is buried deeply in the substance of the sponge. There is often also a thorn on the propodite, which makes with the last joint a more or less perfect chela (Pl. XXXIII, figs. $3 b, 4 b$ ). In many cases, at least, the crab does not confine its choice to one species of sponge. Whether the latter is at first merely a fragment broken off from a larger mass, or is always a whole colony, perhaps specially adapted to this life and not found elsewhere, is not known, but in any case the initiative in forming the partnership must come from

I Bouvier (Bull. Soc. Philomath. Paris, 1896) throws doubt on the correctness of the view which homologises the structures on this segment in Dromiidae with the last pair of limbs

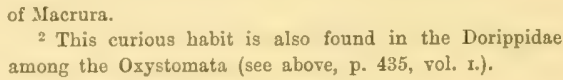


the crab, for the sponge is quite free, and is merely held in position by its host. On the other hand, it must live thus for some time, and grow meanwhile, for it will always be found to have a deep hollow on the underside, closely fitting the back of the crab. No doubt this helps to keep it from slipping, as does also, perhaps, the hairy or woolly coat with which the decapod is usually provided. The hairs of this coat are often very diverse and complicated in shape-pointed or clubbed, feathered or simple (Pl. XXXIII, figs. $1 b-d$, $\left.3 c-f^{1}\right)$-though it is hard to see what end these can serve.

Of the two groups into which the Dromiacea are subdivided, the Homolidea are principally deep-water forms, and were not met with by the expedition. The Dromiidea, on the other hand, are fairly common on the reef, where they are to be found in all possible positions, holding on tightly with the sharp tips of their very mobile walking-legs (Pl. XXXIII). In their habits they are slow and heavy, trusting rather to concealment than to active avoidance and defence.

In the systematy of the Dromiidea much use is made of the sternal grooves of the female. These are a pair of furrows, one on each side, which run longitudinally over the thoracic sternites of the female, beginning on the hindermost and ending on that which corresponds to the first, second, or third pair of legs. Their forward ends may be raised on knobs, and are either wide apart, side by side but not meeting, or curving round to meet. They correspond closely with the position in which the long abdominal limbs of the male are carried, and are therefore probably used for some sexual purpose. Other features of systematic importance in this group are: the presence or absence of epipodites, the proportions of the body and the extent to which furrows are present on the back, dividing it into regions, the shape and relative length of the legs, etc. For specific distinctions, the shape, number and arrangement of the teeth on the front, anterolateral edge, underside of the body, and legs are chiefly used.

The following keys, introduced here in performance of the promise given in the article on the classification of the crabs (p. 426 above), will enable members of the legions and families of the Dromiacea to be recognised:

Key to the legions of the Dromiacea.

I. Sternum of female with longitudinal grooves. Vestiges of 6 th pair of abdominal limbs usually present. Gills $14-20$ on each side. Eyes usually completely sheltered by orbits when retracted. No lineae anomuricae. Dromiidea.

II. Sternum of female without longitudinal grooves. No restiges of 6 th pair of abdominal limbs. Gills 8-14 on each side. Eyes incompletely or not at all sheltered by orbits when withdrawn against the body. Lineae anomuricae usually present. Homolidea.

\section{Key to the families of the Dromiidea.}

I. No vestige of 6th abdominal limb, Carapace longer than broad, with ill-marked side edge. [First three legs with epipodites, fourth and fifth small, subdorsal, and prehensile.] Homolodromiidae.

\footnotetext{
1 For the investigation of this interesting point I am indebted to Mr Edwin Wilson's enthusiasm for the subject.
} 
II. A vestige of the 6th abdominal limb present [except in Hypoconcha, where also no epipodites]. Carapace usually not longer than broad, with well-marked side edge.

A. An epipodite on the first leg (cheliped) only or on none. Fourth and fifth legs small, subdorsal, and usually prehensile. Dromiidae.

B. Epipodites on all the first three pairs of legs. Fifth leg only small and subdorsal. Dynomenidae.

Key to the families of the Homolidea.

I. Gills 13 or 14 on each side. Epipodites on first one or three pairs of legs. First joint of eyestalk not much longer than second. Homolidae.

II. Gills 8 on each side. Epipodites not found on any legs. First joint of eyestalk much longer than second. Latreillidae.

Of the seven species in the present collection three are new, and all the remainder are already recorded from the Indian region. Many of the specimens bear sponges, but, as the species of these have not been determined, no further allusion will be made to them.

\section{Family Dromiidae.}

Generic names in this family are used here in the sense in which they have lately been defined by the writer (Ann. Mag. Nat. Hist. (7) xi, p. 298).

Genus Dromia Fabr., 1798.

1. Dromia rumphi Fabr., 1798 (Pl. XXXIII, fig. 1). Alcock, v. p. 137.

In young specimens, such as the one figured on Pl. XXXIII, there is a distinct tooth at the inner orbital angle, and the teeth on the wrist are also much sharper. The species was dredged in Haddumati Atoll in 40 fathoms.

Genus Dromidiopsis Borradaile, 1900.

2. Dromidiopsis australiensis (Hasw.), 1882.

Dromia (Dromidia) australiensis, Alcock, Cat. Ind. Decap. Crust. Ind. Mus. I. i. p. 76 (1901).

Var. bidens n. Specimens of the variety described by de Man [Zool. Jahrb. Syst. IX. p. 372], with only two of the three teeth behind the orbital angle in the type, were taken in the Maldives. I propose to name this variety bidens. A specimen from Fiji in the Cambridge Museum belongs to the same variety, but there is another Rotuman specimen, and one from Fiji, which have only one of the three side teeth remaining. This I propose to call var. unidens.

Taken on the reef at Hulule, Male Atoll, and dredged in 25 fathoms in South Nilandu Atoll.

3. Dromidiopsis tridentatus n. sp. (Pl. XXXIII, fig. 2).

Diagnosis: "A Dromidiopsis whose carapace is slightly longer than broad; the body and limbs smooth, covered with a fine down; the front triangular with the tip just visible from above, deeply grooved and with low swellings of the sides to form a pair of indistinct teeth; no trace of a tooth at the upper, inner orbital angle, the outer orbital angle strong, 
but not foming a tooth, a deep cleft on the orbital edge just below the outer orbital angle; three small blunt knobs on the anterolateral edge behind the outer orbital angle, two broad notches behind these teeth corresponding to the branchial groove (which is present) and probably to the cervical groove (which is absent); the 2nd and 3rd legs with strong, hooked end-joints, armed with a few thorns underneath, the fourth leg short, subchelate, and the fifth leg as long as the third, also subchelate."

Length: $11 \mathrm{~mm}$. Breadth: $10 \mathrm{~mm}$. Colour in spirit: pale yellow.

One female from Hulule, Male Atoll.

This species much resembles Dromidiopsis australiensis, but may be distinguished by the more distant and more outstanding teeth of the anterolateral edge, which in $D$. australiensis are broader at their base, by the sternal grooves of the female, which meet and end on the segment of the first walking-leg, and by the presence of a spine on the hinder edge of the propodite of the fifth leg. The cheliped has an epipodite.

Genus Dromides Borradaile, 1903.

For a diagnosis of this genus see the paper cited on p. 576 above.

4. Dromides hilgendorfi (de Man), 1887. Alcock, v. p. $145^{1}$.

Dredged in Suvadiva and South Nilandu Atolls, in 30 and 19 fathoms respectively.

Genus Cryptodromia Stimps., 1858.

5. Cryptodromia bullifera Alc., 1898. Alcock, v. p. 143.

Dredged in South Nilandu Atoll in 30 fathoms.

6. Cryptodromia hirsuta n. sp. (Pl. XXXIII, fig. 3).

Diagnosis: "A Cryptodromia with the body broader than long, smooth and hairy, the regions indistinct; the front prominent and bearing three fairly sharp teeth, of which the middle one is somewhat longer than those at the sides; the upper rim of the orbit finely beaded and bearing a tooth near its inner end, a tooth at the outer and another at the lower inner orbital angle; one tooth on the anterolateral edge and a low swelling behind this tooth, a small blunt tooth behind the branchial groove; and a strong conical subhepatic tooth; the carpopodite and propodite of the cheliped and second two pairs of legs knobbed, but without sharp thorns, and the last two pairs of legs short, subequal, and feebly chelate."

Length: $7 \mathrm{~mm}$. Breadth: $8 \mathrm{~mm}$. Colour in spirit: dull yellow, legs often orange.

The sternal grooves of the female end widely apart on the line between the sternites of the first and second walking-legs. There is no epipodite on the cheliped.

Taken on the reef in Minikoi and Male Atolls.

1 For the principle on which references are given in this series of papers see above, Pt. I. p. 192. Alcock's paper on

G. II.
Indian Dromiacea here referred to appeared in Journ. As. Soc. Bengal, Lxvıt. ii. (1899). 


\section{Genus Cryptodromiopsis Borradaile, 1903.}

For a diagnosis of this genus see the paper cited on p. 576 above.

7. Cryptodromiopsis tridens n. sp. (Pl. XXXIII, fig. 4).

Diagnosis: "A Cryptodromiopsis with the body broader than long, smooth and hairy, the grooves between the regions almost wholly lost, a smooth, naked, oval boss on each side of the cardiac region; the three teeth of the front of almost equal length and all sharp; teeth at the upper and lower inner, and at the outer orbital angles; two anterolateral teeth but no tooth at the branchial groove; a subhepatic tooth and a prominent angle of the mouth; the fingers of the chelipeds gaping and two blunt teeth on the wrist; a thorn at the end of the carpopodite in the first two pairs of walking-legs, and another at the end of the propodite in the last two pairs, making with the end-joint a strong chela."

Length: $6 \mathrm{~mm}$. Breadth: $8 \mathrm{~mm}$. Colour in spirit: dull yellow.

There is no epipodite on the cheliped, and the sternal grooves of the female end side by side on the cheliped segment without actually meeting.

Taken on the reef in Male and Minikoi Atolls.

\section{EXPLANATION OF PLATE XXXIII.}

Frg. 1. Dromia rumphi, young individual; $a$. whole animal, $b$. one of the long hairs on the back; $c, d$. short hairs on the back.

FIG. 2. Dromidiopsis tridentatus; $a$. whole animal, from above. The carapace is rather longer than is shown in the figure.

Fig. 3. Cryptodromia hirsuta; $a$. whole animal, $b$. end of the fifth leg, $c$. one of the hairs on the ridge overhanging the furrow just behind the front, $d$. small hairs on the back, e. long hair on the back, $f$. hairs on the legs.

Fig. 4. Cryptodromiopsis tridens; $a$. whole animal, $b$. end of the fifth leg. 

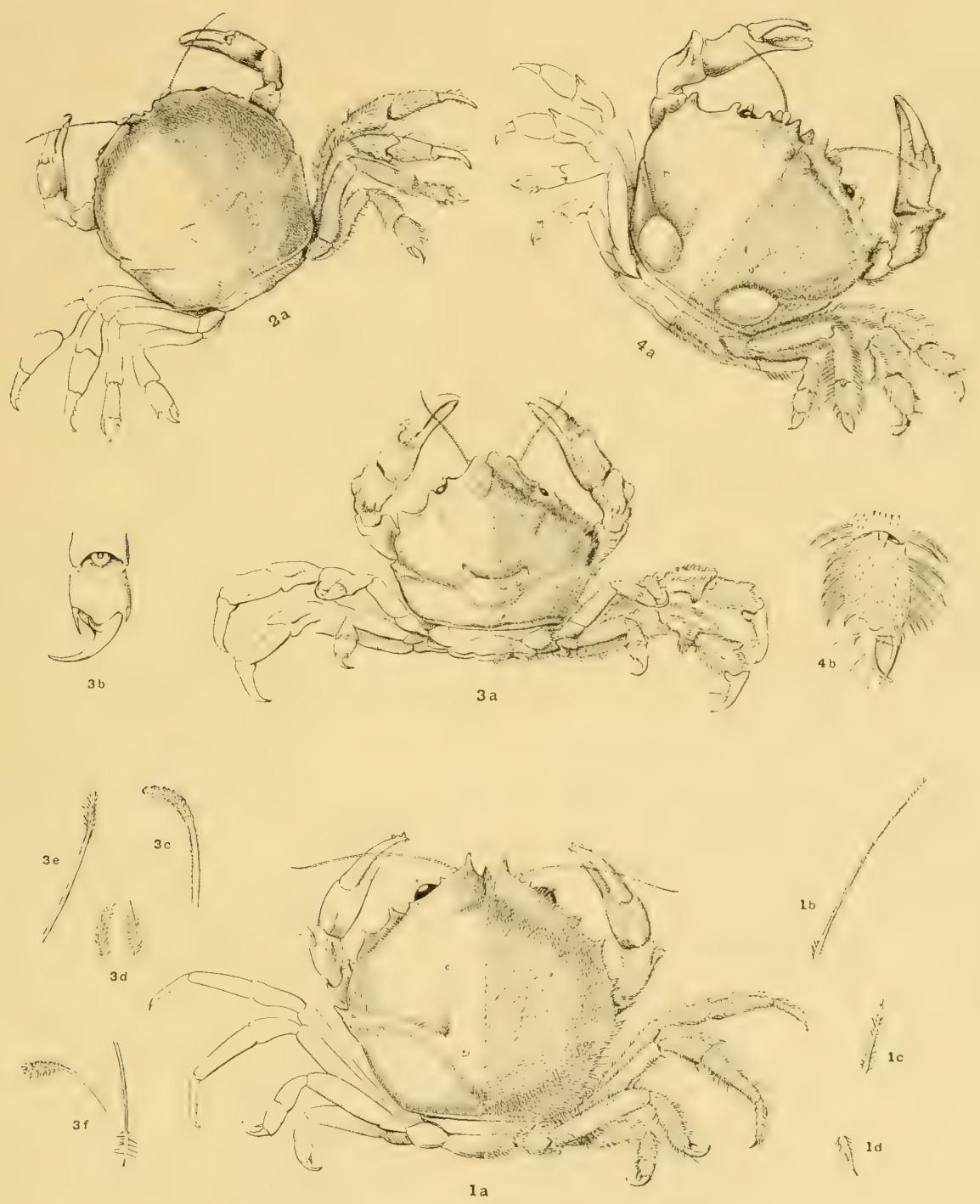

E. W. del.

BORRADAILE_DROMIACEA. 


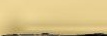




\title{
ON A LAND PLANARIAN FROM HULULE, MALE ATOLL,
}

\section{WITH A NOTE ON LEPTOPLANA PARDALIS LAIDLAW.}

\author{
By Frank Fortescue Laidlaw, B.A. (Cantab.).
}

A single specimen was found of a small species of Rhynchodemus under decaying wood. Its total length is about $25 \mathrm{~mm}$. and breadth a little under $2 \mathrm{~mm}$.

After some hesitation I have referred it to von Graff's Rhynchodemus ceylonicus ${ }^{1}$, a species of which a single specimen was collected by the brothers Sarasin in Ceylon. This the type specimen is considerably larger than that found by $\mathrm{Mr}$ Gardiner (48 mm. long by $3 \mathrm{~mm}$. in breadth), but the colouring agrees fairly well, although owing to the fact that the specimen under discussion has been treated with corrosive sublimate it has rather faded.

There is a somewhat obseure median dorsal dark band and two feebly marked broader lateral bands. Near the middle of the body the small bell-shaped pharynx is protruded.

No land planarian has hitherto been recorded from any coral island in the Indian Ocean. Other islands remote from continental land in this Ocean have, however, a small number of inhabitants belonging to this group. Such are the Seychelles with two species of Amblyplana, and Rodriguez with one species Geoplana whartoni of Gulliver, who also observed a specimen of land planarian on Mauritius. The planarian fauna of these islands is considered by von Graff to be derived from that of the Aethiopian region, whilst the Maldivian species is clearly derived from Ceylon where the genus Rhynchodemus is fairly abundant.

Certain Oriental species of the genus have a wide distribution, such for example is Rlynchodemus nematoides Loman, which is recorded from Ceylon and Java by von Graff in his monograph of the land planarians, whilst I have examined specimens from a height of $2500 \mathrm{ft}$. from a hill in the north-east of the Malay Peninsula.

Species of land planarians are known to occur on at least two coral islands in the Pacific. One of these is Rhynchodemus putzei v. Gr. from the Marquesas Is, the other is Geoplana pelewensis v. Gr. from the Pelew Is.

\footnotetext{
1 von Graff, Monographie die Turbellaria m. Tricladida terricola.
} 


\section{NOTE ON LEPTOPLANA PARDALIS LAIDLAW.}

Since my account ${ }^{1}$ of Mr Gardiner's marine planarians was published, I find that I had inadvertently overlooked the description of Leptoplana subviridis v. Plehn, given by von Plehn in Semon's Zool. Forschungreisen, 5, III. p. 330, Pl. XXIII. figs. 11, 12 . Since three of the four species described and figured in this paper are also described with the same figures in von Plehn's previous paper in the Jena Zeitschrift, I had carelessly put the former on one side, supposing that all the species described in it were also described in the latter.

I find now that the species which I overlooked is identical with my Leptoplana pardalis, which therefore becomes merely a synonym of $L$. subviridis. I find, however, that there are certain discrepancies between our accounts especially as concerns the male apparatus. I have re-examined my sections in consequence and give the following comments.

As regards the vesicula seminalis, von Plehn states that the vasa deferentia have muscular walls and open together into a vesicula seminalis. In my account I stated that the lower ends of the vasa deferentia were dilated to form a pair of vesiculae which opened into a ductus ejaculatorius. In favoux of this latter view I find that in my specimens at any rate, the ends of the vasa deferentia are distinctly dilated, and that the vessel called the vesicula by von Plehn is narrow, and of the same diameter throughout, until it decreases on approaching the penis. In support of von Plehn's view is the fact that her interpretation is more in accord with the condition usually found in Leptoplanas. I an inclined to believe that both views may be right in this case, i.e. that either the lower ends of the vasa deferentia, or the part which I have called the ductus ejaculatorius may function as a vesicula seminalis.

Von Plehn's specimen does not appear to have shown the very distinct narrowing of the two parts of the accessory vesicle and their subsequent dilatation to form a receptaculum seminis on either side, so that each receptaculum is placed as it were on a distinct stalk.

The synonymy of this species then stands as follows:

Leptoplana subviridis v. Plehn.

L. subviridis von Plehn. Semon's Zool. Forschungreisen, 5, III. p. 330. 'If. XXIII. figs. 14, 15.

L. pardalis Laidlaw. Faun. and Geogr. of the Maldives and Laccadives, I. 3, p. 287, Pl. XIV. fig. 9, Pl. XV. fig. 14. Ibid., Proc. Lit. and Phil. Soc. Manchester, XlviI. (1903), no, 5.

I take the opportunity of thanking $\mathrm{M} x$ Stanley Gardiner for permission to call attention to my oversight, which I greatly regret to have committed.

1 "The Marine Turbellaria, etc." Fauna and Geography, Maldives and Laccadives, vol, I. pp. 281-310 (1902). 


\title{
LAG0ON DEPOSITS.
}

\author{
I. GENERAL ACCOUNT.
}

By J. Stanley Gardiner, M.A.

\section{REPORT ON CERTAIN DEPOSITS.}

\author{
By Sir John Murray, K.C.B., F.R.S.
}

(With Plate XXXIV.)

\section{GEneral aCCOUNT (by J. Stanley Gardiner)?}

IN Appendix A, Section II. of my article on "The Maldive and Laccadive Groups" (vol. I. pp. 317-323), I have already referred to some of the deposits found in the atolls and on the banks which we visited. I am greatly indebted to Sir John Murray for kindly examining and giving me the accompanying Report on certain deposits from the lagoons of the atolls which I submitted to him. Perhaps the Section above referred to should be read a second time in connection with this Report, though the latter does not, so far as I can see, invalidate any conclusions therein expressed as to the formation of lagoons, but on the contrary lends them additional important support.

On the most open banks, such as Miladumadulu and North Mahlos, we found, generally speaking, either a hard bottom without any deposit or else a deposit formed by very coarse broken coral and shell fragments, leaves of Halimeda and allied algae, together with a few bottom-living Foraminifera of large size. As might have been expected, there did not appear to have been anywhere a deposit of any thickness except to leeward of certain reefs, where it might have the characters of nos. 11 and 12 of Sir John Murray's Report.

Within shallow atolls, or banks which had assumed the atoll shape, the bottom, except along the lines of the currents, was commonly covered by a deposit of white sand. This was always quite loose and never coherent in any way. It consisted of fine fragments of the same materials as on the more open banks, all more or less rounded or smoothed. Except that the remains of pelagic organisms were rarer, the deposit was the same as that which formed the sand of the lagoon-ward parts of the islands (nos, 14 and 15). The grains varied in size, being in enclosed situations extremely small, such as the centre of Minikoi (no. 16), except for leaves of Halimeda and broken shells. In this position no doubt a great part of the deposit was formed by the washings off the land, but that from the velu (lagoon) of Bodu Faro, North Mahlos, a quite open faro (atollon) 13 fathoms in depth, approaches rather to a mud (no. 13). Nos. 17-19 are also examples of coral sands from the neighbourhood of passages into the lagoon of Suvadiva, where currents of greater or lesser force are felt.

\footnotetext{
1 Sir John Murray suggested that I should give some general account of these deposits, as I necessarily had a local knowledge of the region, which lie did not himself

possess. Consequently, I alone am responsible for any statements or opinions contained in this Section.
} 
It is on this sand deposit that the greatest amount of free animal life is found, while sedentary animals tend to settle upon the more current-swept areas. Among the latter forms are certain Polyzoa and Polytrema, which completely grow round small fragments of stone, turning them into more or less round balls, various Alcyonaria, a few sponges and tunicates and corals of such genera as Dendrophylliu, Alveopora, Goniopora, etc. Of the free forms in the coral sand small lamellibranchs and gastropods are numerous, as well as young echinids. Crustaceans, particularly Portunidae and Oxystomata as well as Macrura, abound. Certain holothurians, sipunculids and polychaets, as well as Ptychodera and Cephalochorda in certain parts of the shallower waters, are quite numerous. Corals are found only where the sand is moderately coarse, and there is some current, but then such forms as Diaseris, Goniopora stokesi, Heteropsammia and Stephanoseris were remarkably abundant locally. Indeed, dead coralla of the first-named were found to be forming the greater part of a series of consolidating masses of rock, dredged from an eddy in one of the northern passages of Suvadiva atoll, of which no. 23 was a specimen.

Lastly, within the most enclosed parts of certain banks and within the lagoons of the deeper atolls a greenish grey ooze, almost a mud, was found (nos. 1-10, 20, 21, 24). A similar deposit may possibly have existed in quite shallow water and have been overlooked by us, but, so far as our soundings and dredgings went, there would almost seem to have been a critical depth at about 30 fathoms below which it was for some reason unable to form. It was generally a fairly clean mud, but below 40 fathoms, when fresh, unctuous, and sometimes smelling slightly of sulphuretted hydrogen. In Suvadiva atoll it was largely composed of the shells of Pteropoda, in which connection it is interesting to remark that one morning at the beginning of November, 1899, the water in the lagoon of Goifurfehendu was positively thick' with the shells of Clio. Pelagic Foraminifera were common, but bottom-living species were by no means numerous. Sedentary organic life, except sponges, scarcely existed upon it, while free life was only represented by a few species of Crustaceans and a still smaller variety of flat fishes. A holothurian was dredged from this class of bottom (p. 339); it was of peculiar interest on account of the relatively large fragments of coral contained in its gut (no. 25).

The most interesting point about this muddy deposit from Suvadiva is the presence in it of large quantities of casts of various organisms, more especially Foraminifera. Its mineralogical constituents are small, and are for the most part those found in the open ocean, being of volcanic origin. In connection with this, one may point out that on the shores of many of the islands there are lines of pumice, which the natives state were washed up about 1885, and would hence have probably owed their origin to the eruption of Krakatoa in 1883. In addition half-decomposed pumice is found, in places at some considerable distance inland, which evidently belonged to an earlier period. The analogy between these casts and those of Greensand appears to me to be very close, and I would suggest that here we have an incipient formation of the latter deposit, which is generally supposed to be largely terrigenous in origin. Greensand essentially owes its origin to the filling in of the shells, particularly of the Foraminifera, by a deposit. It was shown in the Challenger Reports to occur between 100 and 900 fathoms along bold and exposed coasts, where pelagic conditions might be expected to closely approach the shores, though all the elements of its essential constituent, glauconite, may also be present in pumice or the ordinary oceanic, volcanic deposits. That there is any real homology between this deposit and that of Greensand is by no means certain, but, if there be, either the formation of Greensand must depend on physical conditions rather than the proximity of continental land, or Suvadiva atoll at least must have been closely connected with or perhaps founded on the remains of a continental land mass. 
So far as I am aware this is the first recorded occurrence of a true pelagic deposit, i.e. Pteropod Ooze, within the lagoon of an atoll. It is accompanied by much fine matter, the inorganic part of which consists almost entirely of carbonate of lime. The Challenger Report recorded the presence of a similar deposit off many coral reefs and oceanic islands, that around the Fiji Group being particularly noticeable, though in my own experience it is not found in the lagoons of the atoll or barrier reefs of those islands. The presence of this deposit in Suvadiva lagoon at depths over 40 fathoms is interesting as it is not found elsewhere in the shallower lagoons we investigated, and it would naturally be expected that the calcareous remains of such small pelagic organisms would have been rapidly dissolved in the sea-water and removed. A considerable proportion of the deposit being formed of casts shows that its origin cannot have been due to merely temporary eauses. It might reasonably be deduced that the lagoon of Suvadiva below 35 or 40 fathoms is a relatively still one with little circulation in its sea-water, but the reason of this state is not obvious, as that atoll has 38 well-defined passages into its lagoon, of which 7 are about or over 35 fathoms in depth, and 17 about or over 20 fathoms. It is useless, however, theorising on the subject, when it is obvious that practically nothing is known of the physical conditions of this large lagoon. In connection with the question it will be interesting to see what deposits Prof. Agassiz found around the Maldive banks at moderate depths. The presence or absence of manganese nodules or deposits, indicated in no. 24 below, will no doubt be considered also by the sime anthor.

I have appended a chart to Sir John Murray's Report (Pl. XXXIV), underlining the positions from which the samples from Suvadiva atoll were obtained. I add from the same Report a list of the animals of such groups as will otherwise not be treated of in this publication. Names in brackets have been added by me, the bracketed genera of the Foraminifera having been kindly identified by Mr J. J. Lister.

Pelagic Foraminifera :

Globigerina bulloides.

"sacculifera.

" conglobata.

" digitata.

" rubra.
Globigerina aequilateralis. dubia.

Orbulina universa.

Sphaeroidina dehiscens.

Pullenia obliquiloculata.

Bottom Foraminifera:

Biloculina.

(Miliolina).

Spiroloculina.

Peneroplis.

(Orbitolites).

(Alveolina).
Rheophax.

(Textulariu).

Cassidulina.

Lagena.

Nodosaria.
Polymorphina.

Uvigerina.

Pullenia sphaeroides.

Rotalinue.

Polytrema.
Pulvinulina tumida.

" menardii.

" canarinensis.

Cymbalopora.

Mollusca Pteropoda:
Clio subula.
Limacina.
" australis.
Cavolinia.

Mollusca Heteropoda:
Atlanta.
Carinaria.
(Oxygurus).
(Pterotrachea).

(Gypsina).

Amphistegina.

(Polystomella).

(Operculina).

Heterostegina depressa.

Other Mollusea :

Pleurotoma.

Dentalium.

Diatomaceae :

Pleurosigma.

Surirella.

Coscinodiscus. 


\section{REPORT ON CERTAIN DEPOSITS (by Sir JohN MUURAY).}

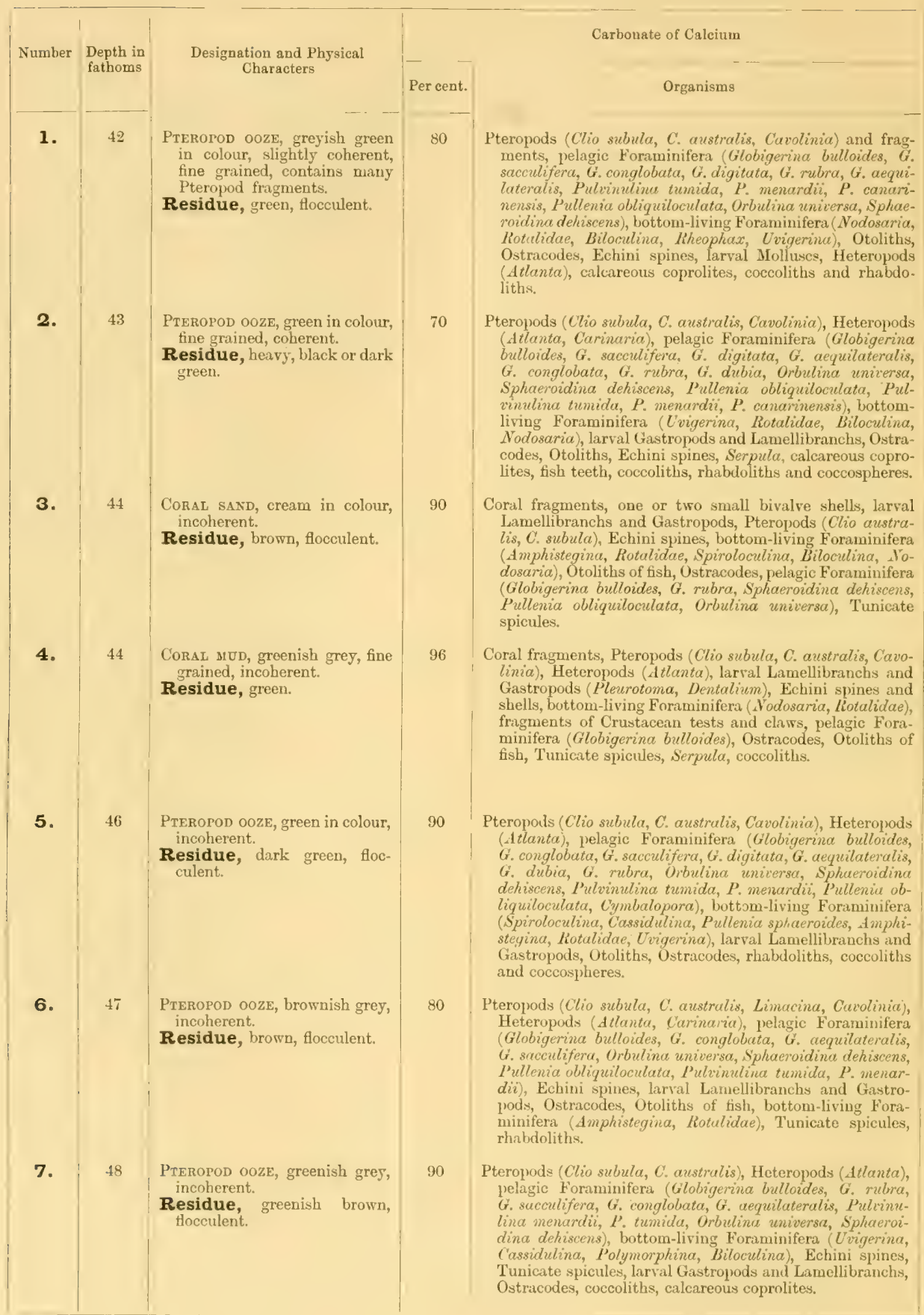




\begin{tabular}{|c|c|c|c|c|}
\hline \multicolumn{4}{|c|}{ Residue } & \multirow{2}{*}{ Position } \\
\hline Per cent. & Minerals & Siliceous Organisms & Fine Washings & \\
\hline 20 & $\begin{array}{l}(2 \%) \text {, angular, mean dia- } \\
\text { meter } 0.15 \mathrm{~mm} \text {., felspar, } \\
\text { hornblende and magnetite. }\end{array}$ & $\begin{array}{l}(3 \%) \text { arenaceous Fora- } \\
\text { minifera, sponge spicules, } \\
\text { many perfect green clayey } \\
\text { casts of Foraninifera, etc., } \\
\text { Radiolaria. }\end{array}$ & $\begin{array}{l}(15 \%) \text {, amorphous clayey } \\
\text { matter with minute frag- } \\
\text { ments of siliceous organ- } \\
\text { isms and minerals less } \\
\text { than } 0.05 \mathrm{~mm} \text {. in diameter. }\end{array}$ & $\begin{array}{l}\text { Suvadiva, N.N.E. } \\
2 \frac{1}{2} \text { miles S. b. W. } \\
\text { JIametu. }\end{array}$ \\
\hline 30 & $\begin{array}{l}(1 \%) \text {, angular, mean dia- } \\
\text { meter } 0.1 \text { mra., felspar and } \\
\text { magnetite. No raanganese } \\
\text { observed. }\end{array}$ & $\begin{array}{l}(5 \%) \text { sponge spicules, } \\
\text { Radiolaria, many clayey } \\
\text { casts of Foraminifera, } \\
\text { clayes coprolites, diatoms. }\end{array}$ & $\begin{array}{l}(24 \%) \text {, amorphous clayey } \\
\text { matter with minute mine- } \\
\text { ral particles less than } \\
0.05 \mathrm{~mm} \text {. in diameter, etc. }\end{array}$ & $\begin{array}{l}\text { Suvadiva, N.E. } \\
4 \frac{1}{2} \text { miles W. Digura. }\end{array}$ \\
\hline 10 & $\begin{array}{l}(1 \%) \text {, angular, mean dia- } \\
\text { meter } 0.06 \mathrm{~mm} ., \text { felspar } \\
\text { only observed. }\end{array}$ & $\begin{array}{l}(3 \%) \text {, diatoms, sponge spi- } \\
\text { cules. }\end{array}$ & $\begin{array}{l}(6 \%) \text {, amorphous clayey } \\
\text { matter, with one or two } \\
\text { minute mineral particles. }\end{array}$ & $\begin{array}{l}\text { Suvadiva, S.E. } \\
2 \text { miles N. Noor- } \\
\text { bhai I. }\end{array}$ \\
\hline 4 & $\begin{array}{l}(1 \%) \text {, angular, mean dia- } \\
\text { meter } 0.08 \mathrm{~mm} \text {, fragments } \\
\text { of glassand felspar, one par- } \\
\text { ticle of felspar measured } \\
0.14 \mathrm{~mm} \text {. ; flakes of iron } \\
\text { rust, probably off the ma- } \\
\text { chine used in collecting the } \\
\text { sample, were also observed. } \\
\text { No manganese observed. }\end{array}$ & $\begin{array}{l}(2 \%) \text {, sponge spicules, Ra- } \\
\text { diolaria, Diatoms (Pleuro- } \\
\text { sigma, Surirella, Coscino- } \\
\text { discus), and many beautiful } \\
\text { green clayey casts of Gas- } \\
\text { tropods, Echini spines, } \\
\text { Foraminifera, etc., copro- } \\
\text { lites, no casts in Pyrite. }\end{array}$ & $\begin{array}{l}(1 \%) \text {, amorphous clayey } \\
\text { matter, with minute frag- } \\
\text { ments of siliceous organ- } \\
\text { isms, and small mineral } \\
\text { particles less than } 0.05 \mathrm{~mm} \text {. } \\
\text { in diameter. }\end{array}$ & $\begin{array}{l}\text { Suvadiva, S.E. } \\
\text { 13 miles N.W. Fulu } \\
\text { I. }\end{array}$ \\
\hline 10 & $\begin{array}{l}(2 \%) \text {, angular, mean dia- } \\
\text { meter } 0.15 \mathrm{~mm} \text {, felspar } \\
\text { and glass, many casts of } \\
\text { Foraminifera, etc. but not } \\
\text { so perfect as in the dry } \\
\text { sample (no. 4). No man- } \\
\text { ganese. }\end{array}$ & $\begin{array}{l}(5 \%) \text {, sponge spicules, } \mathrm{Ra}- \\
\text { diolaria, small sponge, are- } \\
\text { naceous Foraminifera, Di- } \\
\text { atoms. }\end{array}$ & $\begin{array}{l}(3 \%) \text {, amorphous clayey } \\
\text { matter, small casts, etc. }\end{array}$ & $\begin{array}{l}\text { Suvadiva, S. } 2 \\
\text { miles W.S. W. Mafe } \\
\text { I. }\end{array}$ \\
\hline 20 & $\begin{array}{l}(2 \%) \text {, angular, mean dia- } \\
\text { neter } 0.07 \mathrm{~mm} \text {, felspar } \\
\text { only vbserred. }\end{array}$ & $\begin{array}{l}(4 \%) \text {, sponge spicules, } \mathrm{Ra} \text { - } \\
\text { diolaria, Diatoms, one or } \\
\text { two white clayey casts. }\end{array}$ & $\begin{array}{l}(14 \%) \text {, amorphous clayey } \\
\text { matter with minute mine- } \\
\text { ral particles and fragments } \\
\text { of siliceous organisms. }\end{array}$ & $\begin{array}{l}\text { Suvadiva, S. } 3 \\
\text { miles further W. } \\
\text { than last. }\end{array}$ \\
\hline 10 & $\begin{array}{l}(1 \%) \text {, angular, mean dia- } \\
\text { meter } 0.07 \mathrm{~mm} ., \text { felspar, } \\
\text { hornblende and magnetite. }\end{array}$ & $\begin{array}{l}\left(3^{\circ} / \circ\right) \text {, sponge spicules, Ra- } \\
\text { diolaria, Diatoms. }\end{array}$ & $\begin{array}{l}(6 \%) \text {, amorphous clayey } \\
\text { matter with minute mine- } \\
\text { ral particles less than } \\
0.05 \mathrm{~mm} \text {. in diameter and } \\
\text { fragments of siliceous or- } \\
\text { ganisms. }\end{array}$ & $\begin{array}{l}\text { Suvadiva, S. } 2 \\
\text { miles further W. } \\
\text { than last. }\end{array}$ \\
\hline
\end{tabular}

G. II. 


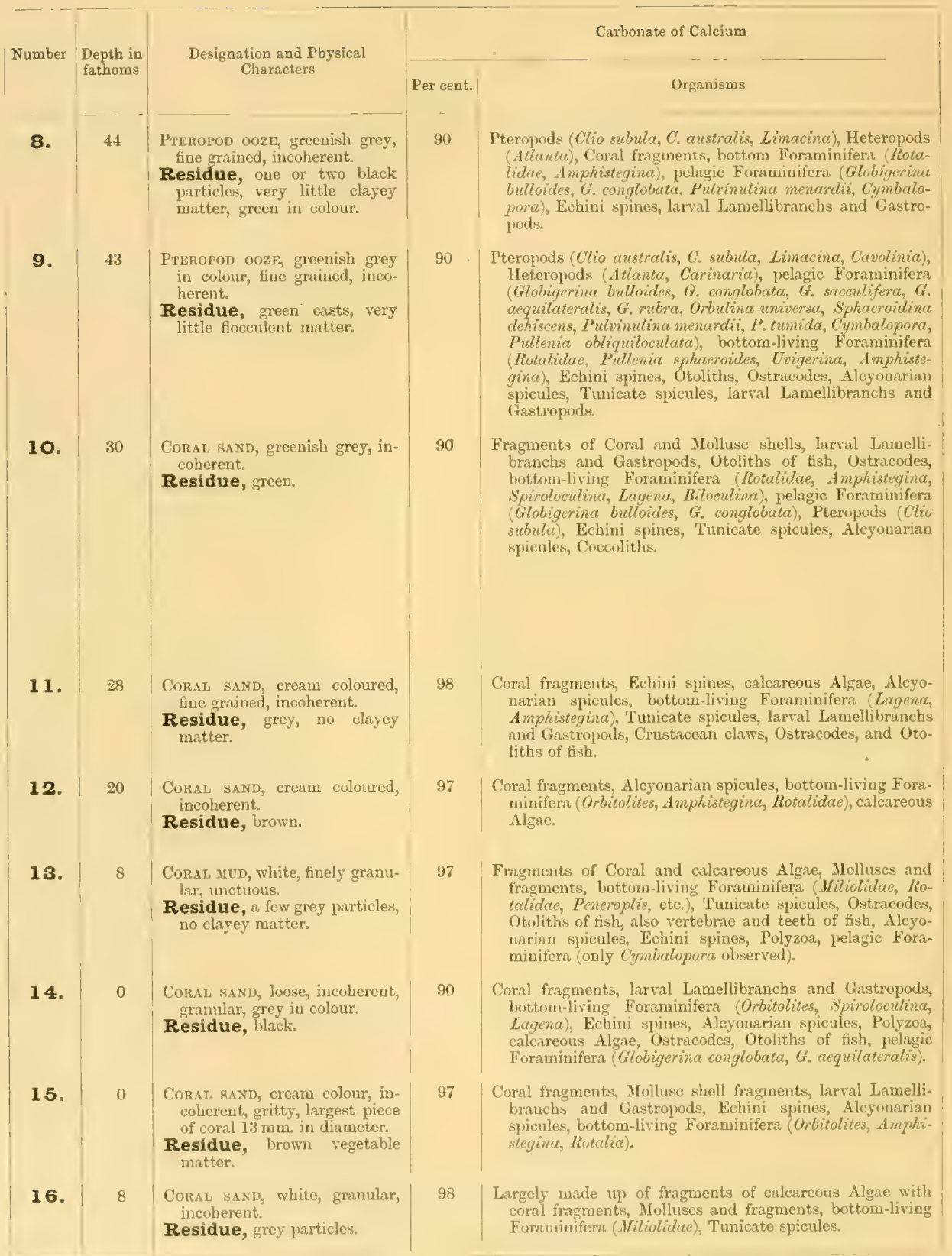




\begin{tabular}{|c|c|c|c|c|}
\hline \multicolumn{4}{|c|}{ Residue } & \multirow{2}{*}{ Position } \\
\hline Per cent. & Minerals & Siliceous Organisms & Fine Washings & \\
\hline 10 & $\begin{array}{l}(1 \%) \text {, angular, mean dia- } \\
\text { meter } 0.6 \mathrm{~mm} \text {, felspar and } \\
\text { magnetite; no manganese } \\
\text { or sulphide of iron ob- } \\
\text { served. }\end{array}$ & $\begin{array}{l}(3 \%) \text {, sponge spicules, a } \\
\text { few green clayey casts of } \\
\text { Foraminifera; Coprolites; } \\
\text { Diatoms. }\end{array}$ & $\begin{array}{l}(6 \%) \text { amorphous clayey } \\
\text { matter with minute frag- } \\
\text { ments of siliceous organ- } \\
\text { isms, casts and mineral } \\
\text { particles less than } 0.05 \mathrm{~mm} \text {. } \\
\text { in diameter. }\end{array}$ & $\begin{array}{l}\text { Suvadiva, W. } 1 \\
\text { mile } \mathrm{W} . \mathrm{b} . \mathrm{S} \text {. of } \mathrm{Ve}- \\
\text { lana } \mathrm{I} \text {. }\end{array}$ \\
\hline 10 & $\begin{array}{l}(1 \%) \text {, angular, mean dia- } \\
\text { meter } 0.6 \text { mm., felspar and } \\
\text { magnetite; no manganese } \\
\text { grains observed. }\end{array}$ & $\begin{array}{l}(5 \%) \text {, green clayey casts of } \\
\text { Foraminifera, etc. ; grey } \\
\text { and black clayey Copro- } \\
\text { lites; no manganese grains } \\
\text { or sulphide of iron. }\end{array}$ & $\begin{array}{l}(4 \%) \text {, amorphous clayey } \\
\text { matter, with minute mine- } \\
\text { ral particles less than } \\
0.05 \mathrm{~mm} \text {, in diarneter. }\end{array}$ & $\begin{array}{l}\text { Suvadiva, W. } 3 \\
\text { miles W. of Havaru } \\
\text { Tinadu. }\end{array}$ \\
\hline 10 & $\begin{array}{l}(3 \%) \text { angular, mean dia- } \\
\text { meter } 0.3 \mathrm{~mm} \text {., volcanic } \\
\text { glass and felspar, one par- } \\
\text { ticle of felspar observed } \\
\text { measured } 0.55 \mathrm{~mm} \text {, in dia- } \\
\text { meter, and a fragment of } \\
\text { volcanic glass measured } \\
2 \text { mm. in length. A small } \\
\text { but perfect crystal, clear } \\
\text { yellow in colour, and of a } \\
\text { wedge shape, probably } \\
\text { sphene (?), was also ob- } \\
\text { served. }\end{array}$ & $\begin{array}{l}(2 \%) \text {, fragments of Radio- } \\
\text { laria; Diatoms. }\end{array}$ & $\begin{array}{l}(5 \%) \text {, amorphous clayey } \\
\text { matter with fragments of } \\
\text { minerals and small Dia- } \\
\text { toms. }\end{array}$ & $\begin{array}{l}\text { Felidu, middle of } \\
\text { atoll. }\end{array}$ \\
\hline 2 & $\begin{array}{l}(1 \%) \text {, angular, mean dia- } \\
\text { meter } 0.18 \text { mm., particles } \\
\text { of felspar only observed. }\end{array}$ & $(1 \%)$, sponge spicules. & Practically none. & $\begin{array}{l}\text { North Mahlos, } \\
\text { middle east side. }\end{array}$ \\
\hline 3 & $\begin{array}{l}(2 \%) \text {, angular, mean dia- } \\
\text { meter } 0.2 \mathrm{~mm} ., \text { felspar, } \\
\text { hornblende and volcanic } \\
\text { glass. }\end{array}$ & $(1 \%)$, sponge spicules. & None. & $\begin{array}{l}\text { North Mahlos, } \\
\text { S.W. Close off Fus- } \\
\text { mundu. }\end{array}$ \\
\hline 3 & $\begin{array}{l}(1 \%) \text {, one or two particles } \\
\text { of felspar and glass. }\end{array}$ & $\begin{array}{l}(2 \%) \text {, sponge spicules, Ra- } \\
\text { diolaria, Diatoms (Suri- } \\
\text { rella, etc.). }\end{array}$ & None. & $\begin{array}{l}\text { North Mahlos, } \\
\text { W. Within lagoon } \\
\text { of Bodu Furo. }\end{array}$ \\
\hline 10 & $\begin{array}{l}(1 \%) \text {, angular, mean dia- } \\
\text { meter } 0.18 \mathrm{~mm} \text {, particles } \\
\text { of felspar observed only. }\end{array}$ & $(1 \%)$, sponge spicules. & $\begin{array}{l}(8 \%) \text {, made up principally } \\
\text { of vegetable fibre and a } \\
\text { great many small brown } \\
\text { cocoons of larvae (insect?). }\end{array}$ & $\begin{array}{l}\text { Minikoi. Soil of } \\
\text { lowplanting ground, } \\
\text { middle of island. }\end{array}$ \\
\hline 3 & None. & $(1 \%)$, sponge spicules. & $(2 \%)$, vegetable fibre. & $\begin{array}{l}\text { Minikoi. Soilfrom } \\
3-4 \text { feet deep near } \\
\text { Lighthouse. }\end{array}$ \\
\hline 2 & None. & $\begin{array}{l}(1 \%) \text {, one or two sponge } \\
\text { spicules. }\end{array}$ & $\begin{array}{l}(1 \%), a \text { few fragments of } \\
\text { vegetable matter. }\end{array}$ & $\begin{array}{l}\text { Minikoi. Centre } \\
\text { of lagoon. }\end{array}$ \\
\hline
\end{tabular}


17. Coral Sand. $31 \mathrm{f}$. Suvadiva, W. 1 mile $\mathrm{E}$. of S. end of Houdedu.

Very little material which appears to have been washed, consisting of small fragments of Coral and Molluse shells, one or two bottom Foraminifera (Amphistegina, Rotalidae, Biloculina, etc.), Serputa.

18. Coral Sand. $30 \mathrm{f}$. Suvadiva, W. Opposite passage between Hondedu and Kandudu.

Very little material, appears to have had the finer material washed away; is grey in colour, granular, and made up mostly of Coral fragments, bottom Foraminifera (Amphistegina, Rotalidae, etc.), broken Mollusc shells, Diatoms, etc.

19. Coral SAND. $33 f$. Suvadiva, W. 1 mile $N$. of last (not shown on Chart).

White, gritty, no fine material, made up of Coral fragments, bottom Foraminifera (Amphistegina, Heterostegina depressa), Serpula, Polyzoa.

20. Coral Sand. $44 f$. Suvadiva, W. 2 miles E. of Kandudu.

Crean colour, gritty, made up largely of fragments of Coral, bottom Foraminifera (Amphistegina, Rotalidae), Echini spines, larral Lamellibranchs and Gastropods, Pteropods (Clio subula), Alcyonarian spicules.

21. PTeropod OOZE. $42 f$. Suvadiva, W. $1 \frac{1}{2}$ miles N.E. of last.

Cream colour, incoherent, appears to be slightly washed, fine grained, contains Pteropods (Clio subula, C. australis), Heteropods (Atlanta, Carinaria), pelagic Foraminifera (Globigerina bulloides, G. conglobata, G. aequilateralis, G. rubra, Sphaeroidina dehiscens, Orbulina universa), bottom Foraminifera (Uvigerina, Cassidulina, Biloculina, Spiroloculina, Lagena, Rotalidae, Amphistegina), Alcyonarian spicules, Tunicate spicules, Coral fragments, larval Lamellibranchs and Gastropods, Polyzoa, Otoliths of fish, Ostracodes.

22. Coral saxd. $34 f$. Suvadiva, W.N.W. 1 mile W. of Thackaru I.

Loose, gritty, grey in colour, made up of angular and rounded fragments of Coral and Mollusc shells, Polyzoa, Serpula, calcareous Algae, larval Lamellibranchs and Gastropods, Alcyonarian spicules, bottom-living Foraminifera (Amphistegina, Polytrema, Rotalidae, Uvigerina, Nodosaria), pelagic Foraminifera (Globigerina bulloides, G. conglobata), Tunicate spicules, Otoliths, Ostracodes, Sponge spicules.

23. Coral conglomerate. 37-8 f. Suvadiva, N.N.W. In Huradu passage.

Piece of coral rock 4 1 with calcareous Algae, Serpula, Polyzoa, attached Mollusc shells, bottom Foraminifera (Amphistegina, Rotalidae, Polytrema, Uvigerina, etc.), larval Lamellibranchs and Gastropods.

24. $36 \mathrm{f}$. Felidu. Centre of S.E. horn.

The material is grey in colour with black particles, shells, etc. coated with Manganese, but no grains of Manganese observed; is gritty and incoherent, appears to be washed, contains small greyish black rock particles, the largest observed being about $3 \mathrm{~mm}$. in maximum diameter. Larval Lamellibranchs and Gastropods (Pleurotoma and Dentalium), Echini spines, Polyzoa, Coral fragments, Alcyonarian spicules, Otoliths of fish, Ostracodes, pelagic Foraminifera (Globigerina conglobata), bottom Foraminifera (Amphistegince, Rotalidae), Pteropods (Clio subula), Tunicate spicules.

25. Sample taken from the gut of a large Holothurian. Suvadiva, between nus. 21 and 8 albove.

The material is coarse and gritty, cream in colour, and consists of angular and rounded fragments of coral, Mollusc shells, Polyzoa, calcareous Algae, Echini spines, Alcyonarian spicules, bottom Foraminifera (Nrbitolites, Rotalidae, Polytrema, Amphistegina, Uvigerina, Nodosaria, Biloculina, Spiroloculina, Cassidulina), pelagic Foraminifera (Globigerina bulloides, G. conglobata, Sphaeroidina dehiscens), Pteropods (Clio subula, C. australis), Heteropods (Atlanta), Ostracodes, Otoliths of fish, Serpula, larval Lamellibranchs and Gastropods, Sponge spicules, Radiolaria, Diatoms and minute particles of minerals, mean diameter $0.06 \mathrm{~mm}$. consisting felspar and magnetite; one or two particles of vegetable matter and fibre were observed. 


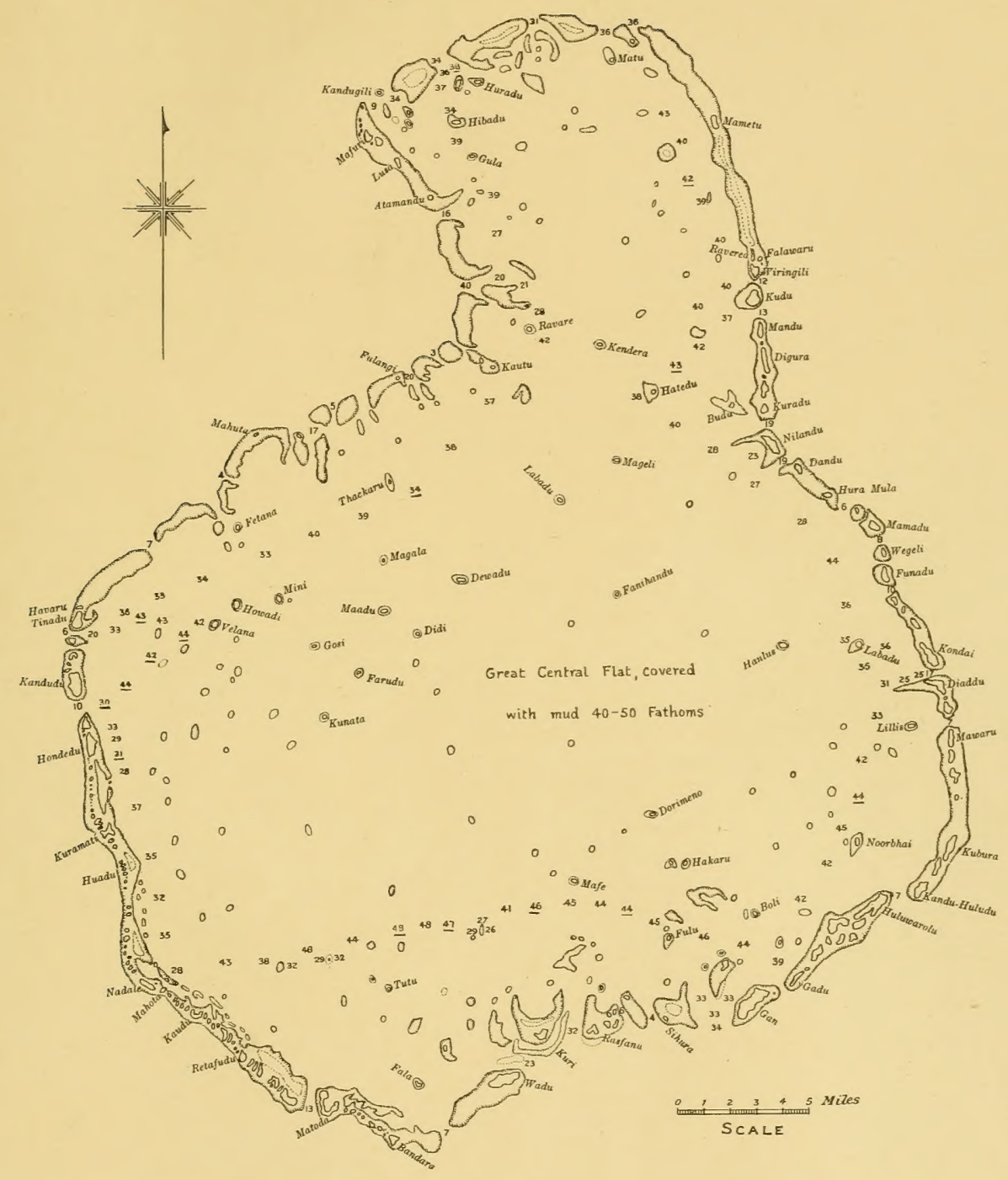

SUVADIVA ATOLL.

(Soundings in the lagoon by the Expedition. Samples described from those underlined.) 

